\title{
MITOCHONDRIAL RESPONSES TO ANOXIA EXPOSURE IN RED EARED SLIDERS (TRACHEMYS SCRIPTA)
}

\author{
by \\ Crisostomo Roberto Gomez
}

B.S., University of Rhode Island 2012

A THESIS SUBMITTED IN PARTIAL FULFILLMENT OF THE REQUIREMENTS FOR THE DEGREE OF

MASTER OF SCIENCE

in

THE FACULTY OF GRADUATE AND POSTDOCTORAL STUDIES (Zoology)

THE UNIVERSITY OF BRITISH COLUMBIA

(Vancouver)

June, 2016

(C) Crisostomo Roberto Gomez, 2016 


\section{ABSTRACT}

The freshwater turtle, Trachemys scripta is considered one of the most anoxia-tolerant vertebrates because of its ability to survive months at cold temperatures in the complete absence of oxygen. When deprived oxygen, mitochondria from anoxia intolerant organisms become one of the largest cellular energy consumers because of the reverse functioning of the $\mathrm{F}_{1} \mathrm{~F}_{\mathrm{o}}$-ATPase (complex V), which hydrolyzes ATP to pump protons out of the mitochondrial matrix, quickly depleting cellular ATP and leading to cellular death. T. scripta has previously shown to inhibit complex $\mathrm{V}$ in response to anoxia exposure, but the regulatory mechanism is still unknown. The goal of this thesis was to explore the mitochondrial response to anoxia in T. scripta. My first objective was to deduce the mechanism responsible for the severe downregulation of Complex $\mathrm{V}$. In heart, brain, and liver tissue from anoxic exposed turtles, complex V activity was significantly reduced to more than $80 \%$ compared with normoxic controls. Employing a proteomics approach, I determined that three subunits of complex V (ATP5A1, ATP5F1, and MT-ATP5J), all associated with the peripheral stalk, decreased in protein expression in response to anoxia. Increasing assay buffer $\mathrm{pH}$, in an attempt to strip Inhibitory Factor-1 ( $\left.\mathrm{IF}_{1}\right)$ from complex V did not increase enzyme activity of normoxic or anoxic exposed samples, but decreasing $\mathrm{pH}<7.5$ decreased activity and at $\mathrm{pH} 6.0$ there was no significant difference in activity between normoxic-and anoxic-exposed samples. Stimulating endogenous phosphatases slightly reduced activity in normoxic samples but had no effect on anoxic samples. Nitric oxide did not have a significant effect on complex $\mathrm{V}$ activity as previously seen in mice. The second objective of this thesis was to characterize the changes in proteins involved in mitochondrial function during anoxia. Proteomic analysis revealed differential expression of numerous enzymes involved with the electron transport system (ETS), the tricarboxyl acid (TCA) cycle, as well as lipid and amino acid metabolism. Overall, results from this thesis demonstrate that 
mitochondria from turtles alter protein expression of numerous proteins in response to anoxia and that reduced complex $\mathrm{V}$ activity is likely related to decreases in the expression of specific complex V subunits. 


\section{PREFACE}

I conducted research under the supervision of Dr. Jeffrey Richards. I wrote all 3 chapters of this thesis and received editorial feedback from Drs. Jeffrey Richards, Patricia Schulte, and Vanessa Auld. All procedures involving animals were performed using protocols approved by the Animal Care Committee, certificate AUP-A13-0254 


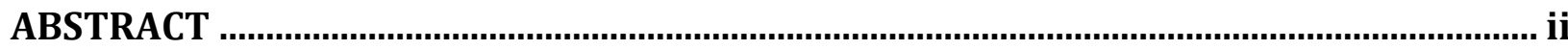

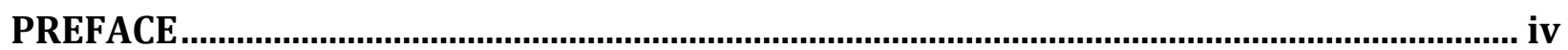

TABLE OF CONTENTS

LIST OF TABLES

LIST OF FIGURES...........................................................................................................ii

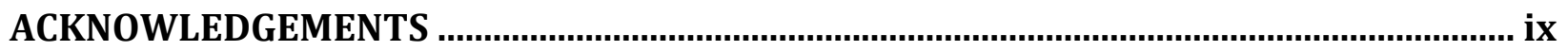

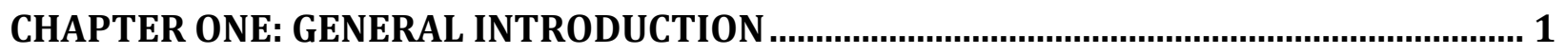

1.1 Mitochondrial Function ....................................................................................................

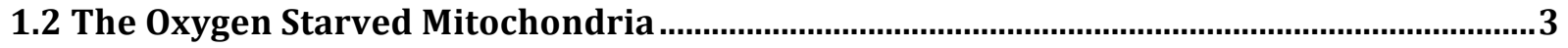

1.3 Anoxic Environments and Facultative Anaerobes .............................................................4

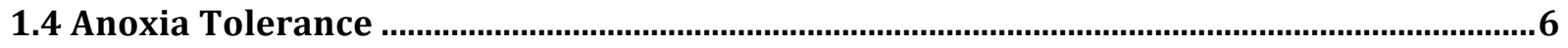

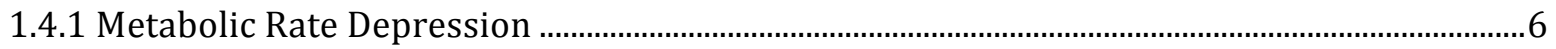

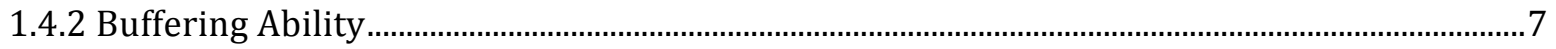

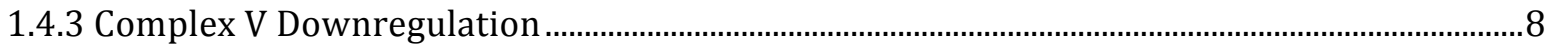

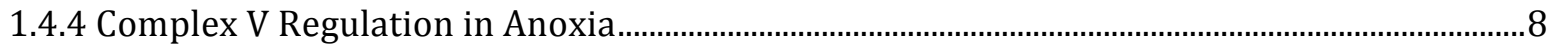

1.4.5 Mitochondrial Response to Anoxia......................................................................................................

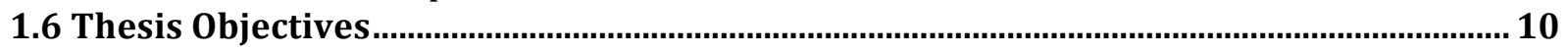

CHAPTER 2: MITOCHONDRIAL ADAPTATION TO ANOXIA............................................14

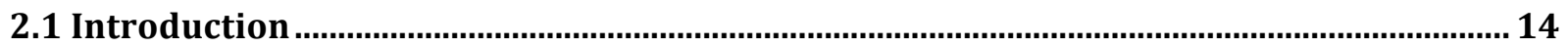

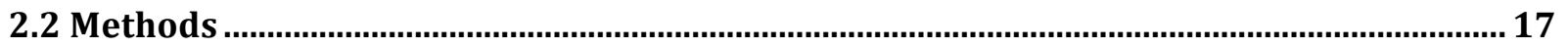

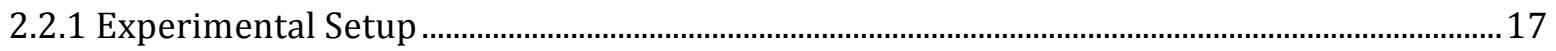

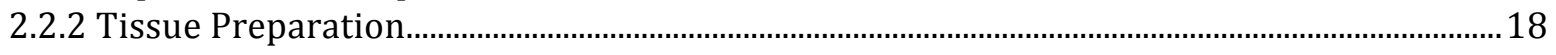

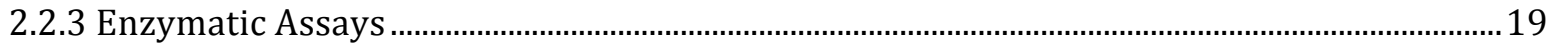

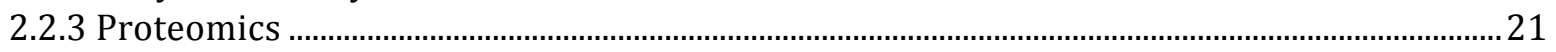

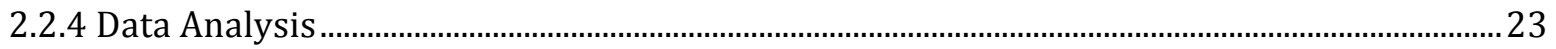

2.3 Results................................................................................................... 24

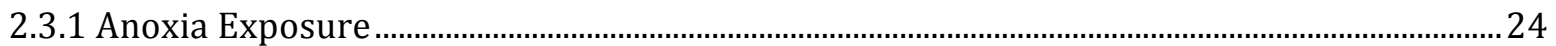

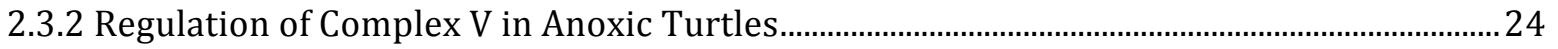

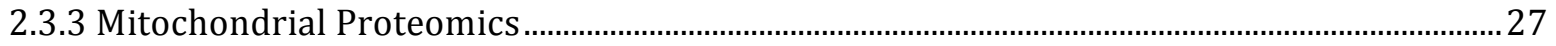

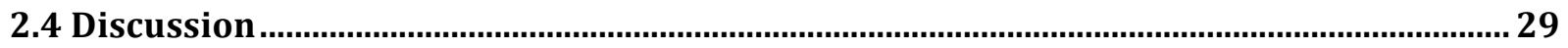

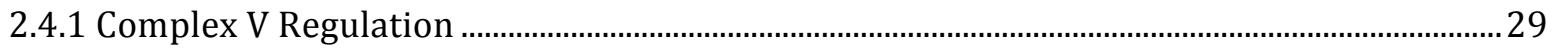

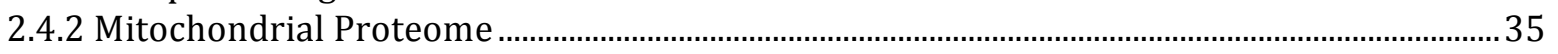

CHAPTER THREE: GENERAL DISCUSSION AND CONCLUSIONS.....................................52

3.1 Complex V Characterization .......................................................................................... 52

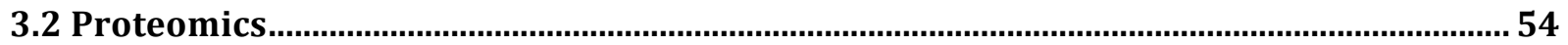

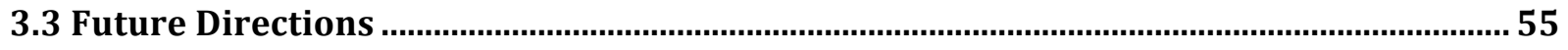

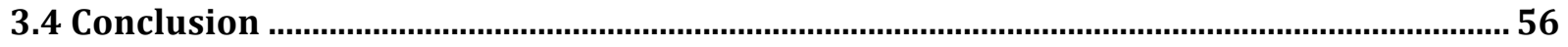

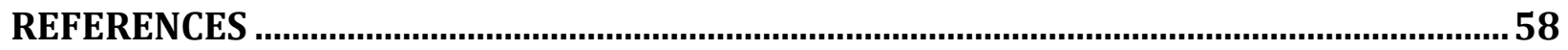

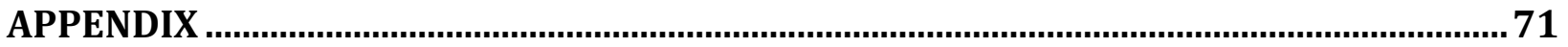

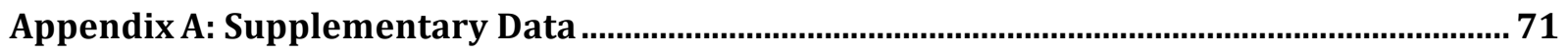


Appendix B: Mitochondrial responses to prolonged anoxia in brain of red-eared slider

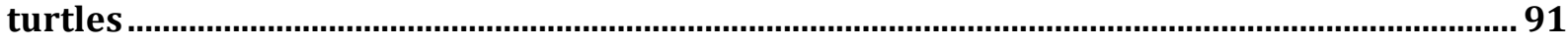

Appendix C: Inhibitory Factor-1 Alignment …................................................................... 


\section{LIST OF TABLES}

Table 2.1 Michaelis-Menten constant $\left(\mathrm{K}_{\mathrm{m}}\right)$ and maximum Complex $\mathrm{V}$ activity $\left(\mathrm{V}_{\max }\right)$ in normoxic- and anoxic-exposed turtle heart tissue and heart mitochondria.

Table 2.2 List of identified mitochondrial $\mathrm{F}_{1} \mathrm{~F}_{\mathrm{o}}$-ATPase subunits after LC-MS/MS analysis isolated heart mitochondria from normoxic and anoxic-exposed turtles.....................41

Table 2.3 List of identified differentially expressed mitochondrial proteins after LC-MS/MS analysis of isolated heart mitochondria.

Table 2.4 List of differentially regulated mitochondrial proteins, organized by their biological function, after LC-MS/MS analysis of isolated heart mitochondria from normoxic-and anoxicexposed turtles...............................................................48 


\section{LIST OF FIGURES}

Figure 1.1 Graphical representations of the ETS, the effects of anoxia and inhibition of the

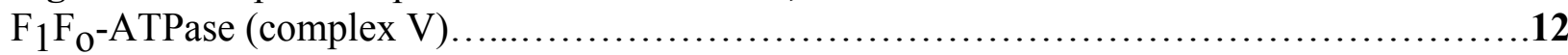

Figure 2.1 The Effect of anoxia on Complex V activity in heart, liver, and brain from normoxiaand anoxia-exposed turtles.

Figure 2.2 The effect of chronic anoxia on the kinetics of Complex $\mathrm{V}$ in heart tissue $(A)$ and isolated turtle heart mitochondria $(B)$ from normoxic-and anoxia-exposed turtle.

Figure 2.3 (A) Effects of chronic anoxia on protein expression of the beta subunit of complex $\mathrm{V}$ in normoxic-and anoxic-exposed turtles. (B) Sample western blots of complex V beta subunit

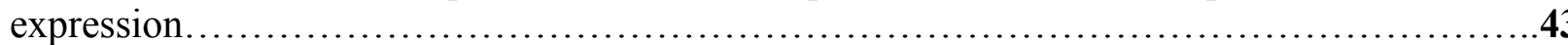

Figure 2.4 The effect of $\mathrm{pH}$ on Complex $\mathrm{V}$ activity in anoxia-and normoxia-exposed turtle heart mitochondria

Figure 2.5 The effect of stimulating endogenous protein phosphatases on Complex V activity in cardiac muscle from normoxic-and anoxic-exposed turtles

Figure 2.6 The effects of GSNO on Complex V activity in isolated heart mitochondria from normoxia and anoxia-exposed turtles, as well as mouse heart tissue included as positive control.....

Figure 2.7 Graphical representation of major mitochondrial proteins/enzymes and their relative changes in expression. 


\section{ACKNOWLEDGEMENTS}

I must first thank my supervisor, Dr. Jeffrey Richards for everything he has done for me. Without his infallible wisdom and regular cheek/motivational speeches, I would still be working on this thesis. Thank you to my committee members, Drs. Vanessa Auld and Trish Shulte, for their valuable perspectives on my research and for their advice on how to cut down on my brazen comma use. Also, tremendous thanks to Gigi Lau, Dillon Chung, and Matthew Pam Pam for teaching me almost every I know in the lab and answering my never-ending line of questions.

During my time in the Zoology department I have been blessed to be among such excellent and admirable people. To my friends: Michelle $\mathrm{Au} / \mathrm{Ou}$, Mike Sackville, Libby McMillan, Millica Mandic, Andrew Thompson, Ryan Shartau, Katelyn Tovey, Joshua Emerman, Norah Brown, Megan Vaughan, Kyle Glenn, and the entire BoZo Frisbee team, who have supported me, made me laugh, and helped me through the tough times- thank you. To Emily Gallagher, thanks for all the great times, your constant smile, and your contagious optimism. You are and will always be missed. To my boys: JP, Adam, Jesse, Troy, Matt, Kieran and Brandon, thanks for keeping me sane with nights full of laughter, debauchery, and just one more game. To Yvonne Dzal, no words (except some written by A\$AP, 2-Chainz, Drake, \& Kendrick) can describe how lucky I feel that you let me crash on your couch when I first moved to Vancouver. A choice that eventually led to my greatest friend/common-law partner. Finally, to my family: Carla, Juan, Adrianna, and Gram, thank you for all the support, encouragement, and love. I wouldn't be where I am or who I am without it. 


\section{CHAPTER ONE: GENERAL INTRODUCTION}

Oxygen is critical to vertebrate life. It acts as the terminal electron acceptor in aerobic respiration, which is responsible for generating the majority of the ATP required by cells to carry out routine function. Oxygen is utilized at the mitochondria as the final step in the ETS, where it is reduced to water. Without oxygen, animals are dependent on ATP produced through anaerobic mechanisms, where only a fraction of the total free energy potentially available from substrates is released. The ATP yield through aerobic metabolism is $\sim 15$ times more than that of anaerobic metabolism alone (Hochachka and Somero 2002). Without ATP produced through mitochondrial oxidative phosphorylation, the available anaerobic fuels will be quickly exhausted, limiting ATP production, ultimately leading to the failure of ATP dependent processes (Boutilier 2001).

\subsection{Mitochondrial Function}

First proposed by Peter Mitchell, the chemiosmotic theory describes the coupling of respiration and ATP synthesis in the mitochondria through oxidative phosphorylation (Mitchell 1966). Respiratory complexes I and II oxidize electron carriers produced through the TCA cycle, glycolysis, and pyruvate processing as well as other sources. Electrons are then passed through the respiratory complexes until they reach Complex IV, catalyzing the final step in the ETS, which reduces oxygen to water. The movement of electrons through the components of the ETS is coupled to the pumping of protons from the matrix to the inner mitochondrial space at Complexes I, III, and IV. This proton pumping along with proton consumption when $\mathrm{O}_{2}$ is reduced to $\mathrm{H}_{2} \mathrm{O}$, generates an electrochemical proton gradient across the inner mitochondrial membrane (Krauss 2001). The $\mathrm{F}_{1} \mathrm{~F}_{\mathrm{o}}$-ATPase (also known as Complex V) utilizes this proton motive force to synthesize ATP from phosphate and ADP thereby coupling the ETS proton pumping to ATP production (Figure 1.1-A). 
ATP is the primary energy currency used by the cell to accomplish work, including among other processes, the maintenance of cell membrane ion gradients, muscle contraction, the synthesis of proteins, nucleotides and other biological molecules (Biro 2013). Since the vast majority of cellular processes are energy consuming, regulating ATP concentrations is a necessity for cellular homeostasis. Under normal physiological conditions Complex V produces the bulk of ATP by catalyzing the following endergonic reaction:

$$
A D P^{3-}+P_{i}^{2-}+H^{+} \leftrightarrow A T P^{4-}+H_{2} O .
$$

Complex $\mathrm{V}$ is composed of two components; the catalytic $\mathrm{F}_{1}$ subcomplex and the membrane imbedded proton translocating $F_{o}$ subcomplex. Proton movement through the $F_{o}$ subcomplex proton channel is converted into torque, which rotates a central stalk, changing the conformation of the $F_{1}$ subunits which provides the driving force to synthesize ATP (Boyer 1993). The $F_{o}$ subcomplex also contains a peripheral stalk that extends from the distal $F_{1}$ subcomplex down into the membrane and acts as a stator, holding the $F_{1}$ subcomplex static relative to the $F_{o}$ subcomplex (Walker and Dickson 2006). Complex V is regulated by transcriptional, posttranslational, interacting proteins, and ionic transients (Long et al. 2015).

Beyond their central role in energy production, mitochondria also play an important role in many other cellular regulatory processes such as cellular ionic balance, cell division, reactive oxygen species (ROS) signaling, and cell fate (Tait and Green, 2012; West et al. 2011). Dysregulation of any of the above-mentioned mitochondrial processes can have implications on programed cell death (apoptosis), which is required for the growth of any multicellular organism but is also pathologically relevant to the development of some cancers and neurodegradation (Santore et al. 2002). The mitochondrial inner membrane space sequesters pro-apoptotic proteins such as cytochrome c, endonuclease G, procaspase-9, and apoptosis inducing factor (Chipuk et al. 2010; Joza et al. 2001; Parrish et al. 2001). Apoptosis can also be linked with many signals 
originating from the mitochondria including depolarization of mitochondrial membrane potential, decreased ATP production, ROS, and changes in $\mathrm{Ca}^{2+}$ homeostasis (Giorgi et al. 2008). Mitochondrial $\mathrm{Ca}^{2+}$ concentrations are tightly coupled with oxidative phosphorylation, but calcium can also cause mitochondrial-induced apoptosis. Generally, controlled increases in mitochondrial $\mathrm{Ca}^{2+}$ can cause a coordinated upregulation of many enzymes involved in oxidative phosphorylation and consequently increase ATP production. Though important for dynamic regulation, mitochondrial $\mathrm{Ca}^{2+}$ overload can cause swelling of the organelle and rupture of the outer mitochondrial membrane, releasing apoptotic factors into the cytosol (Giorgi et al. 2008). Similar to $\mathrm{Ca}^{2+}$, ROS needs to be tightly regulated for normal cellular function. During normal cellular respiration, mitochondrial ETS produces low levels of ROS that act as signaling molecules (Rice 2011). Over production of ROS can cause serious cell damage in the form of DNA and lipid oxidation and activation of proteolytic enzymes leading to potential cell death (Raedschelders et al. 2012).

\subsection{The Oxygen Starved Mitochondria}

Almost all known Eukaryotes are dependent on ATP produced though mitochondrial oxidative phosphorylation. If deprived of oxygen, mitochondria are unable to generate ATP through oxidative phosphorylation. This can become rapidly detrimental due to the cell's high energy demands during normal function. In some environments and pathological situations, oxygen can be completely absent (anoxic) and for most vertebrates, death swiftly ensues. When oxygen is absent, electrons cannot be passed to a terminal electron acceptor and ETS complexes will remain reduced unable to oxidize electron carriers. Without oxygen and electron carrier oxidation, proton pumping will stop, leading to a rapid depolarization of the mitochondrial membrane potential (Rouslin 1983). When the membrane potential depolarizes, the 
mitochondrial $\mathrm{F}_{1} \mathrm{~F}_{0}-\mathrm{ATP}$ synthase (Complex V) will run in reverse, hydrolyzing ATP similar to a proton pump, in an attempt to restore the membrane potential (St-Pierre et al. 2000).

Anoxia-induced reversal of Complex V converts the mitochondria from the largest ATP producer in the cell to a major ATP consumer, which will lead to a cellular energy crisis. Depending on the species, Complex V reversal can account for $50-80 \%$ of ATP utilization during hypoxic/anoxic periods that can occur during tissue ischemia (Rouslin, 1990). Since the vast majority of ATP is produced through mitochondrial oxidative phosphorylation, total ATP production is reduced to that of anaerobic production during anoxia. The reversal of complex $\mathrm{V}$ will further compound this energy crisis by utilizing limited ATP to ineffectively restore membrane potential (Figure 1.1-B). This mismatch between ATP production and utilization will result in s reduction of ATP dependent ion-pumping, resulting in a loss of intracellular ion homeostasis (Walters et al. 2012). This will create a net influx of $\mathrm{Na}^{+}$and efflux of $\mathrm{K}^{+}$into the cell, causing depolarization of organelles and eventually mitochondrial swelling (Boutilier 2001; Matsuyama et al. 2000). High levels extracellular $\mathrm{Ca}^{2+}$ will now be able to flow down their concentration gradient into the cytosol. This increase in $\mathrm{Ca}^{2+}$ can lead to activation of caspases and proteases that can lead to irreversible tissue damage and eventually apoptosis or necrotic cell death (Georgi et al. 2012; Boutilier 2001).

\subsection{Anoxic Environments and Facultative Anaerobes}

Even with the deleterious energetic challenges associated with anoxic environments, there are some organisms that are able to inhabit and survive environments that experience anoxia for extended periods of time. Anoxia generally occurs in aquatic environments that are stagnant or have a physical barrier to the atmosphere, where levels of oxygen consumption exceed oxygen input. Organisms that inhabit these environments are able to survive because they 
effectively down regulate ATP turnover while relying solely on anaerobic metabolism (facultative anaerobes). The crucian carp, Carassius carassius, is able to survive months in anoxia overwintering in ice-covered ponds (Nilsson and Renshaw 2004). Eastern oysters, Cassostrea virginicia, and the ghost shrimp, Lepidophthalmus louisianensis, are subjected to daily anoxic bouts and are able to survive days in complete anoxia (Holman and Hand 2009; Lenihan and Peterson 1998). Embryos of brine shrimp, Artemia franciscana, can survive and delay hatching in a wide variety of extreme environments, including complete anoxia, where encrusted brine shrimp embryos can survive for up to 4 years in complete anoxia with a metabolic rate 50,000 times lower than the aerobic value (Clegg 1997).

The western painted turtle, Chrysemys picta, and the red-eared slider, Trachemys scripta, are often considered the champions of anoxia tolerant vertebrates. Painted turtles are typically found across North America, reaching as far north as southern Canada, while red-eared sliders are primarily found in the southern-eastern United States. Because of pet releases, both species have become established all across North America and the red-eared slider is considered one of the top 100 most invasive species (Lowe et al. 2000). During the winter months, turtles will bury themselves in the mud at the bottom of the ponds, where they can become trapped by ice, which also cuts off diffusion of oxygen back into the water. In these cold, anoxic ice-covered ponds, they can survive for up to 4 months (Ultsch and Jackson 1982). For the remainder of this study I will focus on freshwater turtles, because of their profound ability to survive anoxia and the extensive research that has been done to elucidate the mechanisms underlying their impressive tolerance (Bickler and Buck, 2007; Hochachka et al 1996). The adaptations of metabolic suppression used in the above mentioned facultative anaerobes have a similar molecular basis as estivation and hibernation, and are conserved across phylogenetic lines (Storey 1996). Understanding these biochemical adaptations to anoxia tolerance could help illuminate potential 
clinical applications to mitochondrial and anoxia related pathologies.

\subsection{Anoxia Tolerance}

When relying exclusively on anaerobic metabolism, an organism has but two options, 1 . upregulate oxygen independent means of ATP production (eg increase glycolytic flux) to meet the metabolic demands of the cell (this is generally referred to as the Pasteur effect) or 2. decrease tissue and whole-animal energy demand to match the energy output of anaerobic metabolism. With an infinite source of carbon substrate the former might seem like a feasible long-term anoxia survival strategy, but carbon stores are limited and the accumulation of byproducts of glycolysis and lactate production can be deleterious to normal cellular functions. It is not surprising that facultative anaerobes avoid the potential deleterious effects mentioned above manifested in two general strategies: a profound metabolic rate depression and tolerance to accumulation of anaerobic byproducts (Bickler and Buck, 2007).

\subsubsection{Metabolic Rate Depression}

Metabolic rate depression is considered the primary strategy to survive chronic anoxia. As internal oxygen is depleted the gradual change to anaerobiosis is associated with $85-90 \%$ reduction in metabolism measured directly using calorimetry (Jackson 1968) and indirectly by lactate accumulation (Herbert and Jackson, 1985). Numerous studies have shown that there is a coordinated reduction in ATP turnover rates in multiple tissues in red-eared sliders exposed to anoxia (Wasser et al. 1990; Lutz et al. 1985; Brooks and Storey 1993). Ion pumps are some of the largest ATP sinks for normal cellular homeostasis, accounting for up to $25 \%$ of total ATP usage (Lodish et al. 2000). In the brain and liver of anoxic exposed turtles, ion channel activity decreases, which slows the dissipation of ion gradients (channel arrest). Channel arrest reduces 
the ATP dependent work of ion pumps and decreases the cells total electrical activity (spike arrest). Protein synthesis and degradation are also energetically expensive processes, and when exposed to anoxia there is a $90 \%$ reduction in protein synthesis in the liver (Hochachka et al. 1996). Protein phosphorylation has been shown to regulate the function of many cellular processes such as membrane receptors (e.g., N-methyl-D-aspartate-type glutamate receptor), ion channels $\left(\mathrm{Na}^{+}, \mathrm{Ca}^{2+}, \mathrm{K}^{+}\right.$), and transcription factors in anoxia tolerant turtles (Hochachka and Lutz 2001; Bickler and Buck 2007; Rider et al. 2000).

Since turtles are ectotherms, they have a metabolic rate that is five to ten times lower than that of a similar sized mammal and their metabolic rate is temperature dependent. Unlike the temperature dependent effects on metabolic rate, the processes mentioned above are actively suppressed. With a $\mathrm{Q}_{10}$ of 2-3, metabolic reaction rates drop two to three times for every $10^{\circ} \mathrm{C}$ decrease in body temperature (Jackson 2002). At $3^{\circ} \mathrm{C}$ in submerged in anoxic water, C. picta has a metabolic rate that is only $0.5 \%$ of its aerobic value at $20^{\circ} \mathrm{C}$ (Jackson 2000). When body temperature is accounted for, turtles are approximately 1,000 times more anoxia-tolerant than mammals (Nilsson and Lutz 2004).

\subsubsection{Buffering Ability}

In preparation for overwintering, turtles amass large reserves of glycogen to fuel extended periods of anaerobic glycolysis (Hochachka and Somero 2002). Due to the inability to fully oxidize carbon fuels, sustained anaerobic metabolism requires the regeneration of $\mathrm{NAD}^{+}$ through fermentation. Pyruvate, which is produced through glycolysis, is converted into lactate by lactate dehydrogenase. Even though metabolic suppression reduces the rate at which lactate is produced, concentrations as high as $200 \mathrm{mM}$ have been measured in turtles submerged for 5 months at $3^{\circ} \mathrm{C}$ (Ultsch and Jackson, 1982). T. scripta and C. picta posses an incredible buffering capacity that centralizes around exchange through their shells. The shell releases carbonate 
buffers and ions $\left(\mathrm{Ca}^{2+}, \mathrm{Na}^{+}, \mathrm{Mg}^{2+}\right)$ into the blood, which increase buffering capacity and help form mineral-lactate complexes. The shell also takes up lactate where it can be sequestered for the duration of anoxic exposure (Jackson 2000).

\subsubsection{Complex V Downregulation}

The anoxia-induced cessation of electron transfer and proton pumping leads to inner mitochondrial membrane depolarization causing complex $\mathrm{V}$ to run in reverse, hydrolyzing ATP to restore the mitochondrial membrane potential (Rouslin 1983; St Pierre et al. 2000; Duerr and Podrabsky 2010). In the anoxia tolerant $T$. scripta, long-term oxygen deprivation leads to a severe reduction in Complex V activity (Galli et al. 2013; Pamenter et al. 2016: see appendix B). This reduction in activity is thought to protect the limited stores of ATP produced through anaerobic metabolism. Similar instances of complex V inhibition have been reported in diapausing embryos of annual killifish (Duerr and Pordrabsky 2010) and in severely hypoxic/hibernating common frogs, Rana temporaria (Boutilier and St-Pierre 2002). Even with the substantial reduction in complex $\mathrm{V}$ activity seen in frog muscles exposed to severe hypoxia, some reverse function persists and accounts for $9 \%$ of total ATP turnover (St-Pierre et al. 2000). From the limited number of anoxia/hypoxia tolerant organisms investigated to date, it appears that down regulation of complex $\mathrm{V}$ is a common strategy in response to anoxia, however the mechanisms of complex $\mathrm{V}$ regulation in anoxia are unknown.

\subsubsection{Complex V Regulation in Anoxia}

Inhibition of complex V, which reduces wasteful ATP hydrolysis, is thought to be a common strategy in facultative anaerobes as a mechanism of energy conservation (Galli et al, 2013; St-Pierre et al. 2000). Because of the energy-limited state of the cell during anoxia, constitutively expressed regulatory proteins or post-translational modifications (PTM) are likely regulating Complex V function. Reversible protein phosphorylation has been previously 
described as a mechanism of regulating enzyme function during anoxia (Buck and Hochachka 1993; Storey 1996). Numerous enzymes in the mitochondria have been documented as targets of phosphorylation (Pagliarini and Dixon 2006). Regulation via phosphorylation has also been detected for the beta subunit of complex V in yeast (Kane et al. 2010). S-nitrosylation has also been implicated as a regulator of complex $\mathrm{V}$ activity in mouse heart tissue, where increasing concentrations of S-Nitrosoglutathione (GSNO), a nitric oxide donor (NO), decreases complex V activity in a dose dependent manner (Sun et al. 2007). NO signaling has also been shown to be involved in the adaptive response to anoxia, with increases in circulating nitrates and snitrosylated compounds increase in turtles during an anoxic exposure (Jacobsen et al. 2012; Fago and Jenson 2015).

Inhibitory Factor-1 $\left(\mathrm{IF}_{1}\right)$ is also known to inhibit complex $\mathrm{V}$ reverse hydrolysis during oxidative stress and has been well studied in mammalian models (Campanella et al. 2008). When mitochondrial matrix $\mathrm{pH}$ drops, which occurs when the ETS stops pumping protons into the inner membrane space, the affinity for $\mathrm{IF}_{1}$ binding to complex $\mathrm{V}$ increases (Rouslin and Broge 1990), which results in an inhibition of the activity of complex V. IF $F_{1}$ has also been shown to interact with complex $\mathrm{V}$, creating dimers which cause inner mitochondrial membrane folding, increasing the surface area of the cristae (Campanella et al. 2009). It is hypothesized that complex $\mathrm{V}$ dimerization and subsequent folding increases charge accumulation in the inner mitochondrial space, increasing oxidative phosphorylation efficiency (Minauro-Sanmigeul et al. 2005).

\subsubsection{Mitochondrial Response to Anoxia}

Research on mitochondrial function during anoxia is often overlooked because the ETS is oxygen dependent and it is often assumed that mitochondrial function simply ceases; however, mitochondria are key regulators of the apoptotic cascades and therefore reconfiguration of 
mitochondrial function is paramount to surviving anoxia. Thus, it is important to understand how mitochondria from anoxia tolerant organisms survive the consequences of anoxia exposure. During anoxia protein translation and degradation is suppressed over $90 \%$ in turtle hepatocytes but in heart mitochondria, protein synthesis is suppressed by three-fold after a 2 hour anoxic exposure (Hochachka et al 1996; Bailey and Driedzic 1996). Anoxia-induced gene expression has shown increases in specific subunits of the ETS, antioxidant enzymes, iron storage proteins, serpins, and shock proteins (Storey 2007). Transcripts for mitochondrial-encoded genes COX1 and ND5 increased to levels 3 fold higher than their normoxic controls after a $20 \mathrm{~h}$ anoxia exposure (Cai and Storey, 1996). 2D-gel electrophoresis proteome comparisons of anoxia-and normoxia-exposed T. scripta revealed a decrease in protein levels of many glycolytic enzymes and apoptotic enzymes but did not detect any mitochondrial proteins (Smith et al. 2015). With the energy-limited state due to severe metabolic rate suppression, one would assume that changes in gene expression and protein translation must represent end products that are essential to anaerobic survival. There is little known about the anoxia-induced changes to protein expression in anoxia tolerant turtles and even less known about mitochondrial-specific proteins. $\$

\subsection{Thesis Objectives}

The purpose of this thesis is to explore the mitochondrial response to anoxia in T. scripta. My first objective was to deduce the mechanism responsible for the severe downregulation of Complex V in anoxic exposed T. scripta seen in earlier studies (Galli et al. 2013). To do this, I further characterized enzyme kinetics $\left(\mathrm{K}_{\mathrm{m}} \& \mathrm{~V}_{\max }\right)$ in normoxia-and anoxia-exposed turtles. I then serially tested potential regulatory mechanisms of Complex V by manipulating enzymatic assay conditions to stimulate specific regulators of enzyme function.

The second objective of this thesis was to characterize the changes in proteins involved in mitochondrial function during anoxia. This also helped to characterize regulation of protein 
expression of Complex V during anoxia. To do this we used a proteomics approach to compare changes in expression in mitochondrial proteins in samples of isolated mitochondria from anoxia-and normoxia-exposed turtles. 
Figure 1.1

A

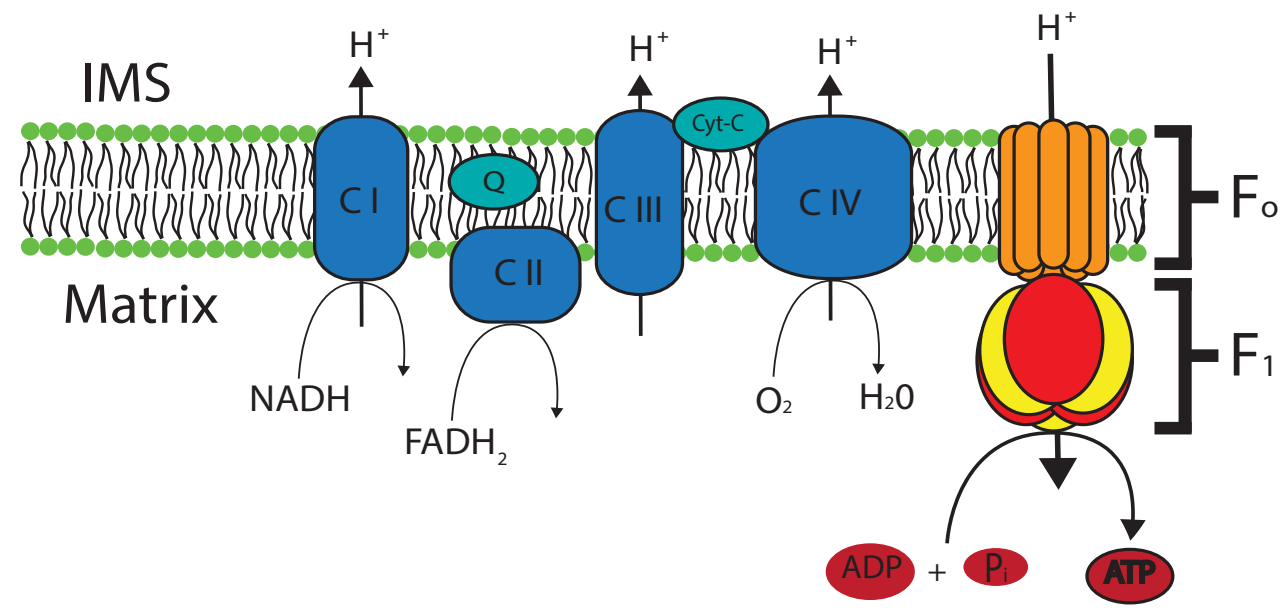

B

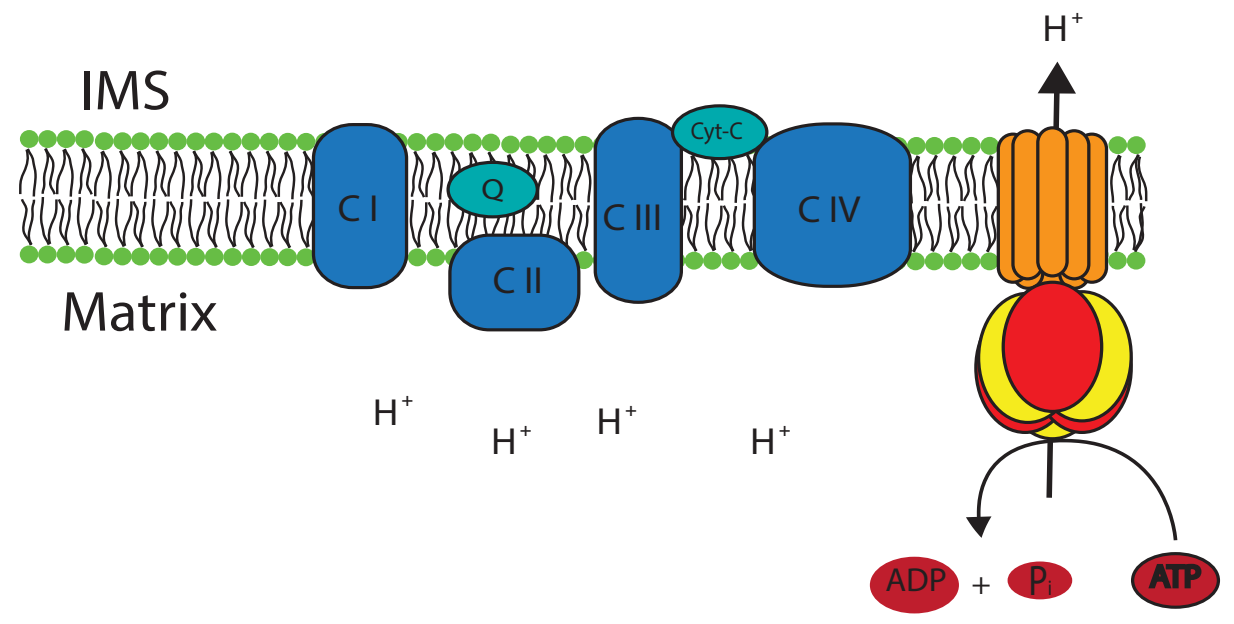

C

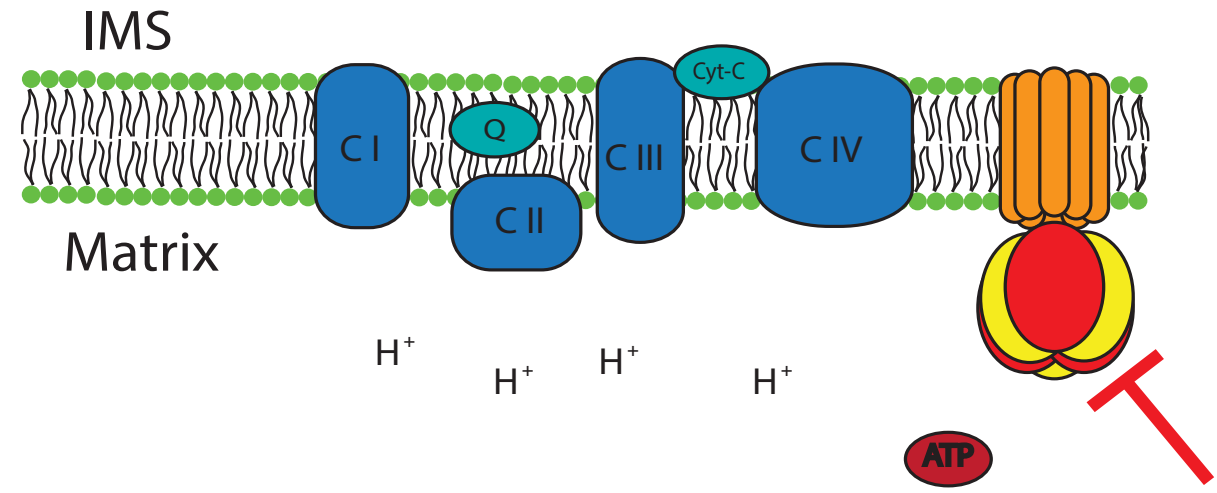


Figure 1.1 Graphical representations of the ETS, the effects of anoxia and inhibition of the $\mathrm{F}_{1} \mathrm{~F}_{\mathrm{O}}$-ATPase (complex $\mathrm{V}$ ). (A) Under normal physiological conditions when oxygen is present, electron carriers produced from substrate oxidation are oxidized by Complexes I and II. Electrons are then passed along the ETS to oxygen which acts as a terminal electron acceptor. Complexes I, III and IV pump protons from the matrix across the inner mitochondrial membrane into the intermembrane space (IMS). Pumping of protons creates the mitochondrial membrane potential $\left(\Delta \Psi_{m}\right)$, which is utilized by Complex $\mathrm{V}\left(\mathrm{F}_{1} \mathrm{~F}_{\mathrm{O}}\right.$-ATPase) to synthesize ATP. (B) In anoxia, the ETS will stop oxidizing electron carriers and subsequently pumping protons into the IMS. Protons will accumulate in the matrix and the $\Delta \Psi_{m}$ will depolarize. Complex $\mathrm{V}$ will run in reverse, hydrolyzing ATP in an effort to restore the $\Delta \Psi_{m} .(C)$ To limit the hydrolysis of valuable ATP during anoxia, organisms can inhibit Complex V. Diagram drawn by C. Gomez. Adapted from (Galli and Richards, 2014). 


\section{CHAPTER 2: MITOCHONDRIAL ADAPTATION TO ANOXIA}

\subsection{Introduction}

Mitochondrial oxidative phosphorylation, which requires a constant supply of oxygen, is the primary ATP-producing pathway for most eukaryotes. Though abundant in the atmosphere, oxygen levels can be reduced in some environments, and in extreme cases the environment can become anoxic. While most vertebrates only survive minutes in anoxia, there are some that can survive for extended periods in these anoxic environments. These facultative anaerobes switch from typical aerobic metabolism, when oxygen is plentiful, to fully anaerobic metabolism with exposure to anoxia. The North American freshwater turtles, Trachemys scripta and Chrysemys picta, are considered the champions of the vertebrate facultative anaerobes because of their ability to survive up to 4 months in cold, anoxic, ice-covered ponds (Jackson, 2002). The biochemical strategies that $T$. scripta and C. picta employ to survive anoxia have been well studied (Hochachka and Lutz 2000; Jackson 2000; Storey 2004; Bickler and Buck 2007) but few researchers have examined how the mitochondria, an organelle inextricably linked to oxygen, functions during anoxia.

Mitochondria are now recognized for their integral role in the progression of many hypoxia/anoxia related pathologies in mammals (e.g. stroke, pulmonary disease, heart attack) and research has focused on a number of therapeutics targeting the mitochondria (Walters et al. 2012). In most hypoxia/anoxia-intolerant mammals, oxygen deprivation at the mitochondria results in an inner-mitochondrial membrane depolarization due to the inability of the ETS to oxidize substrates (Griffiths 2012). As a result of the membrane depolarization, the mitochondrial $\mathrm{F}_{1} \mathrm{~F}_{\mathrm{o}}$-ATPase (complex $\mathrm{V}$ ) runs in reverse hydrolyzing ATP and consequently turning the mitochondria into the largest ATP consumer in the cell (Rouslin et al.1990). This, along with the hypoxia/anoxia-linked reduction in ATP production, ultimately leads to a cellular 
energy deficit, failure of essential ATP dependent processes, and ultimately cell death (Sanderson et al. 2013; Penna et al. 2013). It is well established that during anoxia, turtles suppress their ATP demands to $<10 \%$ of their aerobic use (Jackson 2000). This profound reduction in ATP consumption is largely the result of dramatic reductions in ATP-dependent ion pumping and in cellular protein synthesis (Hochachka et al. 1996). In addition to the aforementioned biochemical modifications, recent work in T. scripta showed a profound remodeling of the anoxic mitochondria that was characterized by reduced complex $\mathrm{V}$ activity in both the heart (Galli et al. 2013) and brain (Pamenter et al. 2016; see Appendix B). Complex V inhibition in response to long-term anoxia exposure has also been reported in diapausing Austrofundulus limnaeus embryos (St-Pierre et al. 2000) indicating that this might be a common strategy for energy conservation among facultative anaerobes.

Although the benefits of reduced complex $\mathrm{V}$ activity during anoxia are clear, the mechanism responsible for complex $\mathrm{V}$ inhibition in facultative anaerobes has not been investigated. There are several candidate pathways that may be responsible for the anoxiainduced inhibition of complex $\mathrm{V}$ in turtles. Inhibitory Factor- $1\left(\mathrm{IF}_{1}\right)$ is a known regulator of Complex $\mathrm{V}$ that is activated by the drop in $\mathrm{pH}$ associated with a de-energized cell (Campanella et al. 2009). $\mathrm{IF}_{1}$ has been well studied in mammalian models and has been shown to inhibit ischemic-driven ATP hydrolysis by complex V (Rouslin and Broge 1990; Campanella et al. 2008) by binding to the C-terminus region of the empty beta subunit of complex V after ATP hydrolysis, inhibiting ejection of products $(\mathrm{ADP}+\mathrm{Pi}$ ) or by inhibiting rotation required to hydrolyze ATP (Gledhill et al. 2007). S-nitrosylation has also been suggested as a potential regulator of complex $\mathrm{V}$ activity in mammalian ischemic preconditioning models (Sun et al. 2007). In turtles, anoxia induces increased levels of circulating nitrates, s-nitroso and ironnitrosyl compounds (Sandvik et al 2012). Phosphorylation has also been well documented as one 
of the primary mechanisms of cellular signaling and has been reported across many species on numerous enzymes in the mitochondria (Pagliarini and Dixon 2006). In yeast, phosphorylation as a mechanism for regulation has also been detected on the beta subunit of complex V (Kane et al. 2010). None of the above mentioned PTMs have been investigated as a mechanism for complex $\mathrm{V}$ inhibition in anoxia-exposed turtles.

Beyond the anoxia-induced inhibition of complex $\mathrm{V}$, few anoxia regulated mitochondrial modifications have been described in turtles. Gene expression analysis revealed an up regulation of mitochondrial genes MT-NAD5 [subunit 5 of NADH ubiquinone oxidoreductase (ND)] and MT-COXI (subunit 1 of cytochrome $\mathrm{C}$ oxidase) in heart, liver, and kidney in $20 \mathrm{~h}$ anoxia exposed T. scripta held at $7^{\circ} \mathrm{C}$ (Cai and Storey 1996). Increased expression of MT-NAD4 (subunit 5 of ND) and MT-CYTB (cytochrome b) was observed in liver of $20 \mathrm{~h}$ anoxia exposed $T$. scripta but no change in expression was detected in heart (Willmore et al. 2001). The same study showed variable changes of the two aforementioned genes across kidney, brain, and muscle revealing tissue-specific responses to anoxia. Proteomics analysis (2D-gel electrophoresis) of whole brain homogenates from C. picta revealed decreased glycolytic enzymes and apoptotic proteins but did not detect mitochondrial proteins (Smith et al. 2015), thus it remains unknown whether the gene expression changes observed by Cai and Storey (1996) and Willmore et al. (2001) resulted in differences in protein content. A more focused analysis of the mitochondrial proteome in anoxia turtles is needed to better understand other mitochondrial modifications important to anoxic survival in turtles.

The objectives of the present study were three fold. First, I examined multiple tissues in anoxic exposed turtles to see if inhibition of complex V was a tissue wide response. Second, I aimed to elucidate the regulatory mechanism responsible for the severe down-regulation of 
complex V in heart of anoxic exposed T. scripta (Galli et al. 2013). To accomplish this goal, I examined the role of S-nitrosylation, $\mathrm{IF}_{1}$, and protein-phosphorylation in regulating complex $\mathrm{V}$ activity. Third, I adopted a proteomics approach to determine if other metabolic, structural, and regulatory changes occurred in turtle heart mitochondria that may be associated with anoxic survival.

\subsection{Methods}

\subsubsection{Experimental Setup}

Thirty turtles, Trachemys scripta, were obtained from Niles Biological (Sacramento, CA, USA) and transported via airfreight to Bellingham, WA, USA. They were then transported by truck to The University of British Columbia (Vancouver BC Canada). All turtles were adults, weighing between 250 and 500 g. Upon arrival, turtles were placed in 100 L holding tanks $\left(18^{\circ} \mathrm{C}\right)$ with basking platforms equipped with UVA/UVB heat lamp (12h:12h, light:dark) with continuous access to food. Turtles were allowed to recover from transport for 8 weeks before they were randomly divided into two groups: anoxic $(n=15)$ and normoxic $(n=15)$. Turtles were placed in $2.5 \mathrm{~cm}$ deep water baths (water not exceeding the plastron) inside of a temperaturecontrolled chamber. Over the course of 2 weeks, temperature was reduced from $18^{\circ} \mathrm{C}$ to $4^{\circ} \mathrm{C}$ and light:dark cycles were reduced to $8 \mathrm{~h}: 16 \mathrm{~h}$. Turtles were held under these final conditions for an additional 4 weeks. After the holding period, the anoxic group was enclosed in weighted mesh cages and submerged in glass aquaria. The aquaria were then fitted with lids sealed using vacuum grease and constantly bubbled with $\mathrm{N}_{2}$ gas for 2 weeks. $\mathrm{N}_{2}$ gas was allowed to escape aquaria through a small one-way air valve. The dissolved oxygen was measured daily using a handheld dissolved oxygen probe (Oakton DO 110 Series, IL, USA) and never exceeded 1\% air saturation. The anoxia-exposed turtles were held in complete darkness to avoid light-induced 
increases in activity (Madsen et al., 2013). The remaining (normoxic) turtles were held at $4{ }^{\circ} \mathrm{C}$ in 8:16 light:dark for an additional 2 weeks. After the exposures, turtles were removed from their aquaria and immediately decapitated. The brain and liver were quickly dissected and frozen in liquid $\mathrm{N}_{2}$. A portion of the heart ventricle was also frozen in liquid $\mathrm{N}_{2}$ and the remainder was used for mitochondrial isolation. All experimental procedures were approved by The University of British Columbia animal care committee under A13-0254.

\subsubsection{Tissue Preparation}

\subsubsection{Whole Tissue}

In order to characterize the effects of anoxia on complex $\mathrm{V}$ and identify potential regulators, I chose to work with brain, liver, and heart tissue homogenates as well as isolated heart mitochondria (procedures for mitochondrial isolation are below). Tissues homogenates were prepared and assayed as previously described (Galli et al. 2013). For enzymatic assays, tissues where ground into a fine powder under liquid $\mathrm{N}_{2}$ using a mortar and pestle. A100 mg aliquot of ground tissue was transferred to $1.5 \mathrm{ml}$ tubes filled with $500 \mu \mathrm{l}$ of ice-cold hypotonic medium ( $25 \mathrm{mM} \mathrm{K}_{2} \mathrm{HPO}_{4}, 5 \mathrm{mM} \mathrm{MgCl}$, $\mathrm{pH}$ 7.2). Samples were sonicated for three 10 -sec bursts on ice (Kontes sonicator, Vineland, NJ, USA) and homogenates were then centrifuged at $600 \mathrm{~g}$ for $10 \mathrm{~min}$ at $4^{\circ} \mathrm{C}$. Supernatant from centrifuged samples was then transferred to a new micro centrifuge tube and centrifuged again at $600 \mathrm{~g}$ for $10 \mathrm{~min}$. Protein levels of the resulting supernatant were determined by Bradford protein assay (Bradford, 1976), then aliquoted and frozen at $-80^{\circ} \mathrm{C}$.

\subsubsection{Isolated Heart Mitochondria}

Mitochondria were isolated from heart tissue as previously described by (Almeida-Val et al., 1994). Heart ventricle muscle was dissected from connective tissue and rinsed with isolation 
buffer (250 mM Sucrose, $0.5 \mathrm{mM}$ NaEDTA, $10 \mathrm{mM}$ Tris, $0.5 \%$ fatty acid free BSA, $\mathrm{pH} 7.4$, $\left.4^{\circ} \mathrm{C}\right)$ to remove blood. Tissue was minced on ice using scissors and fresh isolation buffer. Minced tissue was then digested using 10ml of Trypsin (Type IX, Sigma-Aldrich) for $8 \mathrm{~min}$, then resuspended in Trypsin Inhibitor (Type I-S, Sigma-Aldrich) for 2 min. Sample was transferred to a glass mortar and then homogenized in isolation buffer using a loose fitting Teflon pestle for $30 \mathrm{sec}$ on ice. Homogenate was transferred to polycarbonate centrifuge tubes and centrifuged at $600 \mathrm{~g}$ for $10 \mathrm{~min}$ at $4^{\circ} \mathrm{C}$. Supernatant was filtered through glass wool and centrifuged again at $9000 \mathrm{~g}$ for $10 \mathrm{~min}$ at $4^{\circ} \mathrm{C}$. Supernatant was discarded and the resulting pellet was gently washed with isolation buffer, resuspended in buffer and centrifuged again at $9000 \mathrm{~g}$ for $10 \mathrm{~min}$ at $4^{\circ} \mathrm{C}$. The final pellet was resuspended in $400 \mu \mathrm{l}$ of isolation buffer. Protein levels were determined by Bradford protein assay (Bradford, 1976) then aliquoted and frozen at $-80^{\circ} \mathrm{C}$. After isolation, a fraction of the mitochondrial pellet was transferred to an Oroboros Oxygraph 2k high-resolution respirometry system (Oroboros Instruments, Innsbruck, Austria).

Mitochondrial fractions were assessed by stimulating respiratory flux through the ETS, which was measured using a substrate-uncoupler-inhibitor titration (SUIT) protocol (Lanza and Nair 2009).

\subsubsection{Enzymatic Assays}

\subsubsection{Complex V Activity}

Complex V activity was determined spectrophotometrically using a VersaMax spectrophotometer (Molecular Devices, Sunnyvale, CA, USA) in assay buffer $\left(25 \mathrm{mM} \mathrm{K}_{2} \mathrm{HPO}_{4}\right.$, $5 \mathrm{mM} \mathrm{MgCl}_{2}, 100 \mathrm{mM} \mathrm{KCl}, 2.5 \mathrm{mg} / \mathrm{mL}$ BSA; $\left.\mathrm{pH} 6.0,6.5,7.0,7.4,7.5,8.0,8.5\right)$. Activity was measured as oxidation of NADH (340nm) for $20 \mathrm{~min}$ (5 mM ATP, $2 \mathrm{mM} \mathrm{PEP,} 2 \mathrm{mM} \mathrm{NADH,} 3$

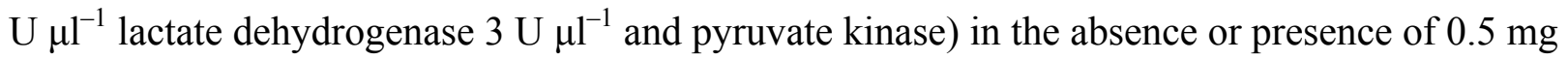
$\mathrm{ml}^{-1}$ oligomycin. The effects of different ATP concentrations $(0.05,0.1,0.5,1.0,2.5,5 \mathrm{mM}$ 
ATP, $\mathrm{pH}$ 7.4) on the reaction rate of complex $\mathrm{V}$ was determined and analyzed assuming standard Michaelis-Menten enzyme kinetics. Initial velocity was determined by calculating the slope the linear portion of the reaction over time.

\subsubsection{Post Translational Modifications}

In an attempt to determine if anoxia-induced complex $\mathrm{V}$ inhibition was due to reversible protein phosphorylation, I attempted to stimulate endogenous phosphatases as previously described by (MacDonald and Storey 1999) by incubating $30 \mu \mathrm{l}$ of heart tissue homogenate with $30 \mu$ stimulation buffer $\left(15 \mathrm{mM} \mathrm{MgCl}_{2}, 1.3 \mathrm{mM} \mathrm{CaCl}_{2}, \mathrm{pH} 7.4\right)$ for $30 \mathrm{~min}$ at room temperature. Corresponding control samples were incubated with $30 \mu 1$ hypotonic medium $(5 \mathrm{mM} \mathrm{MgCl} 2,100$ $\mathrm{mM} \mathrm{KCl})$. In order to determine if s-nitrosylation was responsible for the severe downregulation in anoxia, samples were incubated in the dark for $30 \mathrm{~min}$ at room temperature in the presence or absence of $1 \mathrm{mM}$ S-nitrosoglutathione (GSNO) in assay buffer. After incubations all samples were assayed as described above. As a positive control mouse heart tissue was extracted, treated, and assayed as described above.

\subsubsection{Western Blotting}

Frozen ventricle $(\sim 50 \mathrm{mg})$ was homogenized for $10 \mathrm{sec}$, in $500 \mu$ l of homogonenization buffer [100 mM Tris-HCl, $1 \%(\mathrm{w} / \mathrm{v})$ sodium dodecyl sulfate (SDS), $5 \mathrm{mmol}^{-1}$ ethylenediaminetetraacetic acid, $1 \mu \mathrm{g} \mathrm{ml}^{-1}$ aprotinin, $1 \mu \mathrm{g} \mathrm{ml}^{-1}$ pepstatin $\mathrm{A}, 1 \mu \mathrm{g} \mathrm{ml} l^{-1}$ leupeptin, $20 \mu \mathrm{g} \mathrm{ml}^{1}$ phenylmethanesulphonylfluoride, pH7.5]. Homogenates were centrifuged at $13000 \mathrm{~g}$ for $3 \mathrm{~min}$ at $4^{\circ} \mathrm{C}$. Supernatants were transferred to a clean microcentrifuge tube and total protein was determined using Bradford protein assay (Bradford, 1979). The remaining supernatant was added to SDS-sample buffer (Laemmli 1970) and denatured by placing samples in a dry block heater for $5 \mathrm{~min}$ at $100^{\circ} \mathrm{C}$. SDS-polyacrylamide gels were loaded with $50 \mu \mathrm{g}$ of sample per lane and electrophoresed for $20 \mathrm{~min}$ at $75 \mathrm{~V}$ followed by $90 \mathrm{~min}$ at $160 \mathrm{~V}$. A control sample was 
loaded into each gel to account for gel-to-gel variation. Proteins were then transferred to nitrocellulose membranes (Bio-Rad Laboratories, Hercules, CA, USA) using a Trans-Blot semidry transfer cell (Bio-Rad) for $30 \mathrm{~min}$ at $17 \mathrm{~V}$.

Nitrocellulose membranes were blocked for $60 \mathrm{~min}$ in blocking solution ([TTBS: 17.4 mmol ${ }^{-1}$ Tris- $\mathrm{HCl} ; 2.64 \mathrm{mmol}^{-1}$ Tris Base; $0.5 \mathrm{M}$ sodium chloride $(\mathrm{NaCl})$; and $0.05 \%$ Tween$20(\mathrm{v} / \mathrm{v})]$ with $2 \%(\mathrm{w} / \mathrm{v})$ non-fat powdered milk). Membranes were incubated overnight at $6^{\circ} \mathrm{C}$ in a 1:2000 dilution of either primary antibody: Anti-ATPase Inhibitory Factor-1 antibody (ab110277) or rabbit monoclonal Anti-ATPB (ab14730) (abcam, San Fransisco, CA, USA), in blocking solution. The following day, blots were rinsed in TTBS, and then incubated in 1:5000 dilution of the secondary antibody (Donkey Anti-Rabbit IgG H\&L, HRP conjugate, (ab16284, abcam) in TTBS for 60 min. Blots were rinsed in TTBS then developed using an Optiblot ECL Detect Kit (ab133406, abcam). Bands were visualized using FluorChem 8800 imager (Alpha Innotech, San Leandro CA, USA) and quantified using ImageJ software (1.48v National Institutes of Health, USA). Data were corrected for total protein loaded by staining membranes with coomassie blue.

\subsubsection{Proteomics}

\subsubsection{Digestion, Labeling, and Mass Spectrometry}

To identify changes in the mitochondrial proteome, we conducted quantitative mass spectrometry using standard protocols at the UBC Centre for High-Throughput Biology. Briefly, samples of frozen isolated mitochondria were thawed then suspended in SDS buffer $(62.5 \mathrm{mM}$ Tris, $10 \%$ glycerol, $2 \%$ SDS, $0.02 \%$ Bromophenol Blue, $\mathrm{pH} 6.8$ ) and run on a $10 \%$ SDS-PAGE gel. Proteins were visualized by colloidal coomassie blue staining (Candiano et al. 2004) and digested out of the gel as described in Chan et al. (2006) or digested directly using paramagnetic beads and Single-Pot Solid-Phase-enhanced Sample Preparation (SP3) as described in Hughes et 
al. (2014). Peptide samples were purified by solid phase extraction on C-18 STop And Go Extraction (STAGE) Tips (Ishihama et al., 2002), and each treatment was labeled by reductive dimethylation using formaldehyde isotopologues (Parker et al. 2012).

A preliminary study was conducted using pooled samples of mitochondria isolated from normoxic-and anoxic-exposed turtles hearts. Briefly, individual mitochondrial samples were diluted to $1 \mathrm{mg} \mathrm{ml}^{-1}$ protein prior to pooling and equal volumes were combined to make the final pooled samples. 6 samples of normoxic-exposed mitochondria were pooled and labeled with a light formaldehyde isotopologue while 6 samples of anoxic-exposed mitochondria were pooled and labeled with a heavy formaldehyde isotopologue. Samples were analyzed on a single LCMSMS run as described below.

We repeated this study using individual isolated mitochondrial samples and a control sample across multiple LC-MSMS runs. This study was replicated using the same samples but two separate digestion techniques, in-gel or SP3 digestion. Individual isolated mitochondrial samples were diluted to $1 \mathrm{mg} \mathrm{ml}^{-1}$ protein prior to digestion and labeling. Normoxic samples were labeled with a light formaldehyde isotopologue while anoxic samples were labeled with a medium formaldehyde isotopologue. A control sample, consisting of six separate fractions of isolated mitochondria from normoxic-exposed turtles were pooled together and labeled with a heavy formaldehyde isotopologue.

Individual digested and labeled samples were combined in 1:1:1 ratio [Normoxic(light): Anoxic(medium): Control(heavy)], then loaded onto a Bruker Impact II Q-ToF mass spectrometer (Billerica, Massachusetts, USA). Peptide separation was carried out on a $50 \mathrm{~cm}$ inhouse packed 75um C18 column by a Proxeon EasynLC UPLC system, using 120min water:acetonitrile gradients. Eluted peptides were ionized in positive ion mode, collecting MS/MS spectra for the top 15 peaks $>1000$ counts, with a 30 second dynamic exclusion list. The 
final product again was purified by C18 STAGE tips and analyzed by LC-MSMS. The dimethyl labeling methodology results in mass differences between peptides with similar sequences, it is possible to determine the relative abundance of each peptide and perform a quantitative comparison.

\subsubsection{Data Analysis}

All enzymatic data were analyzed using GraphPad Prism 6 software (La Jolla, CA, USA). For Michaelis-Menten enzyme kinetics, a rectangular hyperbola was fit though the data and $V_{\max }$ and $\mathrm{K}_{\mathrm{m}}$ were calculated from the curve. All other assays were done using $5 \mathrm{mM}$ ATP, which was above the saturating levels calculated in the Michaelis-Menten enzyme kinetics. Data shown in Figure 2.1, 2.3 and Table 2.1 was analyzed using a student's $t$-test where treatment was compared to the corresponding control. To examine the effects of anoxia on complex V activity in multiple tissues, we developed planned comparisons and used t-tests to evaluate the effects of anoxia on complex $\mathrm{V}$ activity in each tissue and corrected for multiple comparisons using Benjamini-Hochberg false discovery rate. All remaining enzymatic data were analyzed using a two-way analysis of variance (ANOVA), and when significant differences were detected, a Holm-Sidak or Tukey post hoc analysis was used to determine where the significant differences occurred. For all statistical analysis, $\mathrm{p}<0.05$ was accepted as significant.

Mass Spectrometry results were loaded into MaxQuant v1.5.1.0 (Munich, Germany) for analysis. Quantitation was performed considering the Dimethyl labels, using a 0.006 da MS tolerance and 40ppm MSMS tolerance, and a house built in silico digested Chrysemys picta bellii proteome database (extracted from NCBI). Ratios reported between separate LC-MSMS runs were normalized against their corresponding control ratio and averaged. All averaged ratios with a corresponding coefficient of variation $>50$ were disregarded. Proteins detected from both SP3 and in-gel digestion techniques were combined. Proteins detected in both digestion treatments 
were analyzed for differential regulation and if protein expression differed in direction or were not consistently above or below our differential expression cut off they were discarded from the analysis. $85 \%$ of the proteins detected in both replicates shared the same differential regulation result. Differential expression was defined as at least a 1.2 fold change in expression between the two treatments. Proteins were organized into general function groups using KEGG orthology (Kanehisa Laboratories; Kyoto, Japan).

\subsection{Results}

\subsubsection{Anoxia Exposure}

Turtles exposed to 2 weeks of anoxia at $5^{\circ} \mathrm{C}$ were comatose with little movement. All turtles sampled had spontaneously beating hearts when dissected. Two separate approaches were taken to understand the effects of chronic anoxia exposure on mitochondria function: a candidate systems approach and a mitochondrial proteomics approach. To further understand the phenomenon of reduced complex $\mathrm{V}$ activity in anoxic turtles, potential mechanisms regulating the enzyme function were investigated. Mass spectrometry-based proteomics was used to elucidate changes in the mitochondrial proteome during chronic anoxia exposure.

\subsubsection{Regulation of Complex $V$ in Anoxic Turtles}

\subsubsection{Complex V Activity}

Reduction in complex V activity had been previously reported in hearts of anoxia exposed T. scripta (Galli et al. 2013). In order to determine if complex V inhibition occurred across tissues we measured complex $\mathrm{V}$ activity in brain and liver tissue after a 2-week anoxia exposure. There was a significant effect of anoxia exposure on complex $\mathrm{V}$ activity in heart, brain, and liver tissue, where anoxia caused an 81 to $87 \%$ decrease in activity compared with normoxic samples (Figure 2.1). 


\subsubsection{Complex V Kinetics}

To further understand the type of inhibition of complex $\mathrm{V}$ across multiple tissues we characterized enzyme kinetics of complex $\mathrm{V}$ in heart homogenates and isolated heart mitochondria. Maximal activity $\left(\mathrm{V}_{\max }\right)$ and the Michaelis-Menten Constant $\left(\mathrm{K}_{\mathrm{m}}\right)$ of complex $\mathrm{V}$ running in the ATP hydrolysis direction were calculated by analyzing the effects of changes in [ATP] on complex V activity using a double rectangular hyperbola plot. In heart tissue homogenates from anoxic-exposed turtles, complex V did not follow typical Michaelis-Menten (MM) kinetics and the responses to varying [ATP] could not be described by a double rectangular hyperbola (Figure $2.2 \mathrm{~A}$ ). We were unable to calculate a $\mathrm{K}_{\mathrm{m}}$ or $\mathrm{V}_{\max }$ from the data using MM kinetics, but assumed that at 5mM ATP the concentration of substrate was saturating. Similar to the data shown in Figure 2.1, there was a significant effect of anoxia on $\mathrm{V}_{\max }$ for complex $\mathrm{V}$ in isolated heart mitochondria at saturating levels of ATP (Figure 2.2 B). Isolated heart mitochondria from normoxic-and anoxic-exposed turtles showed typical Michaelis-Menten kinetics and there was no significant effect of anoxia exposure on $\mathrm{K}_{\mathrm{m}}$ (Table 2.1).

\subsubsection{Complex V Protein Expression}

Since changes in expression of proteins associated with enzymes can change activity we measured protein levels of complex V using two separate proteomics approaches. We detected 11 of the 15 known subunits of complex $\mathrm{V}$ through quantitative formaldehyde labeling LCMS/MS analysis (Table 2.2). Three of the detected subunits, subunit B1 (ATP5F1), subunit $\mathrm{f}$ (ATP5J2), and mitochondrial-encoded coupling factor 6 (MT-ATP5J), had decreased protein expression. Using western blot analysis, we probed for the catalytic beta subunit of complex V (ATP5B). Similar to results obtained using proteomics analysis, western blots revealed no significant changes in expression of the beta subunit between normoxic-and anoxic-exposed turtles (Figure $2.3 \mathrm{~A}$ ). 


\subsubsection{4 pH Effects on Complex V Activity}

In order to determine if Complex $\mathrm{V}$ activity was affected by $\mathrm{IF}_{1}$ binding due to decreasing $\mathrm{pH}$, activity was measured across a $\mathrm{pH}$ range of 6.0 to 8.5 (Figure 2.4). Repeated measures two-way ANOVA analysis revealed a significant effect of $\mathrm{pH}$ and anoxia on complex $\mathrm{V}$ activity with a significant interaction between anoxia and $\mathrm{pH}$. Sidak's multiple comparisons analysis revealed complex $\mathrm{V}$ activity was significantly reduced when the assay was run at lower $\mathrm{pH}$ values in both normoxic and anoxic turtles. It also revealed that at $\mathrm{pH} 6$ there was no significant effect of anoxia on Complex V activity but at $\mathrm{pH} 6.5$ to 8.5 , there was a significant difference in Complex V activity between normoxia-and anoxia-exposed turtles. We attempted to perform western blot analysis to detect the effects of anoxia on $\mathrm{IF}_{1}$, a $\mathrm{pH}$ activated inhibitor of complex $\mathrm{V}$, but it was not detected because antibodies (abcam ab110277) did not react with $\mathrm{IF}_{1}$ from T. scripta.

\subsubsection{Post Translational Modifications}

We examined the effects of activation of endogenous phosphatases and Snitrosoglutathione (GSNO) on complex V activity in turtles. The stimulation of endogenous phosphatases using a buffer previously described by (MacDonald and Storey 1999) in normoxicexposed turtle heart caused a significant reduction in Complex V activity compared to it's corresponding control (Figure 2.5 ). There was a $15 \%$ reduction in activity in heart from normoxic-exposed turtles with activated phosphatases, though the reduction did not match the $87 \%$ reduction seen in hearts from anoxic-exposed turtles (Figure 2.1).

Incubation of samples with 1mM GSNO did not have a significant effect on Complex V activity in heart from both normoxic-and anoxic-exposed turtles. Using mouse heart homogenates as a positive control, we confirmed that our protocols could replicate previously 
observed GNSO mediated responses. Incubation of mouse heart homogenates with 1mM GSNO results in a significant reduction in complex $\mathrm{V}$ activity, consistent with the nitrosylation-induced decreases seen in Sun et al. (2007).

\subsubsection{Mitochondrial Proteomics}

\subsubsection{Pooled Sample Proteomics}

Our initial proteomics analysis compared pooled heart mitochondria samples from 6 normoxic and 6 anoxic-exposed turtles, which were formaldehyde labeled. The labeled and digested samples from each pooled sample were combined and analyzed using LC-MS/MS. This analysis detected and identified a total of 343 proteins fragments (see Appendix A, Table S1 for a full list of proteins detected), but only 29 mitochondrial proteins were identified as differentially regulated with a $20 \%$ difference in expression. Differentially regulated proteins were organized by biological function (Table 2.3) according to KEGG orthology. Analysis of detected proteins revealed that a large number of proteins associated with the ETS were differentially expressed in response to anoxia exposure. In particular, multiple subunits of ND (NDUFB6, NDUFA5, and MT-ND4) increased in expression in response to anoxia exposure. Similarly, there were increases in one subunits of COX (COX5B) and an ETS associated $75 \mathrm{kDa}$ heat shock protein (TRAP1). We also observed two ETS regulatory proteins, ubiquinolcytochrome-c reductase complex assembly factor 2 (UQCC2) and coenzyme Q-binding protein homolog $\mathrm{A}$ or $\mathrm{B}(\mathrm{COQ} 10 \mathrm{~A} / \mathrm{B})$ decrease in expression in anoxia. Proteins associated with amino acid metabolism including methylcrotonoyl-CoA carboxylase subunit alpha (MCCA), hydroxymethylglutaryl-CoA lyase (HMGCL), and methylmalonyl-CoA mutase (MUT) also showed an anoxia-induced increase in expression. In contrast to the increased expression observed with proteins associated with amino acid metabolism, mitochondrial proteins involved lipid metabolism decreased in expression including acyl-CoA dehydrogenase family member 10 
(ACAD10), short-chain specific acyl-CoA dehydrogenase (ACADS), carnitine Opalmitoyltransferase 2 (CP2), very long-chain specific acyl-CoA dehydrogenase (ACADVL), acetyl-coenzyme A synthetase 2-like (ACSS1), succinate-semialdehyde dehydrogenase (ALDH5A1) and, alpha-aminoadipic semialdehyde dehydrogenase (ALDH7A1). Overall analysis of the pooled sample revealed an up-and down-regulation of enzymes and proteins involved in the ETS and amino acid metabolism and down-regulation of proteins involved in the TCA cycle and lipid metabolism in turtles exposed to anoxia.

\subsubsection{Biological Replicate Proteomics}

To conduct biological replicates we ran the same analysis described above with single samples of isolated heart mitochondria from normoxic $(n=3)$ and anoxic-exposed turtles $(n=3)$. Samples were dimethylated using different formaldehyde isotopologues, mixed in a 1:1:1 ratio (Normoxic: Anoxic: Control). The control sample was composed of a pooled group of normoxicisolated mitochondria so data could be compared across mass spectrometry runs.

Normoxic/Anoxic ratios are corrected against the control intensities for each peptides detected in all LC-MS/MS runs. In order to maximize our ability to detect peptides, two separate digestions techniques, SP3 and in-gel digestion, were used before separate proteomics analysis. These two digestion techniques led to the detection of 126 and 331 protein fragments, respectively (see Appendix A, Table S2 for full list of proteins detected) of which 51 peptides overlapped. Of the proteins that were detected in both digestions $85 \%$ of the proteins showed the same directional response (a 1.2 fold mean change in expression between treatments; see materials and methods). The proteins that did not show the same response were discarded from the remaining analysis.

Thus, for all remaining analysis we combined the peptides from both digestion techniques. For all proteomics, corrected ratios were averaged across the biological replicates and of all the proteins identified, there were 55 proteins that were differentially regulated 
according to our 1.2 fold cut off. Differentially regulated proteins were organized by biological function using KEGG orthology (Table 2.4) and it should be noted that these categorical annotations are not meant to define the sole functions of the proteins detected as many enzymes are involved in multiple metabolic pathways. The majority of the proteins differentially regulated were involved with the ETS. There were increases in subunits belonging to respiratory complexes such as COX (COX6B1), ND (NDUFS8), and cytochrome b-c1 (CKMT2 and UQCRFS1). Three subunits of complex V were downregulated, as reported above, as well as single subunit of ND (NDUFA12) and two subunits of electron transfer flavoprotein (ETFA and ETFDH). One subunit of succinate dehydrogenase (SDHA), which is involved in both the ETS and the TCA shows decreased expression. The only other downregulated proteins involved in the TCA cycle were citrate synthase (CS) and isocitrate dehydrogenase (IDH2). The alpha and beta subunits of succinyl-CoA ligase (SUCLG1 and SUCLA2), a key enzyme in the TCA, both increased in expression. Many proteins involved in amino acid metabolism, specifically leucine, isoleucine and valine degradation, showed decreased expression (IVD, ACAA2, MCCC2, AUH, and HSD17B10). Proteins belonging to, regulating, or adjacent to the ETS and TCA cycle with differential expression are depicted visually in Figure 2.7. There were decreases in three heat shock proteins (HSPA8, HSPE1, and HSPD1). Overall, analysis revealed up-and downregulation in anoxia in many proteins involved in major metabolic pathways such as ETS and TCA cycle as well as amino acid, lipid, and carbohydrate metabolism. There was also a down regulation of multiple heat shock proteins and mitochondrial transcription related proteins.

\subsection{Discussion}

\subsubsection{Complex V Regulation}

In anoxia exposed $T$. scripta, we observed the same severe reduction in complex $\mathrm{V}$ activity that was previously shown in heart of the same species (Galli et al. 2013), but we also 
demonstrated that complex $\mathrm{V}$ inhibition in response to anoxia occurs in the liver and brain (Figure 2.1). Of all the tissues examined, Complex V activity appeared to be highest in the heart under normoxic conditions, which is likely due to the high mitochondrial density in heart tissue compared to brain and liver seen in reptiles (Else and Hulbert 1985). Interestingly, although normoxic complex V activity varies across tissues, two-weeks anoxia exposure resulted in similar decreases $(80 \%$ to $87 \%)$ in all tissues examined, suggesting that the same regulatory mechanism may be responsible for the reduction in activity in all tissues. We chose to focus on the heart for the majority of the analysis because the heart is essential for organismal survival because it must continue to function during anoxia, albeit at a highly reduced rate. In the anoxic isolated heart mitochondria, complex $\mathrm{V}$ maximal activity was significantly reduced with no significant differences in enzyme $\mathrm{K}_{\mathrm{m}}$ for ATP (Table 2.1), which suggests a non-competitive inhibition of complex V. There were reduced protein levels of three subunits of complex V (ATP5A1, ATP5F1, and MT-ATP5J) in anoxia that could contribute to the reduction in activity (Table 2.1 \& Figure 2.3), although further analysis will be required. Interestingly, complex V does not appear to be regulated by $\mathrm{IF}_{1}$ (Figure 2.4), nitric oxide (Figure 2.6), or phosphorylation (Figure 2.7), which are all know complex V regulators in mammals (Campanella et al. 2008; Sun et al. 2007; Kane et al. 2010).

\subsubsection{Characterization of Complex V}

Since its discovery, tremendous work has gone into elucidating the molecular mechanisms of ATP synthesis through oxidative phosphorylation (Mitchell 1966; Boyer 1993). The kinetics of complex V has also been investigated thoroughly, attempting to extrapolate the kinetics of endergonic ATP synthesis from enzyme assays measuring the consumption of ATP by reverse hydrolysis (Vinogradov 2000). In mouse heart tissue, the catalytic portion of complex V hydrolyzes ATP following typical MM kinetics with a $\mathrm{K}_{\mathrm{m}}$ of $10 \times 10^{-4} \mathrm{M}$ (Vinogradov 2000). In 
normoxic-isolated mitochondria from $T$. scripta heart, we calculated an apparent $\mathrm{K}_{\mathrm{m}}$ of approximately $2.9 \times 10^{-4} \mathrm{M}$ with no significant difference in $\mathrm{K}_{\mathrm{m}}$ between treatments. I was unable to fit a rectangular hyperbola and calculate $\mathrm{a} \mathrm{K}_{\mathrm{m}}$ in heart from anoxia-exposed heart due to the severe reduction in activity. Isolated mitochondria from anoxic-exposed turtles did, however, exhibit typical Michaelis-Menten kinetics, although we only observed a $40 \%$ reduction in complex $\mathrm{V}$ activity in anoxic isolated mitochondria compared to the $87 \%$ reduction in anoxic heart tissue. This difference in kinetics and inhibition might have arisen through different tissue preparation methods. For the whole-tissues homogenization, heart ventricle was frozen immediately using liquid $\mathrm{N}_{2}$ while isolation of mitochondria can take up to $1 \mathrm{~h}$ while in solutions containing normal oxygen levels. The extended mitochondrial isolation process in the presence of atmospheric oxygen could have partially reduced some of the anoxia-induced inhibition of complex V.

No change in protein expression was detected in the catalytic beta subunits (ATP5B) of complex V using western blots (Figure 2.3). Mass spectrometry based proteomics revealed the same result (Table 2.2), as well as no changes in the expression of the majority of the subunits detected. We did, however, see a decrease in expression of the three complex V subunits [subunit f(ATP5A1), subunit B1 (ATP5F1), and mitochondrial encoded coupling factor-6 (MT-ATP6)] in our proteomic analysis of isolated mitochondria (Table 2.2). All three subunits are associated with the peripheral stalk (Walker and Dickson 2006; Jonckheere et al. 2012), which has been suggested to act as a tether for the storage of elastic force during ATP synthesis (Ogilvie 1997). It is unclear if this downregulation in protein expression in the peripheral stalk is responsible for the drastic reduction in complex $\mathrm{V}$ activity; however, the peripheral stalk is vital for interacting with the catalytic $F_{1}$ portion of complex $V$ while the rotational force of central stalk is used for ATP synthesis (Welch et al. 2011). Mutational analysis of subunits of the peripheral stalk in 
Saccharomyces cerevisiae caused reduced ATPase activity (Welch et al. 2011), thus it is possible that the reduced expression in subunits for the peripheral stalk is decreasing complex $\mathrm{V}$ activity in anoxic turtles. Additional experiments are needed to understand the functional significance of decreased expression of these subunits.

\subsubsection{2 pH Effects on Complex V Activity}

Along with decreased cytosolic $\mathrm{pH}$ when exposed to anoxia, mitochondrial membrane potential depolarizes leading to matrix acidification. Pullman and Monroy (1963) first discovered the nuclear-encoded inhibitory protein $\mathrm{IF}_{1}$ that binds and inhibits the complex $\mathrm{V}$ activity during matrix acidification and ATP hydrolysis, which is typical in oxygen deprived cells (Gledhill 2007). $\mathrm{IF}_{1}$ 's inhibition of complex $\mathrm{V}$ is $\mathrm{pH}$ dependent, binding strongly to complex $\mathrm{V}$ at $\mathrm{pH}$ values $<6.5$ (Cabezon et al. 2000). Other than inhibition of reverse ATP hydrolysis, this small inhibitory protein is involved in maintaining cristae structure by facilitating complex $\mathrm{V}$ dimerization (Campanella et al. 2008) promoting increased cristae surface area (MinauroSanmiguel et al. 2005). $\mathrm{IF}_{1}$ protein sequence and mode of action is highly conserved across organisms with homologues found in animals, plants, and yeast, though most research has been aimed at mammalian models (Campanella et al. 2009). Mammals have high affinity $\mathrm{IF}_{1}$ that inhibit hydrolysis during oxygen deprivation but $T$. scripta have a low affinity $\mathrm{IF}_{1}$ with limited complex V inhibition (Rouslin 1995). Even though $\mathrm{IF}_{1}$ is highly conserved, there are some differences in the primary structure between human and turtle homologs. Aligned peptide sequences (see Appendix C) of $\mathrm{IF}_{1}$ from both C. picta (NCBI: XP_005313615.1) and bovine (NCBI: NP_787010.1) revealed no substitutions of "important" amino acids involved with binding complex $\mathrm{V}$ that were previously explored in bovine $\mathrm{IF}_{1}$ (Gledhill et al. 2007). Interestingly, Bason et al. (2011) showed that mutations of Q27 (glutamine) of bovine $\mathrm{IF}_{1}$ causes reduced binding affinity to complex V. The predicted sequence of $\mathrm{IF}_{1}$ from C. picta shows a 
substitution of alanine, a small hydrophobic amino acid, in place of the glutamine found in bovine $\mathrm{IF}_{1}$. This substitution might play a role in the decrease $\mathrm{IF}_{1}$ affinity for complex $\mathrm{V}$ seen by Rouslin (1995).

Mitochondria isolated from the hearts of normoxic-and anoxic-exposed T. scripta showed significant reduction in activity at $\mathrm{pH}$ values $<7.5$. At $\mathrm{pH} 6$, isolated mitochondria showed no significant difference in complex V between the two treatments. Mitochondria from anoxiaexposed turtles did no show any change in complex $\mathrm{V}$ activity at $\mathrm{pH}$ values $>7.5$ (Figure 2.4 ), where $\mathrm{IF}_{1}$ should be in its deactivated form (Campanella et al. 2009). This suggests that the inhibition in activity is due to a $\mathrm{pH}$ effect on complex $\mathrm{V}$ rather than an inhibition due to $\mathrm{IF}_{1}$. Unfortunately, $\mathrm{IF}_{1}$ was not detected in our proteomic analysis of isolated mitochondria and antibodies did not react with $\mathrm{IF}_{1}$ from $T$. scripta. Further characterization of the functionality of $\mathrm{IF}_{1}$ is needed to understand its role in anoxia tolerant organisms.

\subsubsection{Post Translational Modification Regulating Complex V Activity}

During anoxia exposure, a coordinated reduction in all ATP consuming and producing pathways must occur to allow for long-term survival. Due to the high cost of protein turnover, it is likely that posttranslational modifications (PTMs) are responsible for mediating many of biochemical responses that occur as the turtle enters anoxia (Storey 1996). In turtles, phosphorylation has been shown to be the primary mechanism for inhibiting glycolytic enzymes, voltage gated ion channels, protein synthesis, and membrane receptors (Hochachka and Lutz 2001; Bickler et al. 2007; Storey and Storey 2004), all of which cellular contribute to metabolic rate suppression (Storey 2004). Recent work has shown that the mitochondrial proteome is extensively phosphorylated as part of its dynamic regulation (Foster et al 2008; Pagliarini and Dixon 2006). Recent advances in PTM-specific mass spectrometry have revealed a large number 
of PTMs (phosphorylation, acetylation, trimethylation, nitration, s-nitrosylation and tryptophan oxidation) to the subunits of complex $\mathrm{V}$ in many mammalian species, though no functional significance has been associated with most modifications (Kane and Van Eyk 2009). When endogenous phosphatases were stimulated a significant decrease in activity was detected in hearts in normoxic-exposed turtles (Figure 2.5). This reduction in complex V activity due to the stimulation of endogenous phosphatases was small (only $15 \%$ ) compared with the $80 \%$ reduction seen in anoxic-exposed turtles, suggesting that although reversible phosphorylation may play a role in regulation complex $\mathrm{V}$ activity, it is not likely responsible for the severe anoxia-induced inhibition observed in turtles. Our data suggest that reverse phosphorylation does not play a role in severe reduction in activity seen in anoxia-exposed turtles though activation of phosphatases did slightly decrease activity, suggesting that phosphorylation does have some role in regulating complex $\mathrm{V}$. This protocol for activating endogenous phosphatases has been successfully used in other studies (MacDonald and Storey 1999), but our analysis could be improved by including an alkaline phosphatase treatment. In addition, although I followed the protocol outlined in MacDonald and Storey (1999) precisely and observed changes in complex V activity (albeit not as expected), this analysis should have also included a positive control in a previously studied species to ensure that the protocol worked as expected.

NO signaling in the form of s-nitrosylation has been shown to protect mammalian cells from ischemia (anoxia)/reperfusion damage. Moderate levels of NO have been shown to inhibit ETS complexes and reduce reactive oxygen species production (Rakhit 1999). In turtles and crucian carp, anoxia induces increased levels of circulating nitrates, s-nitroso and iron-nitrosyl compounds (Jensen 2014; Sandvik et al 2012). There has also been evidence suggesting that nitric oxide plays a role in complex $\mathrm{V}$ regulation in mammalian ischemic preconditioning models. In mice, Complex V activity is modulated by s-nitrosylation, decreasing activity with 
increasing concentrations of GSNO, a nitric oxide donor (Sun et al. 2007). Indeed, in heart homogenates from mice, we demonstrated that incubation with $1.0 \mathrm{mM}$ GSNO reduces complex $\mathrm{V}$ activity over $60 \%$, which is consistent with other published data. Interestingly however, application of the same GSNO protocol to isolated heart mitochondria did not affect complex V activity in either normoxic or anoxia turtles. These data suggest that even though s-nitrosylation plays a role in the regulation of complex $\mathrm{V}$ in mammals, it does not appear to be involved in regulating complex $\mathrm{V}$ in $T$. scripta.

\subsubsection{Mitochondrial Proteome}

When T. scripta is exposed to anoxia, ATP turnover rates decrease dramatically due to a coordinated reduction in all ATP producing and consuming pathways (Hochachka et al. 1996). One of the largest ATP sinks for normal homeostatic function is protein turnover, estimated to utilize one third of the total energy produced in the cell (Lahtvee et al. 2014). Not surprisingly there is a $90 \%$ reduction in protein turnover in turtle hepatocytes after anoxic exposure (Land et al. 1993; Land and Hochachka 1994). Similarly it has been shown that there is a 3-fold reduction in protein synthesis in both heart and isolated heart mitochondria after just 2 hours of anoxic perfusion (Bailey and Driedzic 1996). Because of the energy-limited state of the cell, one would expect that changes in protein synthesis or degradation during anoxia must represent vital changes essential to surviving anaerobiosis.

Previous work on anoxia-induced changes in anoxic turtles has focused on gene expression after a relatively short-term anoxia exposure (Cai and Storey 1996; Storey and Storey 2004; Hochachka et al. 1996). Though useful in showing which genes are up or down regulated in anoxia, gene expression data has limitations as mRNA expression may not necessarily correspond to protein expression. This is the first study using mass-spectrometry based 
proteomics to quantify total protein changes in any vertebrate facultative anaerobe. We show a series of proteins involved in major metabolic pathways, including ETS, TCA cycle, and enzymes feeding into these pathways that are differentially regulated. The aim of this study was to further illuminate the scope in which mitochondrial proteins change during chronic anoxic exposure. We chose to focus on the mitochondrial proteins because Galli et al. (2013) showed that after exposure to chronic-anoxia T. scripta exhibited a unique mitochondrial phenotype with reduced aerobic capacity. This was the partly the result of reduced complex V activity which our candidate systems approach did not reveal the regulatory mechanism responsible.

Our analysis detected differential regulation in proteins involved in the main metabolic pathways (ETS, the TCA cycle, amino acid, and lipid metabolism) in the mitochondria of $T$. scripta when exposed to chronic anoxia. The list of biological processes is not intended to be an exhaustive list, as many of the proteins detected are involved in anaplerotic reactions in the mitochondria. It must also be noted that, in the case of enzymes, protein expression may not correspond to enzyme activity. We only detected a single mitochondrial-encoded protein, coupling factor 6 (MT-ATP5J), which is discussed above. One would assume that the lack of oxygen would lead to the down-regulation of ETS enzymes, but we see up regulation of a subunit in ND (NDUFS8), two subunits of cytochrome b-c1 complex (UQCRFS1 and CKMT2) and one subunit in COX (COX6B1). Similarly after a 20h anoxia exposure, transcript levels for mitochondrial-encoded genes, COX1 and ND5, rose to levels 3 fold higher than their normoxic controls (Cai and Storey, 1996). We also see a down regulation of multiple subunits of complex V (ATP5A1, MT-ATP5J, and ATP5F1), two subunits of electron transfer flavoprotein (ETFA and ATFDH) and subunit 12 of ND (NDUFA12). Though there are changes in the relative expression of subunits of all the ETS complexes it is important to note that these changes do not affect maximal enzyme activity of complexes I, III and IV as shown previously using standard 
enzyme analysis (Galli et al. 2013).

Interestingly we also see one subunit of succinate dehydrogenase (SDH) decrease in expression. SDH has a keystone role in mitochondrial metabolism as the only enzyme that has components involved in both the ETS and the TCA cycle. Other than the ETS and TCA cycle, we see differential expression in multiple enzymes involved in lipid metabolism, amino acid metabolism, and mitochondrial biogenesis. Though certain enzymes feeding in and out of the TCA have different expression levels, it is still unclear whether these expression changes result in functional changes to oxidative phosphorylation. During times of anaerobiosis, alternate forms of metabolism occur and fuel preference needs to change to meet metabolic demands. A large number of proteins involved in leucine, isoleucine and valine degradation, show decreased expression (IVD, ACAA2, MCCC2, AUH, and HSD17B10) as well as many proteins involved in lipid metabolism (ACADM, ALDH9A1, CRAT, ECH1, SLC44A2). Many of these proteins are directly associated with or have products that feed into the TCA cycle (Figure 2.7).

Another clear outcome of the proteomics analysis is the decreased expression of three heat shock proteins (HSP); 60kDa heat shock protein (HSPD1), its co-chaperone 10kDa heat shock protein (HSPE1), and heat shock cognate $71 \mathrm{kDa}$ protein (HSPA8). This conflicts with previous studies that show an increase in expression of HSP60s and HSP72/73s after a $12 \mathrm{hr}$ anoxic exposure (Chang et al. 2000). Many HSPs are located in subcellular compartments and even found outside the cell (De Maio 2014). We only chose to focus on mitochondrial proteins by analyzing isolated mitochondria, so this decrease in response to anoxia might be indicative of proteins being sequestered in other subcellular locations. More studies are needed to understand if there are actual changes in protein expression or if HSP are sequestered to different subcellular compartments. 
The proteins we detected through LC-MS/MS analysis represent just a small fraction of proteins found in the mitochondria and this is by no means a comprehensive list of all differentially expressed proteins in response to anoxia. Facultative anaerobes, like $T$. scripta and C. picta, have adapted to survive in complete anoxia for overwintering periods up to 4 months. The overarching strategy to surviving anoxia is a mass suppression of all ATP consuming and producing processes. Protein expression is energetically expensive so any changes in protein levels are thus likely to represent necessary expressional changes that offer protection to the cell during anoxia. We also see a severe reduction in complex $\mathrm{V}$ activity across multiple tissues as another mechanism of ATP conservation. Decreased expression in certain complex V subunits might be responsible for this reduction in activity. Other than complex V, we see changes in expression in many proteins involved in other oxidative pathways. Further work is needed to understand the functional significance of these changes in protein levels and how they aid in anoxia tolerance. 


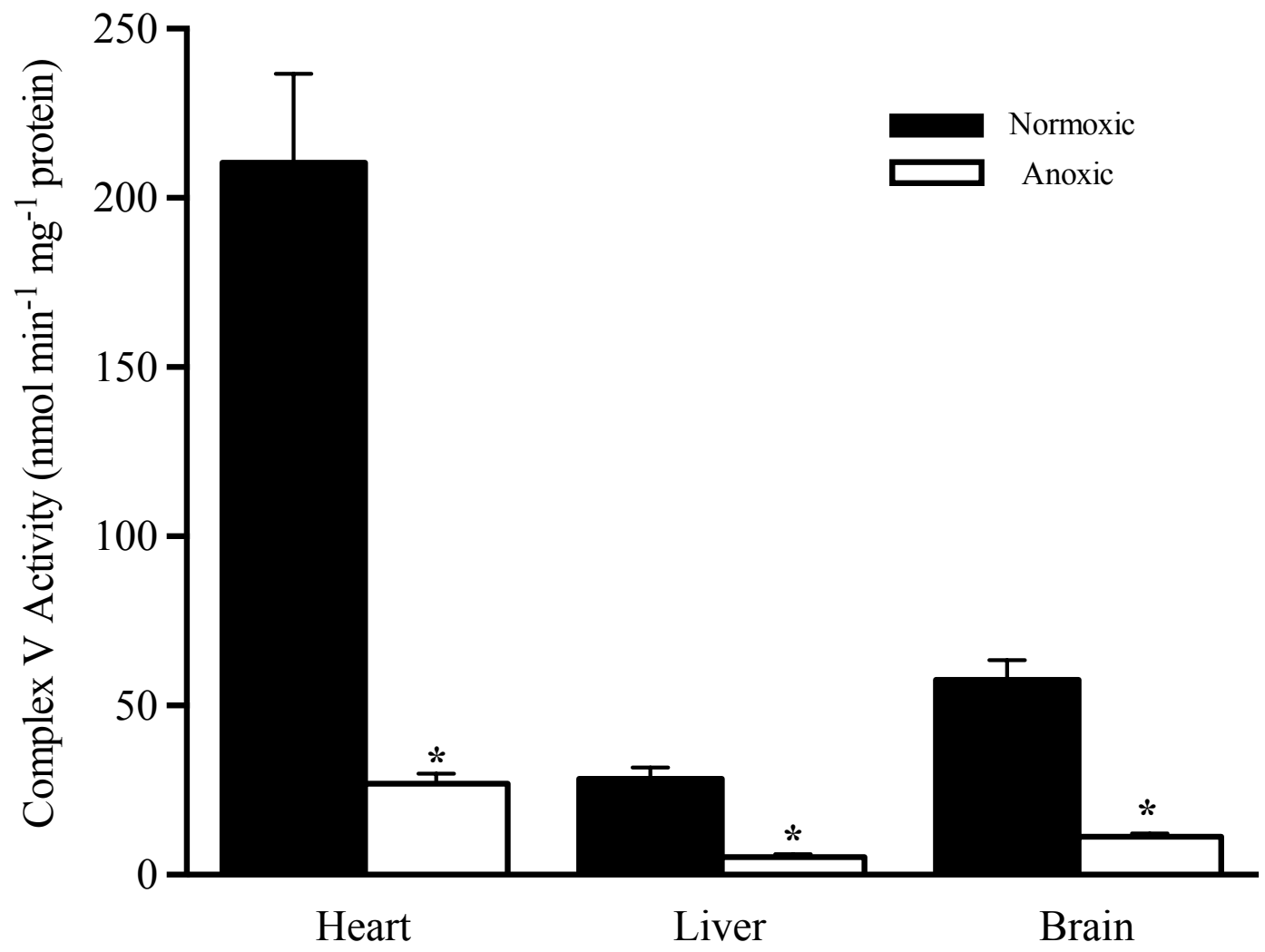

Figure 2.1 The Effect of anoxia on Complex V activity in heart $(n=6)$, liver $(n=8)$, and brain $(n=6)$ from normoxic-(black bars) and anoxic-exposed (white bars) turtles. Data are means \pm SEM. Asterisks indicate a significant difference between normoxia- and anoxia-exposed turtles $(\mathrm{p}<0.05, \mathrm{t}$-test $)$ 
Table 2.1 Michaelis constant $\left(\mathrm{K}_{\mathrm{m}}\right)$ and maximum Complex $\mathrm{V}$ activity $\left(\mathrm{V}_{\max }\right)$ in normoxic- and anoxic-exposed turtle heart tissue and heart mitochondria. All values reported as Mean $\pm \mathrm{SEM}$. Asterisks denote a significant difference between it's corresponding control exposure $(\mathrm{p}<0.05, \mathrm{t}$ test)

\begin{tabular}{|c|c|c|c|c|}
\hline & Exposure & $\begin{array}{c}\mathbf{K}_{\mathbf{m}} \\
(\mathrm{ATP} \mathrm{mM})\end{array}$ & $\begin{array}{c}\mathbf{V}_{\mathbf{m a x}} \\
\text { (nmol min-1 mg-1 protein) }\end{array}$ & $\mathrm{R}^{2}$ \\
\hline \multirow{2}{*}{ Whole Heart Tissue } & Normoxic & $0.1548 \pm 0.0561$ & $149.80 \pm 11.10$ & 0.5929 \\
\hline & Anoxic & N/A & N/A & $-2.4 \times 10^{-12}$ \\
\hline \multirow{2}{*}{$\begin{array}{l}\text { Isolated Heart } \\
\text { Mitochondria }\end{array}$} & Normoxic & $0.2949 \pm 0.1035$ & $1219.00 \pm 99.03$ & 0.6455 \\
\hline & Anoxic & $0.2474 \pm 0.0748$ & $769.40 \pm 51.64 *$ & 0.7074 \\
\hline
\end{tabular}


Table 2.2 List of identified mitochondrial $\mathrm{F}_{1} \mathrm{~F}_{0}$-ATPase subunits after LC-MS/MS analysis isolated heart mitochondria from normoxic $(n=3)$-and anoxic-exposed turtles $(n=3)$. Samples were dimethylated using different formaldehyde isotopes, mixed in a 1:1:1 ratio (Normoxic: Anoxic: Control), and either SP3 digested or ran on SDS-PAGE followed by in gel digestion. Ratios of detected peptides shown are expressed against the their respective control intensities. Average ratios with a coefficient of variation (CV) exceeded 50 were not reported. Differential expression was defined as a 1.2 fold change in protein expression between the two conditions.

\begin{tabular}{cllcc}
\multicolumn{5}{c}{$\boldsymbol{F}_{\mathbf{1}} \boldsymbol{F}_{\boldsymbol{o}}$-ATPase Protein Levels } \\
\hline protein ID & & \multicolumn{3}{c}{ average } \\
subunit & gene & normoxic/anoxic & CV \\
XP_008172424.1 & $\mathrm{e}$ & ATP5I & 0.852 & 23.978 \\
XP_005303393.1 & O & ATP5O & 0.856 & 22.289 \\
XP_005302390.1 & delta & ATP5D & 0.859 & 5.432 \\
XP_008164277.1 & alpha & ATP5A1 & 0.897 & 7.762 \\
XP_008173484.1 & beta & ATP5B & 0.922 & 2.748 \\
XP_005299830.1 & g & ATP5L & 0.975 & 1.273 \\
XP_005297517.1 & d & ATP5H & 0.987 & 9.677 \\
XP_005291975.1 & gamma & ATP5C1 & 1.004 & 8.71 \\
YP_009022049.1 & coupling factor 6 & MT-ATP5J & 1.217 & 10.033 \\
XP_008169959.1 & B1 & ATP5F1 & 1.2201 & 14.0159 \\
XP_005289114.1 & f & ATP5J2 & 1.482 & 44.867
\end{tabular}


A
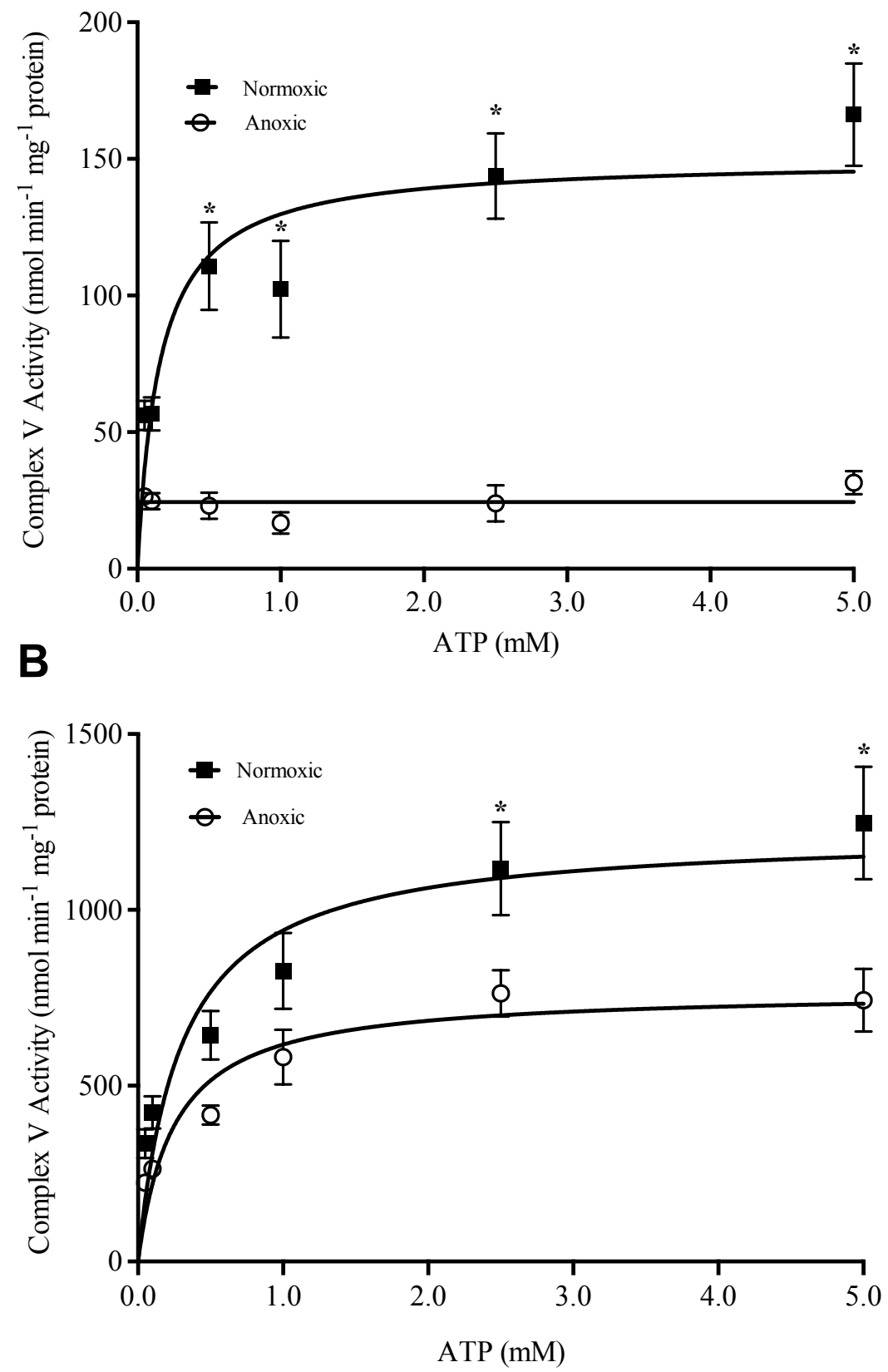

Figure 2.2 The effect of chronic anoxia on the kinetics of Complex V activity in heart tissue $(A)$ and isolated turtle heart mitochondria $(B)$ from normoxic- (filled squares; $n=5$ ) and anoxiaexposed (open circles; $n=5$ ) turtles. Data are means \pm SEM. Asterisks indicate a significant difference between normoxia- and anoxia-exposed turtles $(\mathrm{p}<0.05$, two-way ANOVA) 


\section{A}

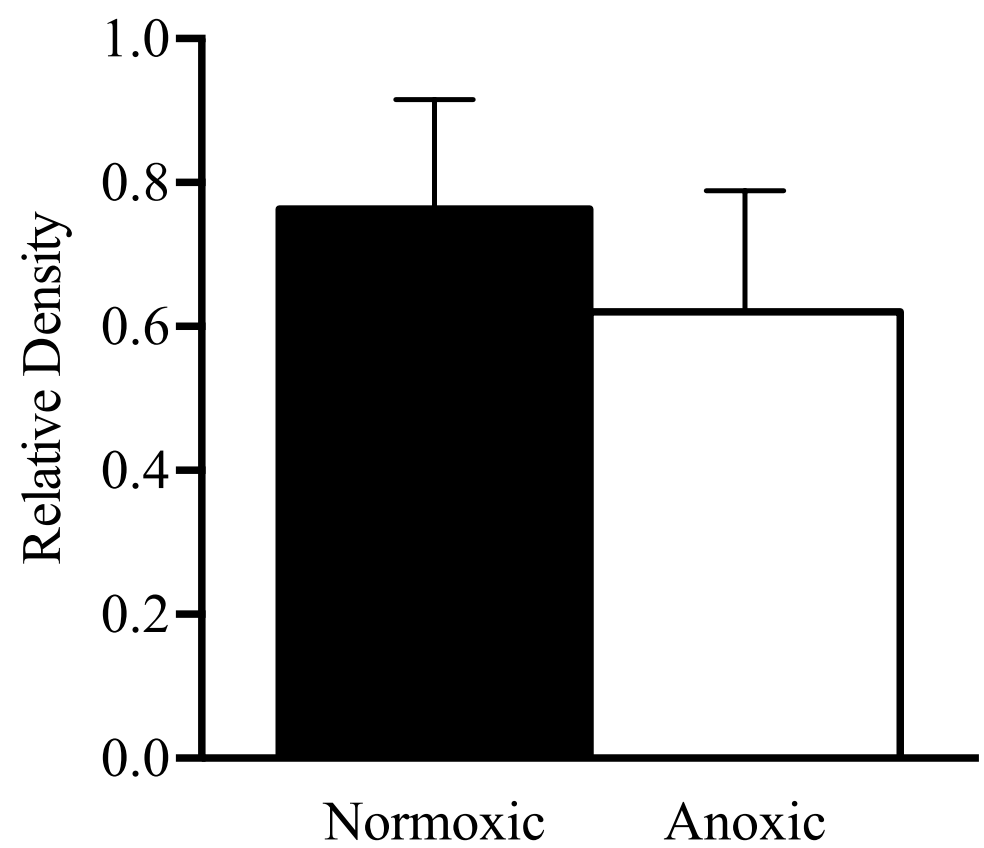

B

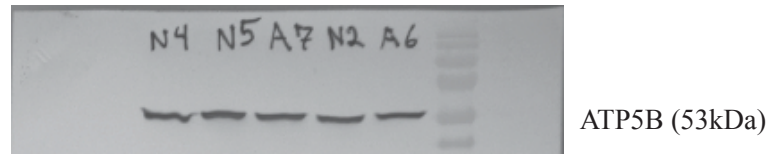

Figure 2.3 (A) Effects of chronic anoxia on protein expression of the beta subunit of complex V in normoxic-(black bars, $n=6$ ) and anoxic-(white bars, $n=4)$ exposed turtles. Data are means \pm SEM. (B) Sample western blots of complex V beta subunit expression in normoxic-(N) and anoxic-(A) exposed turtles. 


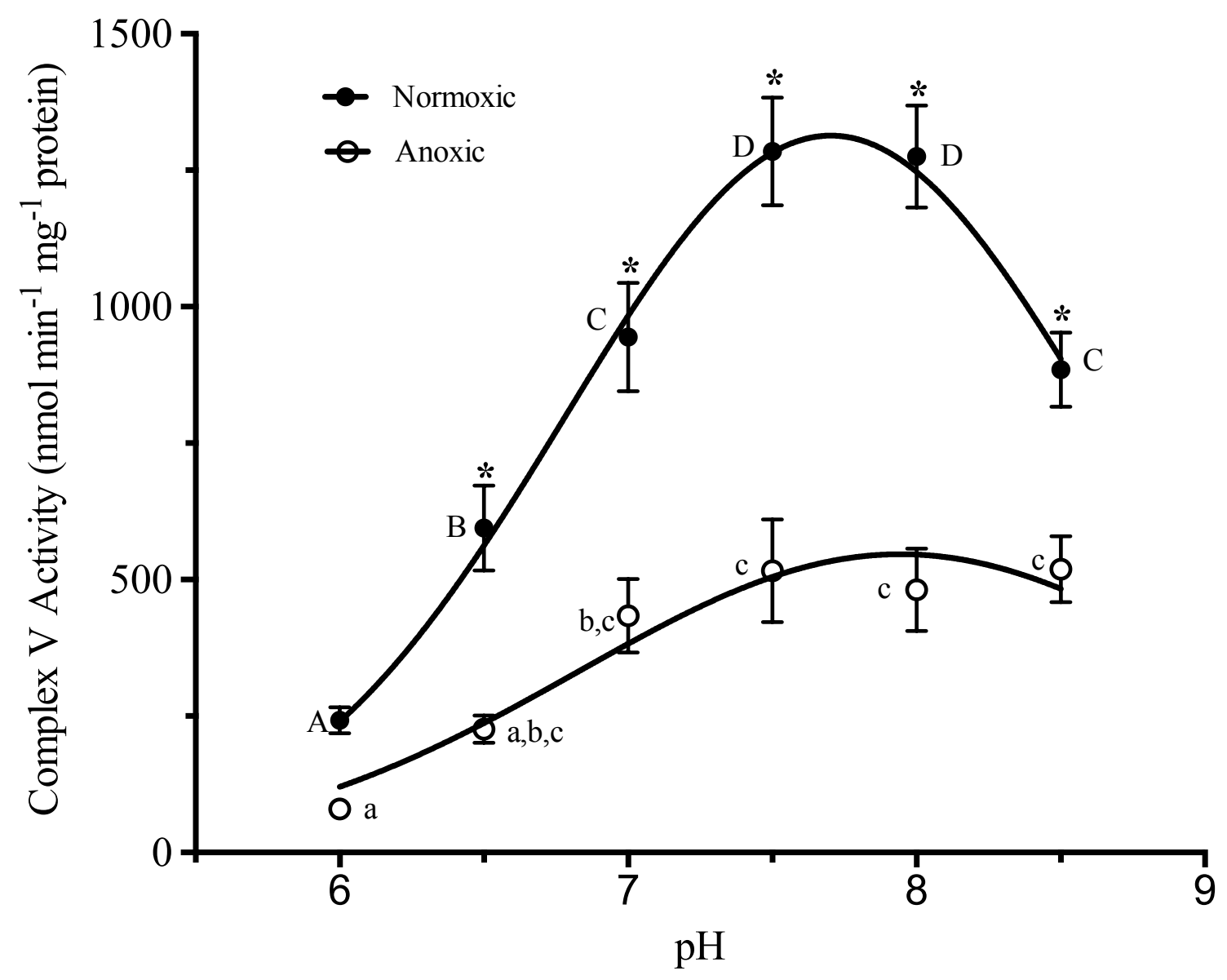

Figure 2.4 The effect of $\mathrm{pH}$ on Complex V activity in anoxia- (open circles; $n=6$ ) and normoxia-exposed (closed circles; $n=6$ ) turtle heart mitochondria. Data are means $\pm \mathrm{SEM}$. Data was fit with a Gaussian function. Asterisks indicate a significant difference between normoxiaand anoxia-exposed mitochondria ( $\mathrm{p}<0.05$, two-way ANOVA Tukey's multiple comparisons). Within the same exposure group, values that share a common letter are not significantly different ( $\mathrm{p}<0.05, \mathrm{RM}$ two-way ANOVA Sidak's multiple comparisons). 


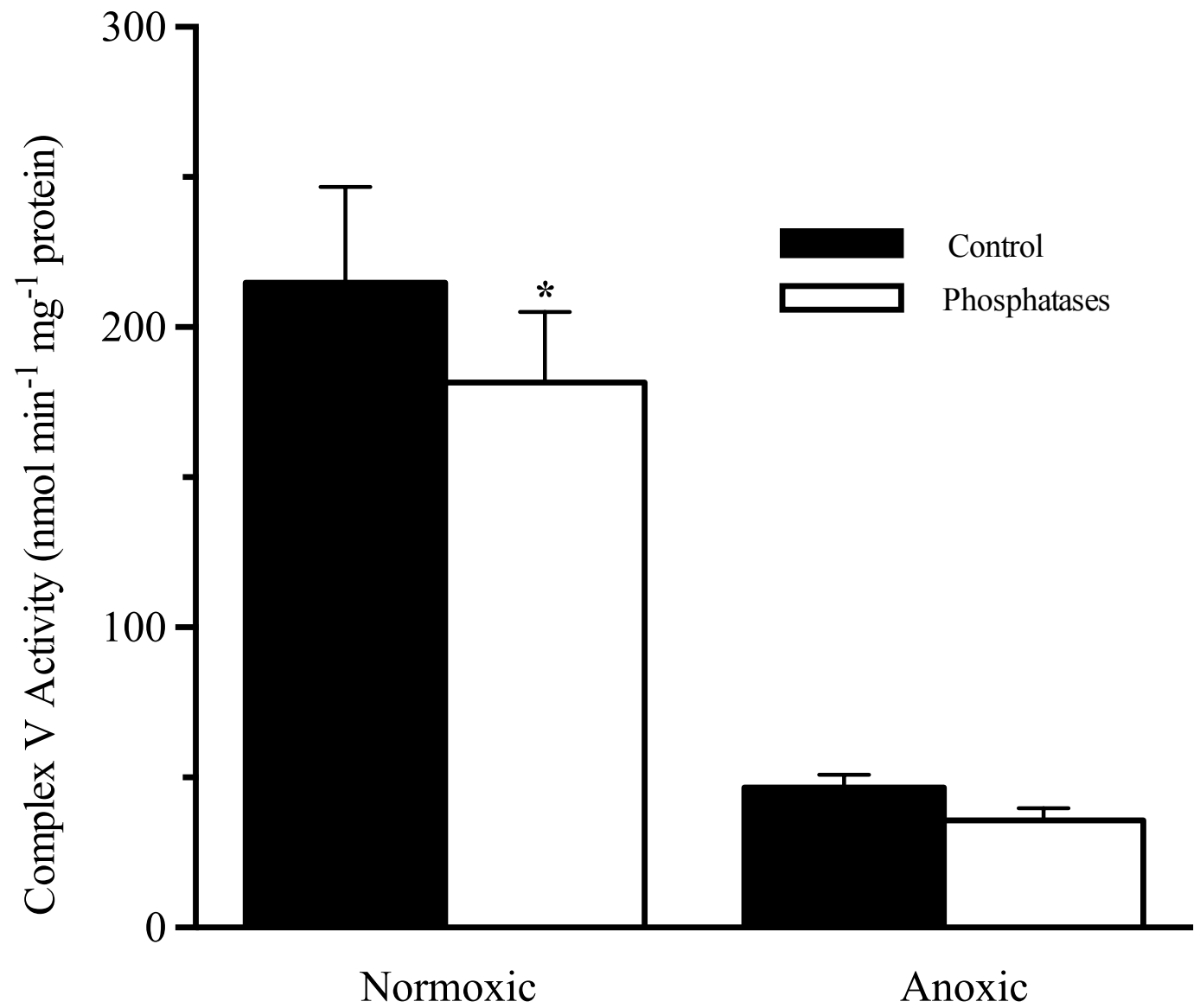

Figure 2.5 The effect of stimulating endogenous protein phosphatases on Complex $\mathrm{V}$ activity in cardiac muscle from normoxic $(n=5)$ - and anoxic-exposed $(n=5)$ turtles. Data are means \pm SEM. Asterisks indicate a significant difference between stimulated phosphatases (white bars) and its corresponding control (black bars) $(\mathrm{p}<0.05$, paired t-test). 


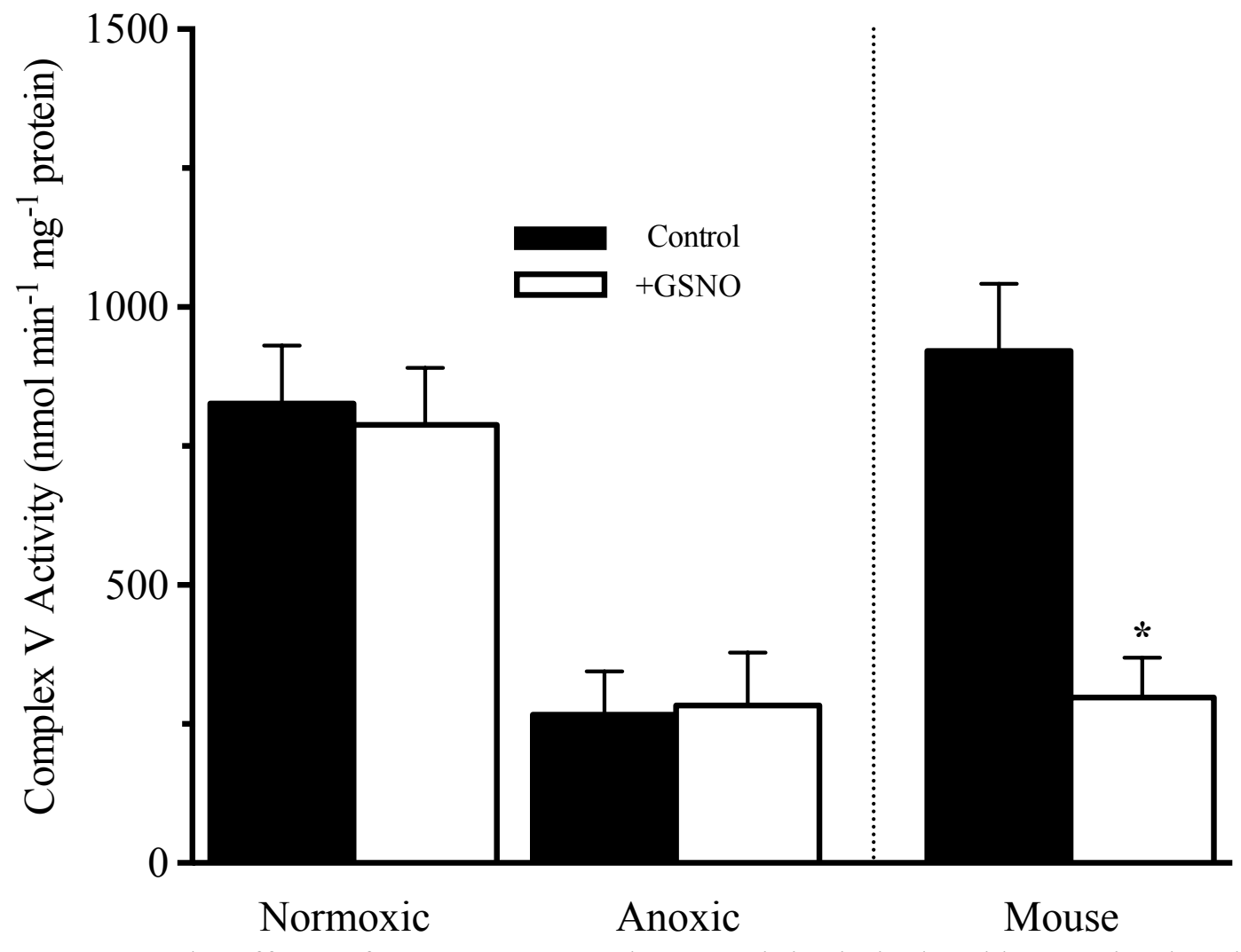

Figure 2.6 The effects of GSNO on Complex V activity in isolated heart mitochondria from normoxia $(n=6)$-and anoxia-exposed $(n=6)$ turtles as well as mouse heart tissue included as positive control. Data are means \pm SEM. Asterisks indicate a significant difference between GSNO treatment (white bars) and its corresponding control (black bars) $(\mathrm{p}<0.05$, paired t-test). 
Table 2.3 List of identified differentially expressed mitochondrial proteins after LC-MS/MS analysis of isolated heart mitochondria. Isolated mitochondrial samples from normoxic and anoxic exposed turtles were pooled (6 each). Pooled samples were dimethylated using different formaldehyde isotopes, mixed in a 1:1 ratio (Normoxic: Anoxic), and ran on SDS-PAGE followed by in gel digestion. Proteins are grouped by their biological function. Differential expression was defined as a 1.2 fold change in protein expression between the two conditions. Protein fragments were referenced against a house built in silico digested Chrysemys picta bellii proteome database (extracted from NCBI)

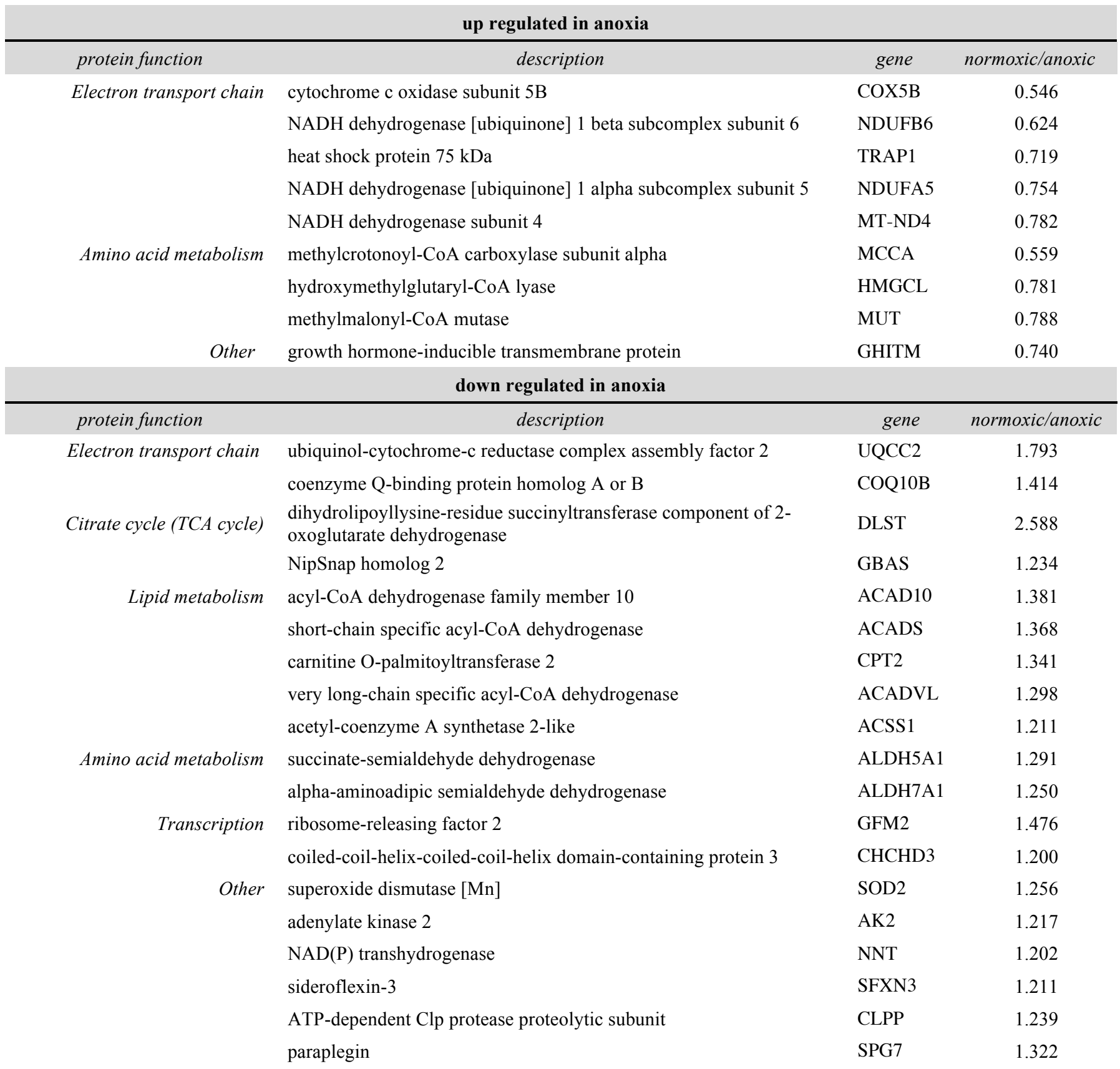


Table 2.4 List of differentially regulated mitochondrial proteins, organized by their biological function, after LC-MS/MS analysis of isolated heart mitochondria from normoxic $(n=3)$-and anoxic-exposed turtles $(n=3)$. Samples were dimethylated using different formaldehyde isotopes, mixed in a 1:1:1 ratio (Normoxic: Anoxic: Control), and either SP3 digested or ran on SDSPAGE followed by in gel digestion. Ratios of detected peptides shown are expressed against the their respective control intensities. Average ratios with a coefficient of variation $(\mathrm{CV})$ exceeded 50 were not reported. Differential expression was defined as a 1.2 fold change in protein expression between the two conditions. Top 10 up-and down-regulated proteins are bolded. Protein fragments were referenced against a house built in silico digested Chrysemys picta bellii proteome database (extracted from NCBI)

\begin{tabular}{|c|c|c|c|c|}
\hline \multicolumn{5}{|c|}{ up regulated in anoxia } \\
\hline protein function & description & gene & $\begin{array}{c}\text { average } \\
\text { normoxic/anoxic }\end{array}$ & $C V$ \\
\hline \multirow[t]{6}{*}{ Electron Transport Chain } & cytochrome c oxidase subunit $6 \mathrm{~B} 1$ & COX6B1 & 0.6500 & 42.2541 \\
\hline & NADH dehydrogenase [ubiquinone] iron-sulfur protein 8 & NDUFS8 & 0.6593 & 30.0307 \\
\hline & cytochrome c1, heme protein & CKMT2 & 0.8004 & 9.9250 \\
\hline & cytochrome b-c1complex subunit Rieske & UQCRFS1 & 0.8059 & 20.0684 \\
\hline & CDGSH iron-sulfur domain-containing protein 1 & CYC1 & 0.7766 & 29.8099 \\
\hline & ADP/ATP translocase 1 & CISD1 & 0.7672 & 35.8220 \\
\hline \multirow[t]{4}{*}{ Citrate cycle (TCA cycle) } & succinyl-CoA ligase [ADP-forming] subunit beta & SUCLA2 & 0.7408 & $\mathbf{2 4 . 8 8 8 4}$ \\
\hline & succinyl-CoA ligase [ADP/GDP-forming] subunit alpha & SUCLG1 & 0.8137 & 13.8129 \\
\hline & fumarate hydratase & FH & 0.8300 & 25.9773 \\
\hline & dihydrolipoamide dehydrogenase & DLD & 0.8155 & 13.5322 \\
\hline \multirow[t]{2}{*}{ Amino acid metabolism } & creatine kinase S-type & ACADSB & 0.8072 & 2.9182 \\
\hline & amine oxidase [flavin-containing] $A$ & SLC25A4 & 0.7341 & 4.4430 \\
\hline Lipid metabolism & short/branched chain acyl-CoA dehydrogenase & MAOA & 0.7326 & 17.7363 \\
\hline Carbohydrate metabolism & hexokinase-1 & HK1 & 0.7837 & 34.9093 \\
\hline \multirow[t]{2}{*}{ Mitochondrial biogenesis } & MICOS complex subunit MIC60 & IMMT & 0.6026 & 26.1333 \\
\hline & sorting and assembly machinery component 50 homolog & SAMM50 & 0.8249 & 23.5910 \\
\hline \multicolumn{5}{|c|}{ down regulated in anoxia } \\
\hline protein function & description & gene & $\begin{array}{c}\text { average } \\
\text { normoxic/anoxic }\end{array}$ & $C V$ \\
\hline \multirow[t]{6}{*}{$\begin{array}{r}\text { Electron Transport Chain } \\
\text { (ETS) }\end{array}$} & ATP synthase subunit $f$ & ATP5A1 & 1.4819 & 44.8691 \\
\hline & NADH dehydrogenase [ubiquinone] 1 alpha subunit 12 & NDUFA12 & 1.2096 & 6.9435 \\
\hline & ATP synthase-coupling factor 6 & ATP5J & 1.2165 & 10.0321 \\
\hline & ATP synthase subunit B1 & ATP5F1 & 1.2201 & 14.0159 \\
\hline & electron transfer flavoprotein subunit alpha & ETFA & 1.3814 & 33.2413 \\
\hline & electron transfer flavoprotein-ubiquinone oxidoreductase & ETFDH & 1.5018 & 29.6649 \\
\hline $\begin{array}{r}\text { ETS \& Citrate cycle }(T C A \\
\text { cycle })\end{array}$ & $\begin{array}{l}\text { succinate dehydrogenase [ubiquinone] flavoprotein } \\
\text { subunit }\end{array}$ & SDHA & 1.4055 & 40.6694 \\
\hline \multirow[t]{2}{*}{ TCA cycle } & citrate synthase & CS & 1.6342 & 36.7963 \\
\hline & isocitrate dehydrogenase [NADP] & IDH2 & 1.3442 & 33.1653 \\
\hline \multirow[t]{2}{*}{ Amino acid metabolism } & isovaleryl-CoA dehydrogenase & IVD & 1.2524 & 35.2851 \\
\hline & 3-hydroxyacyl-CoA dehydrogenase type-2 & HSD17B10 & 1.2668 & 4.6117 \\
\hline
\end{tabular}




\begin{tabular}{|c|c|c|c|c|}
\hline protein function & description & gene & $\begin{array}{c}\text { average } \\
\text { normoxic/anoxic }\end{array}$ & $C V$ \\
\hline \multirow{9}{*}{ Lipid metabolism } & methylglutaconyl-CoA hydratase & AUH & 1.2927 & 28.3712 \\
\hline & methylcrotonoyl-CoA carboxylase beta chain & $\mathrm{MCCC} 2$ & 1.4558 & 1.1460 \\
\hline & propionyl-CoA carboxylase beta chain & PCCB & 1.2038 & 6.3746 \\
\hline & 3-ketoacyl-CoA thiolase & ACAA2 & 1.2177 & 28.1664 \\
\hline & medium-chain specific acyl-CoA dehydrogenase & ACADM & 1.2045 & 25.8757 \\
\hline & 4-trimethylaminobutyraldehyde dehydrogenase & ALDH9A1 & 1.3560 & 16.8924 \\
\hline & carnitine $\mathrm{O}$-acetyltransferase & CRAT & 1.2584 & 19.7961 \\
\hline & delta(3,5)-delta(2,4)-dienoyl-CoA isomerase & ECH1 & 1.2268 & 10.8648 \\
\hline & choline transporter-like protein 2 & SLC44A2 & 1.2155 & 30.8988 \\
\hline \multirow[t]{4}{*}{ Carbohydrate metabolism } & glyceraldehyde-3-phosphate dehydrogenase & GAPDH & 1.6512 & 12.8675 \\
\hline & pyruvate kinase PKM & PKM & 1.3010 & 19.1959 \\
\hline & NAD-dependent malic enzyme & ME2 & 1.4003 & 44.4049 \\
\hline & pyruvate dehydrogenase (acetyl-transferring) kinase & PDK2 & 1.6040 & 30.4353 \\
\hline \multirow[t]{3}{*}{ Heat Shock Proteins } & $60 \mathrm{kDa}$ heat shock protein & HSPD1 & 1.3647 & 23.0924 \\
\hline & heat shock cognate $71 \mathrm{kDa}$ protein & HSPA8 & 1.2508 & 43.9593 \\
\hline & $10 \mathrm{kDa}$ heat shock protein & HSPE1 & 1.3186 & 31.3724 \\
\hline \multirow[t]{8}{*}{ Mitochondrial biogenesis } & LETM1 and EF-hand domain-containing protein 1 & LETM1 & 1.3642 & 31.6586 \\
\hline & dynamin-like $120 \mathrm{kDa}$ protein & OPA1 & 1.2332 & 16.2350 \\
\hline & mitochondrial 10-formyltetrahydrofolate dehydrogenase & ALDH1L2 & 1.2379 & 45.7022 \\
\hline & $\mathrm{NAD}(\mathrm{P})$ transhydrogenase & NNT & 1.2518 & 1.5865 \\
\hline & O-acetyl-ADP-ribose deacetylase MACROD1 & MACROD1 & 1.4053 & 9.5875 \\
\hline & elongation factor $\mathrm{Tu}$ & TUFM & 1.2343 & 39.3270 \\
\hline & protein-glutamine gamma-glutamyltransferase 2 & TGM2 & 1.6709 & 45.1867 \\
\hline & calcium-binding mitochondrial carrier protein Aralar1 & SLC25A12 & 1.2653 & 6.0388 \\
\hline
\end{tabular}




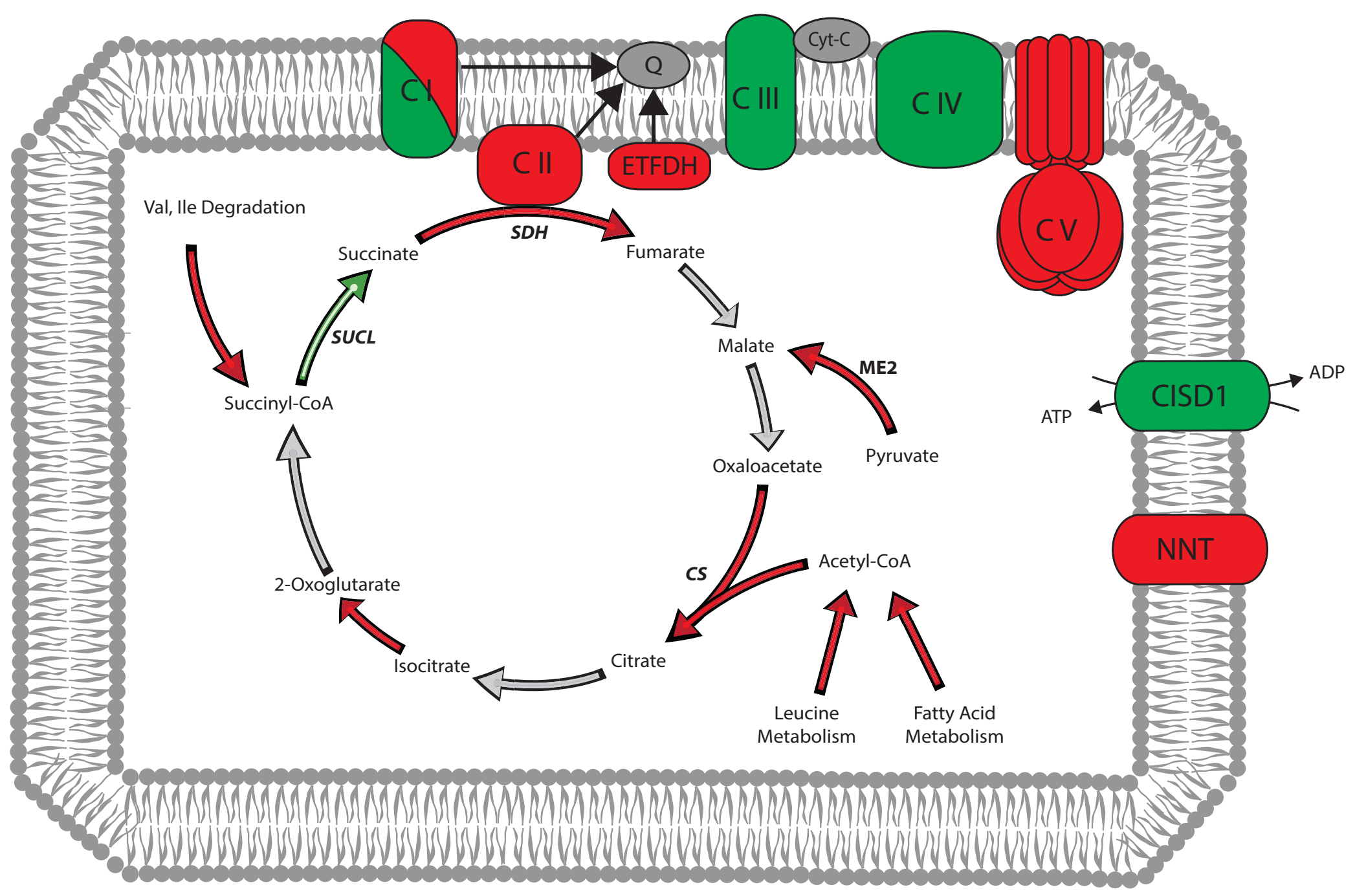


Figure 2.7 Graphic representation of major mitochondrial proteins/enzymes and their relative changes in expression. Mitochondrial outer membrane omitted for clarity. Thick arrows represent metabolic enzymes/reactions. Increased protein expression (green) and decreased protein expression (red) are highlighted while gray proteins represent no change in protein expression. Up-or down-regulation was defined as a 1.2 fold change in protein expression between the two conditions. CISD1, ADP/ATP translocase 1; NNT, NAD $(\mathrm{P})$ transhydrogenase; $\mathrm{CS}$, citrate synthase; ME2- NAD-dependent malic enzyme; SDH succinate dehydrogenase (ubiquinone); Q- ubiquinone; Cyt-c- cytochrome-c; CI-V, complexes I-V; SUCL- succinyl-CoA ligase (ADP-forming). 


\section{CHAPTER THREE: GENERAL DISCUSSION AND CONCLUSIONS}

Mitochondria are more than just the powerhouse of the cell. These complex organelles are signaling platforms for other regulatory processes such as cellular ionic balance, cell division, ROS signaling, and cell fate. They also play a fundamental role in the progression of anoxia/hypoxia induced cell death (Chen et al. 2007). However, little research has focused on how mitochondria are modified in organisms such as $T$. scripta, which can survive for up to 4 months without oxygen. Recent work has shown a remodeling of the mitochondria in response to 2 weeks of anoxia exposure where a reduction in complex $\mathrm{V}$ activity is a critical component to anoxic survival (Galli et al. 2013). In this thesis, I followed up on previous work (Galli et al. 2013) and aimed to further characterize the effects of chronic anoxia on mitochondrial function by 1. attempting to elucidate the mechanism responsible for the anoxia-induced inhibition of complex V 2. adopting a quantitative proteomics approach to characterize the changes in the mitochondrial proteins in response to anoxia.

\subsection{Complex V Characterization}

Limiting wasteful ATP usage is paramount during times of oxidative stress. In anoxia intolerant organisms, ischemia can induce complex $\mathrm{V}$ to run in reverse, which results in the mitochondria becoming the main site of cellular ATP use resulting in ATP depletion and induction of mitochondrial-mediated apoptosis (Rouslin, 1990; Georgi et al. 2012). It is then not surprising that we see a severe inhibition of complex $\mathrm{V}$ during anoxia in $T$. scripta. I have confirmed this anoxia-induced inhibition of complex V, which had been previously seen in heart (Galli et al. 2013), and I also demonstrated that complex V is inhibited in brain (Pamenter et al. 2016; see appendix B) and liver of T. scripta during anoxia exposure. Similar complex V inhibition has also been shown in overwintering common frogs, Rena temporaria (Boutilier and St-Pierre 2002) and diapausing A. limnaeus embryos (St-Pierre et al. 2000), making it a common 
strategy in facultative anaerobes to conserve ATP during anoxia. In isolated mitochondria from heart tissue, no differences in the $\mathrm{K}_{\mathrm{m}}$ of complex V for ATP were detected. This partially revealed the type of inhibition that is occurring in anoxia-exposed turtles. Since complex V affinity for binding ATP did not change, the inhibitory mechanism is likely to be due to changes in complex $\mathrm{V}$ expression or covalent modification of one or multiple components of the protein.

Our proteomics analysis revealed decreased expression of three subunits of complex $\mathrm{V}$ that are part of the peripheral stalk (MT-ATP6, ATP5F1, and ATP5J2) but no changes in the catalytic subunit (ATP5B) were detected in our proteomics analysis or using western blot analysis. The role of the peripheral stalk in complex V function is not entirely clear. It is thought to act as a stator, which acts as a stationary part of the rotary system, holding the catalytic $\mathrm{F}_{1}$ subcomplex and the membrane bound a-subunit in place. The rest of the $\mathrm{F}_{\mathrm{o}}$ subcomplex and central stalk rotates which generates torque for ATP synthesis (Walker and Dickson 2006). MTATP6 and ATP5F1 have both been shown to functionally interact with the catalytic ATP5B and the alpha subunit (ATP5A1) as well as many other mitochondrial proteins (Hein et al. 2015).

We were unable to identify $\mathrm{IF}_{1}$ using western blot analysis or LC-MSMS proteomics, but our attempts to reverse the effects of $\mathrm{IF}_{1}$ in anoxic mitochondria by assaying them at high $\mathrm{pH}$ did not release the anoxia-induced inhibition of complex V. Similar trends of decreasing activity were observed in both normoxic and anoxic samples at $\mathrm{pH}$ values $<7.5$. Decreasing the assay buffer $\mathrm{pH}$ yielded a lower activity in for normoxic samples, but this decrease in activity is likely due to the buffer $\mathrm{pH}$ moving away from the optimum $\mathrm{pH}$ of complex $\mathrm{V}$. Thus, our indirect analysis suggests that IF1 is not involved in complex V regulation during anoxia in turtles, but additional studies are require to confirm this finding. To investigate the possibility that protein nitrosylation contributes to complex $\mathrm{V}$ regulation in turtles, as suggested in mouse heart (Sun et al. 2007), we incubated isolated mitochondria with GSNO, which is well-known to lead to 
protein nitrosylation, but these incubations did not result in an inhibition of complex $\mathrm{V}$ in turtles despite the fact we also demonstrated that our GSNO incubation protocol resulted in complex V inhibition in mice. To investigate the role of phosphorylation in complex $\mathrm{V}$ regulation, we attempted to de-phosphorylate complex V by stimulating endogenous phosphatases. When samples of heart homogenate were incubated in a phosphatases stimulation buffer, there was a reduction in complex $\mathrm{V}$ activity in normoxic-exposed turtles, but the reduction was very small compared with the inhibition observed in anoxia-exposed turtles. Thus, our data suggest that other mechanisms, beyond IF1, s-nitrosylation, and phosphorylation are responsible for the inhibition of complex $\mathrm{V}$ in anoxia-exposed turtles, but more detailed analysis is required before a firm conclusion can be drawn. In addition, more work should focus on defining the role of the peripheral stalk proteins MT-ATP6, ATP5F1, and ATP5J2 in hopes of elucidating their role in the regulation of complex $\mathrm{V}$ activity in turtles.

\subsection{Proteomics}

This is the first study to use mass spectrometry-based proteomics to quantify protein expression in a vertebrate facultative anaerobe exposed to anoxia. We essentially ran 3 separate types of analysis; one using a single mass spectrometry run to analyze 2 separate pooled isolated mitochondria samples from anoxic-and normoxic-exposed turtles and the other two experiments used multiple mass spectrometry runs with biological replicates. The later two experiments were replicates of each other only differing in digestion technique (in-gel digestion or SP3 digestion). The use of multiple runs generated biological replicates where we could detect variability, allowing more confidence then the technical replicates from our pooled sample analysis. All analyses revealed changes in the expression of many enzymes associated with metabolic pathways including the ETS, TCA cycle, amino acid metabolism, and lipid metabolism. Not surprisingly many of these enzymes are associated with multiple pathways making them 
keystone points of regulation. The functional outcome of increasing or decreasing the expression of most of these proteins remains unknown, but this analysis points to several important modifications that should be investigated further. For example, we see a decrease in CS and a subunit of SDH (SDHA), two enzymes that act as regulators to the ETS and TCA cycle. We detected increases in nuclear encoded subunits associated with ND and COX (NDUFS8, and COX6B1) as well as decreases in another subunit of ND (NDUFA12). Despite these changes in expression of proteins involved in various components of complexes I to IV of the ETS and CS, previous analysis of the effects of anoxia exposure on the activity of these enzymes does not reveal any changes in activity. It is possible that these changes in protein expression contribute to regulatory changes in ETS components but have no effect on maximal activity of the enzyme. We also see a large number of enzymes associated with leucine, isoleucine, and valine degradation changing in expression after anoxia exposure. Interestingly, leucine or some metabolites of leucine have been shown to regulate protein synthesis and degradation (Tischler et al. 1982; Garlick 2005). Overall, our proteomics analysis reveals several unique findings; the decrease in three complex V subunits, up and down regulation of multiple ETS complexes, a decrease in lipid metabolism enzymes, and a decrease in many enzymes directly involved and feeding into the TCA cycle, but more work is needed to fully understand how these changes in protein amount affect overall mitochondrial function.

\subsection{Future Directions}

Though the exact mechanism of complex $\mathrm{V}$ regulation during anoxia remains elusive, we have shown that known regulators of complex $\mathrm{V}$ (s-nitrosylation, phosphorylation, and $\mathrm{IF}_{1}$ ) are likely not involved in the severe inhibition in activity seen in anoxia-exposed turtles. I hypothesize that decreased expression of subunits of complex $\mathrm{V}$ are likely responsible for inhibited complex V activity and therefore future research should be geared towards 
understanding the exact role of the peripheral stalk in both ATP synthesis and hydrolysis. Genetic manipulations of peripheral stalk subunits in yeast cells has resulted in decreased complex V activity (Welch et al. 2011). To tease out the functional roles of different subunits, genetic manipulations altering expression of different subunits of complex $\mathrm{V}$ would be informative and could lead to phenotypes that are "more" tolerant than others.

The wealth of data uncovered through LC-MSMS proteomics can lead to an almost endless list of conceivable experiments deciphering the exact function of increased or decreased protein expression. Since protein synthesis is energetically expensive, the products of increased expression must be vital to surviving anoxia or the subsequent reoxygenation. Future research on specific enzymes or pathways identified through our LC-MSMS analysis should be validated first by running western blot analysis on the specific proteins of interest. It would also be illuminating to directly couple mRNA expression with the corresponding proteomics data, which could lead to insights revealing differences not only in the detection technique but also transcriptional and translational response to anoxia. Because of the energy limited state of the cell, changes in expression of subunits ETS does raise the question: What does changing expression alter about the complex I-IVs function, if not altering enzyme activity. These modifications might be important to anoxic survival or for protection in preparation for reoxygen. With the clinical implications, future research should focus on the specific functions of these ETS enzyme subunits and their implications to anoxia tolerance.

\section{$\underline{3.4 \text { Conclusion }}$}

In this thesis, I have shown that inhibition of complex $\mathrm{V}$ in response to anoxia occurs across multiple tissues and that $\mathrm{IF}_{1}$, protein phosphorylation, or s-nitrosylation are likely not responsible for anoxia induced inhibition of complex V. Using quantitative proteomics, I also 
characterized the changes in proteins involved in mitochondrial function during anoxia. This thesis highlights the complexities of the regulatory controls of metabolism during anoxia and illuminates some of the changes occurring in the anoxic mitochondria from anoxia-tolerant turtles. 


\section{REFERENCES}

Almeida-Val, V. M., Buck, L. T. and Hochachka, P. W. (1994). Substrate and acute temperature effects on turtle heart and liver mitochondria. American Journal of Physiology - Regulatory, Integrative and Comparative Physiology 266, R858-R862.

Bailey, J. R. and Driedzic, W. R. (1996). Decreased total ventricular and mitochondrial protein synthesis during extended anoxia in turtle heart. Am. J. Physiol. 271, R1660-1667.

Bason, J. V., Runswick, M. J., Fearnley, I. M. and Walker, J. E. (2011). Binding of the Inhibitor Protein IF1 to Bovine F1-ATPase. J Mol Biol 406, 443-453.

Bergmeyer, H. U. (1983). Methods of Enzymatic Analysis. New York, NY: Academic Press.

Bickler, P. E. and Buck, L. T. (2007). Hypoxia Tolerance in Reptiles, Amphibians, and Fishes: Life with Variable Oxygen Availability. Annual Review of Physiology 69, 145-170.

Biro, G. P. (2013). From the Atmosphere to the Mitochondrion: The Oxygen Cascade. In Hemoglobin-Based Oxygen Carriers as Red Cell Substitutes and Oxygen Therapeutics (ed. Kim, H. W.) and Greenburg, A. G.), pp. 27-53. Springer Berlin Heidelberg.

Boutilier, R. G. (2001). Mechanisms of cell survival in hypoxia and hypothermia. Journal of Experimental Biology 204, 3171-3181.

Boutilier, R. G. and St-Pierre, J. (2002). Adaptive plasticity of skeletal muscle energetics in hibernating frogs: mitochondrial proton leak during metabolic depression. Journal of Experimental Biology 205, 2287-2296.

Boyer, P. D. (1993). The binding change mechanism for ATP synthase - Some probabilities and possibilities. Biochimica et Biophysica Acta (BBA) - Bioenergetics 1140, 215-250.

Bradford, M. M. (1976). A rapid and sensitive method for the quantitation of microgram quantities of protein utilizing the principle of protein-dye binding. Analytical Biochemistry 72, 248-254. 
Brookes, P. S., Yoon, Y., Robotham, J. L., Anders, M. W. and Sheu, S.-S. (2004). Calcium, ATP, and ROS: a mitochondrial love-hate triangle. American Journal of Physiology - Cell Physiology 287, C817-C833.

Brooks, S. P. and Storey, K. B. (1993). De novo protein synthesis and protein phosphorylation during anoxia and recovery in the red-eared turtle. American Journal of Physiology - Regulatory, Integrative and Comparative Physiology 265, R1380-R1386.

Buck, L. T. and Hochachka, P. W. (1993). Anoxic suppression of Na(+)-K(+)-ATPase and constant membrane potential in hepatocytes: support for channel arrest. American Journal of Physiology Regulatory, Integrative and Comparative Physiology 265, R1020-R1025.

Buck, L. T., Land, S. C. and Hochachka, P. W. (1993). Anoxia-tolerant hepatocytes: model system for study of reversible metabolic suppression. American Journal of Physiology - Regulatory, Integrative and Comparative Physiology 265, R49-R56.

Cabezon, E., Butler, P. J. G., Runswick, M. J. and Walker, J. E. (2000). Modulation of the Oligomerization State of the Bovine F1-ATPase Inhibitor Protein, IF1, by pH. J. Biol. Chem. 275, 25460-25464.

Cai, Q. and Storey, K. B. (1996). Anoxia-Induced Gene Expression in Turtle Heart. European Journal of Biochemistry 241, 83-92.

Campanella, M., Casswell, E., Chong, S., Farah, Z., Wieckowski, M. R., Abramov, A. Y., Tinker, A. and Duchen, M. R. (2008). Regulation of Mitochondrial Structure and Function by the F1FoATPase Inhibitor Protein, IF1. Cell Metabolism 8, 13-25.

Campanella, M., Parker, N., Tan, C. H., Hall, A. M. and Duchen, M. R. (2009). IF1: setting the pace of the F1Fo-ATP synthase. Trends in Biochemical Sciences 34, 343-350. 
Candiano, G., Bruschi, M., Musante, L., Santucci, L., Ghiggeri, G. M., Carnemolla, B., Orecchia, P., Zardi, L. and Righetti, P. G. (2004). Blue silver: a very sensitive colloidal Coomassie G-250 staining for proteome analysis. Electrophoresis 25, 1327-1333.

Chan, Q. W. T., Howes, C. G. and Foster, L. J. (2006). Quantitative Comparison of Caste Differences in Honeybee Hemolymph. Mol Cell Proteomics 5, 2252-2262.

Chang, J., Knowlton, A. A. and Wasser, J. S. (2000). Expression of heat shock proteins in turtle and mammal hearts: relationship to anoxia tolerance. American Journal of Physiology - Regulatory, Integrative and Comparative Physiology 278, R209-R214.

Chipuk, J. E., Moldoveanu, T., Llambi, F., Parsons, M. J. and Green, D. R. (2010). The BCL-2 Family Reunion. Mol Cell 37, 299-310.

Clegg, James (1997). Embryos of Artemia franciscana survive four years of continuous anoxia: the case for complete metabolic rate depression. J. Exp. Biol. 200, 467-475.

Das, A. M. (2003). Regulation of the mitochondrial ATP-synthase in health and disease. Molecular Genetics and Metabolism 79, 71-82.

De Maio, A. (2014). Extracellular Hsp70: export and function. Curr. Protein Pept. Sci. 15, $225-231$.

Djidja, M.-C., Chang, J., Hadjiprocopis, A., Schmich, F., Sinclair, J., Mršnik, M., Schoof, E. M., Barker, H. E., Linding, R., Jørgensen, C., et al. (2014). Identification of Hypoxia-Regulated Proteins Using MALDI-Mass Spectrometry Imaging Combined with Quantitative Proteomics. J. Proteome Res. 13, 2297-2313.

Duerr, J. M. and Podrabsky, J. E. (2010). Mitochondrial physiology of diapausing and developing embryos of the annual killifish Austrofundulus limnaeus: implications for extreme anoxia tolerance. J Comp Physiol B 180, 991-1003. 
Else, P. L. and Hulbert, A. J. (1985). An allometric comparison of the mitochondria of mammalian and reptilian tissues: The implications for the evolution of endothermy. J Comp Physiol B 156, $3-11$.

Fago, A. and Jensen, F. B. (2015). Hypoxia Tolerance, Nitric Oxide, and Nitrite: Lessons From Extreme Animals. Physiology 30, 116-126.

Foster, D. B., O'Rourke, B. and Van Eyk, J. E. (2008). What can mitochondrial proteomics tell us about cardioprotection afforded by preconditioning? Expert Rev Proteomics 5, 633-636.

Galli, G. L. J. and Richards, J. G. (2014). Mitochondria from anoxia-tolerant animals reveal common strategies to survive without oxygen. Journal of Comparative Physiology B.

Galli, G. L. J., Lau, G. Y. and Richards, J. G. (2013). Beating oxygen: chronic anoxia exposure reduces mitochondrial F1FO-ATPase activity in turtle (Trachemys scripta) heart. J Exp Biol 216, $3283-3293$.

Garlick, P. J. (2005). The Role of Leucine in the Regulation of Protein Metabolism. J. Nutr. 135, 1553S-1556S.

Giorgi, C., Baldassari, F., Bononi, A., Bonora, M., De Marchi, E., Marchi, S., Missiroli, S., Patergnani, S., Rimessi, A., Suski, J. M., et al. (2012). Mitochondrial $\mathrm{Ca}^{2+}$ and apoptosis. Cell Calcium 52, 36-43.

Gledhill, J. R., Montgomery, M. G., Leslie, A. G. W. and Walker, J. E. (2007). How the regulatory protein, IF1, inhibits F1-ATPase from bovine mitochondria. PNAS 104, 15671-15676.

Hein, M. Y., Hubner, N. C., Poser, I., Cox, J., Nagaraj, N., Toyoda, Y., Gak, I. A., Weisswange, I., Mansfeld, J., Buchholz, F., et al. (2015). A human interactome in three quantitative dimensions organized by stoichiometries and abundances. Cell 163, 712-723.

Herbert, C. V. and Jackson, D. C. (1985). Temperature Effects on the Responses to Prolonged Submergence in the Turtle Chrysemys picta bellii. II. Metabolic Rate, Blood Acid-Base and 
Ionic Changes, and Cardiovascular Function in Aerated and Anoxic Water. Physiological Zoology 58, 670-681.

Hochachka, P. W. (1986). Defense Strategies against Hypoxia and Hypothermia. Science 231, 234 241.

Hochachka, P. W. (1986). Metabolic arrest. Intensive Care Med 12, 127-133.

Hochachka, P. W. and Lutz, P. L. (2001). Mechanism, origin, and evolution of anoxia tolerance in animals. Comparative Biochemistry and Physiology Part B: Biochemistry and Molecular Biology 130, 435-459.

Hochachka, P. W. and Somero, G. N. (2002). Biochemical Adaptation: Mechanism and Process in Physiological Evolution. Oxford: Oxford University Press.

Hochachka, P. W., Buck, L. T., Doll, C. J. and Land, S. C. (1996). Unifying theory of hypoxia tolerance: molecular/metabolic defense and rescue mechanisms for surviving oxygen lack. Proceedings of the National Academy of Sciences 93, 9493-9498.

Holman, J. D. and Hand, S. C. (2009). Metabolic Depression is Delayed and Mitochondrial Impairment Averted during Prolonged Anoxia in the ghost shrimp, Lepidophthalmus louisianensis (Schmitt, 1935). J. Exp. Mar. Biol. Ecol. 376, 85-93.

Hughes, C. S., Foehr, S., Garfield, D. A., Furlong, E. E., Steinmetz, L. M. and Krijgsveld, J. (2014). Ultrasensitive proteome analysis using paramagnetic bead technology. Mol. Syst. Biol. 10, 757.

Jackson, D. C. (1968). Metabolic depression and oxygen depletion in the diving turtle. Journal of Applied Physiology 24, 503-509.

Jackson, D. C. (2000). Living without oxygen: lessons from the freshwater turtle. Comparative Biochemistry and Physiology Part A: Molecular \& Integrative Physiology 125, 299-315. 
Jackson, D. C. (2002). Hibernating without oxygen: physiological adaptations of the painted turtle. $J$ Physiol 543, 731-737.

Jacobsen, S. B., Hansen, M. N., Jensen, F. B., Skovgaard, N., Wang, T. and Fago, A. (2012). Circulating nitric oxide metabolites and cardiovascular changes in the turtle Trachemys scripta during normoxia, anoxia and reoxygenation. Journal of Experimental Biology 215, 2560-2566.

Jensen, F. B., Hansen, M. N., Montesanti, G. and Wang, T. (2014). Nitric oxide metabolites during anoxia and reoxygenation in the anoxia-tolerant vertebrate Trachemys scripta. J Exp Biol 217, $423-431$.

Jonckheere, A. I., Smeitink, J. A. M. and Rodenburg, R. J. T. (2012). Mitochondrial ATP synthase: architecture, function and pathology. J Inherit Metab Dis 35, 211-225.

Joza, N., Susin, S. A., Daugas, E., Stanford, W. L., Cho, S. K., Li, C. Y., Sasaki, T., Elia, A. J., Cheng, H. Y., Ravagnan, L., et al. (2001). Essential role of the mitochondrial apoptosisinducing factor in programmed cell death. Nature 410, 549-554.

Kane, L. A. and Van Eyk, J. E. (2009). Post-translational modifications of ATP synthase in the heart: biology and function. $J$ Bioenerg Biomembr 41, 145-150.

Kane, L. A., Youngman, M. J., Jensen, R. E. and Eyk, J. E. V. (2010). Phosphorylation of the F1Fo ATP Synthase $\beta$ Subunit Functional and Structural Consequences Assessed in a Model System. Circulation Research 106, 504-513.

Kelly, D. A. and Storey, K. B. (1988). Organ-specific control of glycolysis in anoxic turtles. American Journal of Physiology - Regulatory, Integrative and Comparative Physiology 255, R774-R779.

Krauss, S. (2001). Mitochondria: Structure and Role in Respiration. In $e L S$, John Wiley \& Sons, Ltd. 
Krupenko, N. I., Dubard, M. E., Strickland, K. C., Moxley, K. M., Oleinik, N. V. and Krupenko, S. A. (2010). ALDH1L2 is the mitochondrial homolog of 10-formyltetrahydrofolate dehydrogenase. J. Biol. Chem. 285, 23056-23063.

Laemmli, U. K. (1970). Cleavage of Structural Proteins during the Assembly of the Head of Bacteriophage T4. Nature 227, 680-685.

Lahtvee, P.-J., Seiman, A., Arike, L., Adamberg, K. and Vilu, R. (2014). Protein turnover forms one of the highest maintenance costs in Lactococcus lactis. Microbiology (Reading, Engl.) 160, $1501-1512$.

Land, S. C. and Hochachka, P. W. (1994). Protein turnover during metabolic arrest in turtle hepatocytes: role and energy dependence of proteolysis. American Journal of Physiology - Cell Physiology 266, C1028-C1036.

Land, S. C., Buck, L. T. and Hochachka, P. W. (1993). Response of protein synthesis to anoxia and recovery in anoxia-tolerant hepatocytes. American Journal of Physiology - Regulatory, Integrative and Comparative Physiology 265, R41-R48.

Lanza, I. R. and Nair, K. S. (2009). Functional assessment of isolated mitochondria in vitro. Meth. Enzymol. 457, 349-372.

Lenihan, H. S. and Peterson, C. H. (1998). How Habitat Degradation Through Fishery Disturbance Enhances Impacts of Hypoxia on Oyster Reefs. Ecological Applications 8, 128-140.

Lodish, H., Berk, A., Zipursky, S. L., Matsudaira, P., Baltimore, D. and Darnell, J. (2000). Active Transport by ATP-Powered Pumps.

Long, Q., Yang, K. and Yang, Q. (2015). Regulation of mitochondrial ATP synthase in cardiac pathophysiology. Am J Cardiovasc Dis 5, 19-32. 
Lowe, S., Browne, M., Boudjelas, S. and De Poorter, M. (2000). 100 of the world's worst invasive alien species: a selection from the global invasive species database. Invasive Species Specialist Group Auckland.

Lutz, P. L., Rosenthal, M., \& Sick, T. J. (1985). Living without Oxygen-Turtle Brain as a Model of Anaerobic Metabolism. Molecular Physiology 8, 411-425.

MacDonald, J. A. and Storey, K. B. (1999). Regulation of Ground Squirrel Na+K+-ATPase Activity by Reversible Phosphorylation during Hibernation. Biochemical and Biophysical Research Communications 254, 424-429.

Matsuyama, S., Llopis, J., Deveraux, Q. L., Tsien, R. Y. and Reed, J. C. (2000). Changes in intramitochondrial and cytosolic $\mathrm{pH}$ : early events that modulate caspase activation during apoptosis. Nat Cell Biol 2, 318-325.

Minauro-Sanmiguel, F., Wilkens, S. and García, J. J. (2005). Structure of dimeric mitochondrial ATP synthase: Novel F0 bridging features and the structural basis of mitochondrial cristae biogenesis. PNAS 102, 12356-12358.

Mitchell, P. (1966). Chemiosmotic coupling in oxidative and photosynthetic phosphorylation. Glynn Research Bodmin.

Mitchell, P. (1966). Chemiosmotic coupling in oxidative and photosynthetic phosphorylation. Glynn Research Bodmin.

Nilsson, G. E. and Lutz, P. L. (2004). Anoxia Tolerant Brains. J Cereb Blood Flow Metab 24, 475486.

Nilsson, G. E. and Renshaw, G. M. C. (2004). Hypoxic survival strategies in two fishes: extreme anoxia tolerance in the North European crucian carp and natural hypoxic preconditioning in a coral-reef shark. Journal of Experimental Biology 207, 3131-3139. 
Ogilvie, I., Aggeler, R. and Capaldi, R. A. (1997). Cross-linking of the $\delta$ Subunit to One of the Three $\alpha$ Subunits Has No Effect on Functioning, as Expected if $\delta$ Is a Part of the Stator That Links the F1 and F0 Parts of the Escherichia coli ATP Synthase. J. Biol. Chem. 272, 1665216656.

Pagliarini, D. J. and Dixon, J. E. (2006). Mitochondrial modulation: reversible phosphorylation takes center stage? Trends Biochem. Sci. 31, 26-34

Pamenter, M. E., Gomez, C. R., Richards, J. G. and Milsom, W. K. (2016). Mitochondrial responses to prolonged anoxia in brain of red-eared slider turtles. Biology Letters 12, 20150797.

Paradies, G., Petrosillo, G., Pistolese, M., Di Venosa, N., Serena, D. and Ruggiero, F. M. (1999). Lipid peroxidation and alterations to oxidative metabolism in mitochondria isolated from rat heart subjected to ischemia and reperfusion. Free Radical Biology and Medicine 27, 42-50.

Parker, R., Guarna, M. M., Melathopoulos, A. P., Moon, K.-M., White, R., Huxter, E., Pernal, S. F. and Foster, L. J. (2012). Correlation of proteome-wide changes with social immunity behaviors provides insight into resistance to the parasitic mite, Varroa destructor, in the honey bee (Apis mellifera). Genome Biol. 13, R81.

Parrish, J., Li, L., Klotz, K., Ledwich, D., Wang, X. and Xue, D. (2001). Mitochondrial endonuclease $\mathrm{G}$ is important for apoptosis in C. elegans. Nature 412, 90-94.

Pullman, M. E. and Monroy, G. C. (1963). A Naturally Occurring Inhibitor of Mitochondrial Adenosine Triphosphatase. J. Biol. Chem. 238, 3762-3769.

Raedschelders, K., Ansley, D. M. and Chen, D. D. Y. (2012). The cellular and molecular origin of reactive oxygen species generation during myocardial ischemia and reperfusion. Pharmacol. Ther. 133, 230-255.

Rakhit, R. D., Edwards, R. J. and Marber, M. S. (1999). Nitric oxide, nitrates and ischaemic preconditioning. Cardiovascular Research 43, 621-627. 
Reeds, P. J., Hay, S. M., Glennie, R. T., Mackie, W. S. and Garlick, P. J. (1985). The effect of indomethacin on the stimulation of protein synthesis by insulin in young post-absorptive rats. Biochemical Journal 227, 255-261.

Rice, M. E. (2011). H2O2: a dynamic neuromodulator. Neuroscientist 17, 389-406.

Rider, M. H., Hussain, N., Dilworth, S. M. and Storey, K. B. (2009). Phosphorylation of translation factors in response to anoxia in turtles, Trachemys scripta elegans: role of the AMPactivated protein kinase and target of rapamycin signalling pathways. Mol. Cell. Biochem. 332, $207-213$.

Rouslin, W. (1983). Mitochondrial complexes I, II, III, IV, and V in myocardial ischemia and autolysis. American Journal of Physiology - Heart and Circulatory Physiology 244, H743-H748.

Rouslin, W. and Broge, C. W. (1990). Regulation of the mitochondrial adenosine 5'-triphosphatase in situ during ischemia and in vitro in intact and sonicated mitochondria from slow and fast heart-rate hearts. Archives of Biochemistry and Biophysics 280, 103-111.

Rouslin, W., Frank, G. D. and Broge, C. W. (1995). Content and binding characteristics of the mitochondrial ATPase inhibitor, IF1 in the tissues of several slow and fast heart-rate homeothermic species and in two poikilotherms. Journal of bioenergetics and biomembranes $\mathbf{2 7}$, $117-125$.

Sánchez-Cenizo, L., Formentini, L., Aldea, M., Ortega, Á. D., García-Huerta, P., SánchezAragó, M. and Cuezva, J. M. (2010). Up-regulation of the ATPase Inhibitory Factor 1 (IF1) of the Mitochondrial H+-ATP Synthase in Human Tumors Mediates the Metabolic Shift of Cancer Cells to a Warburg Phenotype. J. Biol. Chem. 285, 25308-25313.

Sandvik, G. K., Nilsson, G. E. and Jensen, F. B. (2012). Dramatic increase of nitrite levels in hearts of anoxia-exposed crucian carp supporting a role in cardioprotection. American Journal of Physiology - Regulatory, Integrative and Comparative Physiology 302, R468-R477. 
Santore, M. T., McClintock, D. S., Lee, V. Y., Budinger, G. R. S. and Chandel, N. S. (2002). Anoxia-induced apoptosis occurs through a mitochondria-dependent pathway in lung epithelial cells. American Journal of Physiology - Lung Cellular and Molecular Physiology 282, L727L734.

Smith, R. W., Cash, P., Hogg, D. W. and Buck, L. T. (2015). Proteomic changes in the brain of the western painted turtle (Chrysemys picta bellii) during exposure to anoxia. Proteomics 15, 15871597.

St-Pierre, J., Brand, M. D. and Boutilier, R. G. (2000). Mitochondria as ATP consumers: cellular treason in anoxia. Proceedings of the National Academy of Sciences 97, 8670-8674.

Stone, D., Darley-Usmar, V., Smith, D. R. and O’Leary, V. (1989). Hypoxia-reoxygenation induced increase in cellular $\mathrm{Ca} 2+$ in myocytes and perfused hearts: the role of mitochondria. Journal of Molecular and Cellular Cardiology 21, 963-973.

Storey, K. B. (1996). Metabolic adaptations supporting anoxia tolerance in reptiles: Recent advances. Comparative Biochemistry and Physiology Part B: Biochemistry and Molecular Biology 113, $23-35$.

Storey, K. B. (2004). Molecular mechanisms of anoxia tolerance. International Congress Series 1275, 47-54.

Storey, K. B. (2007). Anoxia tolerance in turtles: Metabolic regulation and gene expression. Comparative Biochemistry and Physiology Part A: Molecular \& Integrative Physiology 147, 263-276.

Storey, K. B. and Storey, J. M. (2004). Metabolic rate depression in animals: transcriptional and translational controls. Biological Reviews 79, 207-233.

Storey, K. B. and Storey, J. M. (2007). Tribute to P. L. Lutz: putting life on 'pause' - molecular regulation of hypometabolism. Journal of Experimental Biology 210, 1700-1714. 
Strauss, M., Hofhaus, G., Schröder, R. R. and Kühlbrandt, W. (2008). Dimer ribbons of ATP synthase shape the inner mitochondrial membrane. The EMBO Journal 27, 1154-1160.

Sun, J., Morgan, M., Shen, R.-F., Steenbergen, C. and Murphy, E. (2007). Preconditioning Results in S-Nitrosylation of Proteins Involved in Regulation of Mitochondrial Energetics and Calcium Transport. Circulation Research 101, 1155-1163.

Tait, S. W. G. and Green, D. R. (2012). Mitochondria and cell signaling. J Cell Sci 125, 807-815.

Tischler, M. E., Desautels, M. and Goldberg, A. L. (1982). Does leucine, leucyl-tRNA, or some metabolite of leucine regulate protein synthesis and degradation in skeletal and cardiac muscle? J. Biol. Chem. 257, 1613-1621.

Ultsch, G. R. and Jackson, D. C. (1982). Long-Term Submergence at $3^{\circ} \mathrm{C}$ of the Turtle, Chrysemys Picta Bellii, in Normoxic And Severely Hypoxic Water: I. Survival, Gas Exchange And AcidBase Status. Journal of Experimental Biology 96, 11-28.

Vander Heide, R. S., Hill, M. L., Reimer, K. A. and Jennings, R. B. (1996). Effect of Reversible Ischemia on the Activity of the Mitochondrial ATPase: Relationship to Ischemic Preconditioning. Journal of Molecular and Cellular Cardiology 28, 103-112.

Vinogradov, A. D. (2000). Steady-state and pre-steady-state kinetics of the mitochondrial F (1) F (o) ATPase: is ATP synthase a reversible molecular machine? Journal of Experimental Biology 203, $41-49$.

Walker, J. E. and Dickson, V. K. (2006). The peripheral stalk of the mitochondrial ATP synthase. Biochimica et Biophysica Acta (BBA) - Bioenergetics 1757, 286-296.

Walters, A. M., Porter, G. A. and Brookes, P. S. (2012). Mitochondria as a Drug Target in Ischemic Heart Disease and Cardiomyopathy. Circulation Research 111, 1222-1236. 
Wasser, J. S., Freund, E. V., Gonzalez, L. A. and Jackson, D. C. (1990). Force and acid-base state of turtle cardiac tissue exposed to combined anoxia and acidosis. American Journal of Physiology - Regulatory, Integrative and Comparative Physiology 259, R15-R20.

Welch, A. K., Bostwick, C. J. and Cain, B. D. (2011). Manipulations in the Peripheral Stalk of the Saccharomyces cerevisiae F1F0-ATP Synthase. J. Biol. Chem. 286, 10155-10162.

West, A. P., Shadel, G. S. and Ghosh, S. (2011). Mitochondria in innate immune responses. Nat Rev Immunol 11, 389-402.

Willmore, W. G. and Storey, K. B. (1997). Antioxidant systems and anoxia tolerance in a freshwater turtle Trachemys scripta elegans. Mol. Cell. Biochem. 170, 177-185. 


\title{
APPENDIX
}

\author{
Appendix A: Supplementary Data
}

\section{Table A1: List of proteins detected through pooled sample LC-MSMS proteomics}

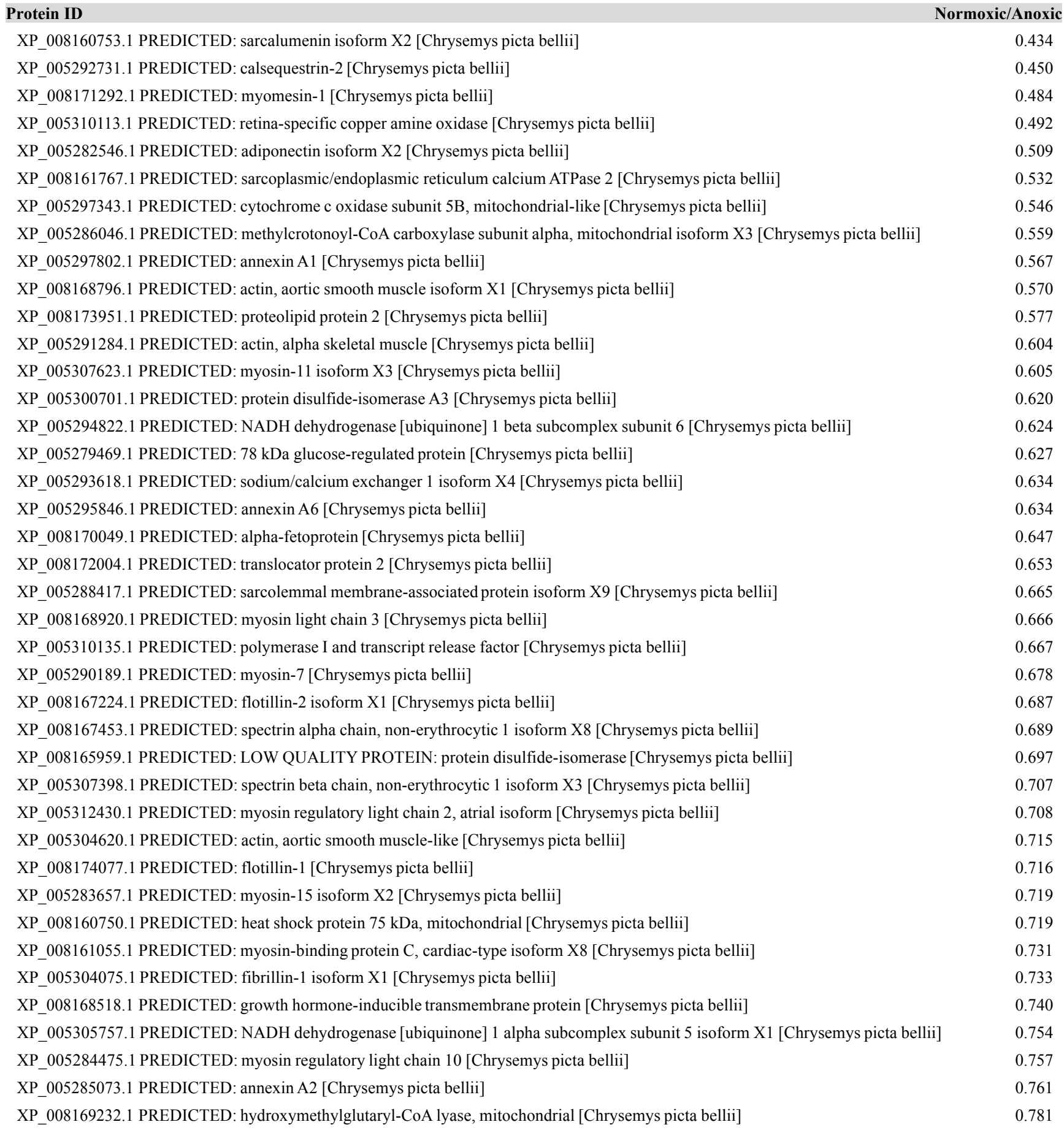




\section{Protein ID}

XP_005286556.1 PREDICTED: fumarylacetoacetate hydrolase domain-containing protein 2A isoform X2 [Chrysemys picta bellii] 
XP_008175618.1 PREDICTED: monofunctional C1-tetrahydrofolate synthase, mitochondrial isoform X2 [Chrysemys picta bellii]

XP_008162617.1 PREDICTED: AFG3-like protein 2 isoform X2 [Chrysemys picta bellii]

XP_005300960.1 PREDICTED: lipoamide acyltransferase component of branched-chain alpha-keto acid dehydrogenase complex, mitochondri

XP_005293831.1 PREDICTED: NADH dehydrogenase [ubiquinone] iron-sulfur protein 2, mitochondrial [Chrysemys picta bellii]

XP_005281432.2 PREDICTED: glutaryl-CoA dehydrogenase, mitochondrial [Chrysemys picta bellii]

XP_008167560.1 PREDICTED: fumarate hydratase, mitochondrial isoform X2 [Chrysemys picta bellii] 
XP_005312065.1 PREDICTED: triosephosphate isomerase [Chrysemys picta bellii]

XP_005287580.1 PREDICTED: NADP-dependent malic enzyme, mitochondrial isoform X1 [Chrysemys picta bellii] 
XP_008171609.1 PREDICTED: hydroxysteroid dehydrogenase-like protein 2, partial [Chrysemys picta bellii] 1.085

XP_005283737.1 PREDICTED: mitochondrial pyruvate carrier 2 [Chrysemys picta bellii] 1.086

XP_005282018.1 PREDICTED: ectonucleotide pyrophosphatase/phosphodiesterase family member 6 isoform X2 [Chrysemys picta bellii] 1.087

XP_008169449.1 PREDICTED: NAD-dependent protein deacylase sirtuin-5, mitochondrial isoform X2 [Chrysemys picta bellii] 1.088

XP_008168434.1 PREDICTED: acyl-coenzyme A thioesterase 9, mitochondrial isoform X4 [Chrysemys picta bellii] 1.089

XP_005297326.2 PREDICTED: elongation factor Ts, mitochondrial [Chrysemys picta bellii] 1.090

XP_005301634.1 PREDICTED: acetyl-coenzyme A synthetase 2-like, mitochondrial isoform X1 [Chrysemys picta bellii] 1.092

XP_005287209.1 PREDICTED: succinyl-CoA ligase [ADP-forming] subunit beta, mitochondrial [Chrysemys picta bellii] 1.092

XP_005279048.1 PREDICTED: ubiquitin-60S ribosomal protein L40 [Chrysemys picta bellii] 1.093

XP_008165531.1 PREDICTED: delta-1-pyrroline-5-carboxylate dehydrogenase, mitochondrial [Chrysemys picta bellii] 1.094

XP_005287959.1 PREDICTED: hydroxyacyl-coenzyme A dehydrogenase, mitochondrial [Chrysemys picta bellii] 1.098

XP_005299438.1 PREDICTED: regulator of microtubule dynamics protein 1 isoform X2 [Chrysemys picta bellii] 1.100

XP_005312088.1 PREDICTED: prohibitin-2 [Chrysemys picta bellii];XP_005312087.1 PREDICTED: prohibitin-2 [Chrysemys picta bellii] 1.102

XP_005284174.1 PREDICTED: trifunctional enzyme subunit alpha, mitochondrial isoform X2 [Chrysemys picta bellii] 1.103

XP_005301830.1 PREDICTED: amine oxidase [flavin-containing] A [Chrysemys picta bellii] 1.105

XP 008169571.1 PREDICTED: methylglutaconyl-CoA hydratase, mitochondrial isoform X1 [Chrysemys picta bellii] 1.107

XP_005295025.1 PREDICTED: NADH dehydrogenase [ubiquinone] iron-sulfur protein 8, mitochondrial [Chrysemys picta bellii] 1.109

XP_005312172.1 PREDICTED: mitochondrial fission 1 protein isoform X2 [Chrysemys picta bellii] 1.110

XP_005283844.1 PREDICTED: NADH dehydrogenase [ubiquinone] 1 alpha subcomplex subunit 7 [Chrysemys picta bellii] 1.112

XP_005286020.1 PREDICTED: NADH dehydrogenase [ubiquinone] 1 beta subcomplex subunit 5, mitochondrial isoform X1 [Chrysemys pict 1.114

XP_005289996.1 PREDICTED: glucose-6-phosphate isomerase [Chrysemys picta bellii];CON_Q3ZBD7 1.116

XP_005305607.1 PREDICTED: O-acetyl-ADP-ribose deacetylase MACROD1 isoform X2 [Chrysemys picta bellii] 1.116

XP_005288141.1 PREDICTED: hydroxyacid-oxoacid transhydrogenase, mitochondrial [Chrysemys picta bellii] 1.116

XP_005282036.1 PREDICTED: long-chain-fatty-acid--CoA ligase 1 [Chrysemys picta bellii] 1.117

XP_005297937.1 PREDICTED: voltage-dependent anion-selective channel protein 1 [Chrysemys picta bellii] 1.118

XP_005300824.1 PREDICTED: mitochondrial 10-formyltetrahydrofolate dehydrogenase isoform X1 [Chrysemys picta bellii] 1.123

XP_005294354.1 PREDICTED: $60 \mathrm{kDa}$ heat shock protein, mitochondrial [Chrysemys picta bellii] 1.123

XP_005310318.1 PREDICTED: propionyl-CoA carboxylase beta chain, mitochondrial isoform X1 [Chrysemys picta bellii] 1.123

XP_008169774.1 PREDICTED: mitochondrial coenzyme A transporter SLC25A42 [Chrysemys picta bellii] 1.130

XP_008163120.1 PREDICTED: blood vessel epicardial substance isoform X2 [Chrysemys picta bellii] 1.131

XP_008174073.1 PREDICTED: uncharacterized protein C6orf136 homolog [Chrysemys picta bellii] 1.141

XP_008171916.1 PREDICTED: protein DJ-1 [Chrysemys picta bellii];XP_005287110.1 PREDICTED: protein DJ-1 [Chrysemys picta bellii] 1.147

XP_008172678.1 PREDICTED: isocitrate dehydrogenase [NAD] subunit beta, mitochondrial [Chrysemys picta bellii] 1.147

XP_005314861.1 PREDICTED: histidine triad nucleotide-binding protein 2, mitochondrial [Chrysemys picta bellii] 1.147

XP_008170907.1 PREDICTED: alpha-aminoadipic semialdehyde synthase, mitochondrial [Chrysemys picta bellii] 1.150

XP_008162160.1 PREDICTED: acyl-CoA synthetase family member 2, mitochondrial isoform X2 [Chrysemys picta bellii] 1.150

XP_008173362.1 PREDICTED: enoyl-CoA hydratase, mitochondrial [Chrysemys picta bellii] 1.151

XP_008171404.1 PREDICTED: delta(3,5)-Delta(2,4)-dienoyl-CoA isomerase, mitochondrial [Chrysemys picta bellii] 1.153

XP_005296359.1 PREDICTED: epoxide hydrolase 1-like isoform X3 [Chrysemys picta bellii] 1.153

XP_005302498.1 PREDICTED: thiosulfate sulfurtransferase [Chrysemys picta bellii] 1.158

XP_005296688.1 PREDICTED: L-lactate dehydrogenase B chain [Chrysemys picta bellii] 1.160

XP_005309837.1 PREDICTED: acyl-CoA dehydrogenase family member 9, mitochondrial [Chrysemys picta bellii] 1.164

XP_005295736.1 PREDICTED: creatine kinase M-type [Chrysemys picta bellii] 1.166

XP_005284774.1 PREDICTED: isovaleryl-CoA dehydrogenase, mitochondrial [Chrysemys picta bellii] 1.168 
XP_005291923.1 PREDICTED: coiled-coil-helix-coiled-coil-helix domain-containing protein 3, mitochondrial isoform X2 [Chrysemys picta b 1.200 XP_008166943.1 PREDICTED: NAD(P) transhydrogenase, mitochondrial [Chrysemys picta bellii] 1.202

XP_005291239.1 PREDICTED: alpha-actinin-2 isoform X1 [Chrysemys picta bellii] 1.203

XP_008162642.1 PREDICTED: cytosolic non-specific dipeptidase isoform X2 [Chrysemys picta bellii] 1.208

XP_005303528.1 PREDICTED: sideroflexin-3 [Chrysemys picta bellii] 1.211

XP_005296417.1 PREDICTED: single-stranded DNA-binding protein, mitochondrial [Chrysemys picta bellii] 1.211

XP_005293591.1 PREDICTED: acetyl-coenzyme A synthetase 2-like, mitochondrial isoform X3 [Chrysemys picta bellii] 1.211

XP_005302197.1 PREDICTED: adenylate kinase 2, mitochondrial isoform X3 [Chrysemys picta bellii] 1.217

XP_008170555.1 PREDICTED: neural cell adhesion molecule 1 isoform X16 [Chrysemys picta bellii] 1.223

XP_008172294.1 PREDICTED: LOW QUALITY PROTEIN: filamin-C [Chrysemys picta bellii] 1.232

XP_005283491.1 PREDICTED: protein NipSnap homolog 2 isoform X2 [Chrysemys picta bellii] 1.234

XP_005279612.1 PREDICTED: ATP-dependent Clp protease proteolytic subunit, mitochondrial [Chrysemys picta bellii] 1.239

XP_005287264.1 PREDICTED: malate dehydrogenase, cytoplasmic isoform X2 [Chrysemys picta bellii] 1.250

XP_005310780.1 PREDICTED: alpha-aminoadipic semialdehyde dehydrogenase [Chrysemys picta bellii] 1.250

XP_005291601.1 PREDICTED: superoxide dismutase [Mn], mitochondrial [Chrysemys picta bellii] 1.256

XP_005290800.1 PREDICTED: laminin subunit gamma-1 [Chrysemys picta bellii] 1.256

XP_005295339.1 PREDICTED: beta-enolase [Chrysemys picta bellii] 1.273

XP_005308611.1 PREDICTED: probable acyl-CoA dehydrogenase 6 isoform X2 [Chrysemys picta bellii] 1.274

XP_005308031.1 PREDICTED: alpha-actinin-3 [Chrysemys picta bellii] 1.277

XP_005307994.1 PREDICTED: glycogen phosphorylase, muscle form [Chrysemys picta bellii] 1.277

XP_005281550.1 PREDICTED: succinate-semialdehyde dehydrogenase, mitochondrial [Chrysemys picta bellii] 1.291

XP_008174802.1 PREDICTED: LOW QUALITY PROTEIN: very long-chain specific acyl-CoA dehydrogenase, mitochondrial [Chrysemys pi 1.298

XP_005308236.1 PREDICTED: paraplegin [Chrysemys picta bellii] 1.322

XP_005305411.1 PREDICTED: cysteine and glycine-rich protein 3 [Chrysemys picta bellii] 1.328

XP_008166137.1 PREDICTED: carnitine O-palmitoyltransferase 2, mitochondrial isoform X3 [Chrysemys picta bellii];XP_005284889.1 PRE 1.341

XP_008170377.1 PREDICTED: protein-glutamine gamma-glutamyltransferase 2 [Chrysemys picta bellii] 1.358

XP_005288726.1 PREDICTED: short-chain specific acyl-CoA dehydrogenase, mitochondrial [Chrysemys picta bellii] 1.368

XP_008161834.1 PREDICTED: acyl-CoA dehydrogenase family member 10 isoform X5 [Chrysemys picta bellii] 1.381

XP_005294357.1 PREDICTED: coenzyme Q-binding protein COQ10 homolog B, mitochondrial isoform X3 [Chrysemys picta bellii] 1.414

XP_005279757.1 PREDICTED: desmin [Chrysemys picta bellii];XP_005282498.1 PREDICTED: vimentin [Chrysemys picta bellii] 1.424

XP_008165745.1 PREDICTED: ribosome-releasing factor 2, mitochondrial isoform X3 [Chrysemys picta bellii] 1.476

XP_008168500.1 PREDICTED: LIM domain-binding protein 3 isoform X19 [Chrysemys picta bellii] 1.484

XP_008167457.1 PREDICTED: prostaglandin E synthase 2 [Chrysemys picta bellii] 1.512

XP_008175319.1 PREDICTED: histone H2B 8 [Chrysemys picta bellii] 1.725

XP_005309414.1 PREDICTED: ubiquinol-cytochrome-c reductase complex assembly factor 2 isoform X1 [Chrysemys picta bellii] 1.793

XP_005307037.1 PREDICTED: four and a half LIM domains protein 2 isoform X1 [Chrysemys picta bellii 1.994

XP_008172414.1 PREDICTED: histone H3 type 3-like [Chrysemys picta bellii];XP_005313474.2 PREDICTED: histone H3-like [Chrysemys 2.207

XP_008162862.1 PREDICTED: ras-related C3 botulinum toxin substrate 1 [Chrysemys picta bellii] 2.283

XP_005301650.1 PREDICTED: dihydrolipoyllysine-residue succinyltransferase component of 2-oxoglutarate dehydrogenase complex, mitoch 2.588 XP_005305090.1 PREDICTED: LOW QUALITY PROTEIN: probable 2-oxoglutarate dehydrogenase E1 component DHKTD1, mitochondrial [Chrysemys p XP_005282574.1 PREDICTED: 28S ribosomal protein S22, mitochondrial [Chrysemys picta bellii]

XP_005288210.1 PREDICTED: cytochrome c oxidase subunit 7C, mitochondrial [Chrysemys picta bellii] 
XP_005290314.1 PREDICTED: L-2-hydroxyglutarate dehydrogenase, mitochondrial [Chrysemys picta bellii]

XP_005304603.1 PREDICTED: catalase isoform X2 [Chrysemys picta bellii];XP_005304602.1 PREDICTED: catalase isoform X1 [Chrysemys picta bellii] XP_005305771.1 PREDICTED: 39S ribosomal protein L18, mitochondrial [Chrysemys picta bellii]

XP_005307578.1 PREDICTED: glutaredoxin-related protein 5, mitochondrial [Chrysemys picta bellii]

XP_005311592.1 PREDICTED: heat shock protein beta-6 [Chrysemys picta bellii]

XP_008174334.1 PREDICTED: enoyl-CoA delta isomerase 1, mitochondrial isoform X1 [Chrysemys picta bellii]

XP_008174855.1 PREDICTED: carnitine O-acetyltransferase-like [Chrysemys picta bellii] 
Table A2: List of proteins detected through LC-MSMS proteomics using SP3 and in-gel digestion

\begin{tabular}{|c|c|c|c|c|}
\hline Protein ID & R1 & $\mathbf{R 2}$ & $\mathbf{R 3}$ & $\begin{array}{l}\text { Average } \\
\text { Ratio }\end{array}$ \\
\hline XP_005289294.1PREDICTED:innercentromereprotein[Chrysemyspictabellii] & & 0.338 & & 0.338 \\
\hline XP_008168518.1PREDICTED:growthhormone-inducibletransmembraneprotein[Chrysemyspictabellii] & & 0.396 & & 0.396 \\
\hline XP_005292731.1PREDICTED:calsequestrin-2[Chrysemyspictabellii] & 0.450 & 0.359 & 0.389 & 0.399 \\
\hline XP_005300032.1PREDICTED:actin,alphacardiacmuscle1[Chrysemyspictabellii] & 0.293 & 0.500 & 0.744 & 0.513 \\
\hline XP_008176722.1PREDICTED:glycerol-3-phosphatedehydrogenase,mitochondrialisoformX2[Chrysemyspictabellii] & & 0.522 & & 0.522 \\
\hline XP_005280272.1PREDICTED:ethylmalonyl-CoAdecarboxylase[Chrysemyspictabellii] & 0.535 & & & 0.535 \\
\hline XP_005294115.1PREDICTED:proteinNDRG2isoformX4[Chrysemyspictabellii] & & & 0.535 & 0.535 \\
\hline XP_008168920.1PREDICTED:myosinlightchain3[Chrysemyspictabellii & 0.283 & 0.515 & 0.848 & 0.549 \\
\hline XP_008167946.1PREDICTED:uncharacterizedproteinLOC101952408[Chrysemyspictabellii] & & 0.572 & & 0.572 \\
\hline XP_008173951.1PREDICTED:proteolipidprotein2[Chrysemyspictabellii] & 0.921 & 0.494 & 0.310 & 0.575 \\
\hline XP_005283319.1PREDICTED:ADP/ATPtranslocase3[Chrysemyspictabellii] & & 0.584 & & 0.584 \\
\hline XP_005283657.1PREDICTED:myosin-15isoformX2[Chrysemyspictabellii] & 0.376 & 0.412 & 1.057 & 0.615 \\
\hline XP_008160754.1PREDICTED:sarcalumeninisoformX3[Chrysemyspictabellii] & 0.655 & & 0.586 & 0.621 \\
\hline XP_005304620.1PREDICTED:actin,aorticsmoothmuscle-like[Chrysemyspictabellii] & 0.400 & 0.440 & 1.040 & 0.627 \\
\hline XP_008174988.1PREDICTED:thioredoxin,mitochondrial[Chrysemyspictabellii] & & 0.637 & & 0.637 \\
\hline XP_005307623.1PREDICTED:myosin-11isoformX3[Chrysemyspictabellii] & & & 0.640 & 0.640 \\
\hline XP_008167928.1PREDICTED:mitochondrialinnermembraneproteinisoformX4[Chrysemyspictabellii] & 0.736 & 0.564 & 0.643 & 0.648 \\
\hline XP_008167561.1PREDICTED:fumaratehydratase,mitochondrialisoformX3[Chrysemyspictabellii] & & 0.649 & & 0.649 \\
\hline XP_005306644.1PREDICTED:collagenalpha-1(III)chain[Chrysemyspictabellii] & 0.649 & & & 0.649 \\
\hline XP_005281395.1PREDICTED:cytochromecoxidasesubunit6B1[Chrysemyspictabellii] & 0.725 & 0.346 & 0.880 & 0.650 \\
\hline XP_008162944.1PREDICTED:myosin-7-like[Chrysemyspictabellii] & 0.275 & & 1.026 & 0.650 \\
\hline XP_008174683.1PREDICTED:ES1proteinhomolog,mitochondrial[Chrysemyspictabellii] & & & 0.654 & 0.654 \\
\hline XP_005295025.1PREDICTED:NADHdehydrogenase[ubiquinone]iron-sulfurprotein8,mitochondrial[Chrysemyspict & t 0.879 & 0.603 & 0.496 & 0.659 \\
\hline XP_008173277.1PREDICTED:chaperoneactivityofbc1complex-like,mitochondrialisoformX2[Chrysemyspictabellii] & & & 0.660 & 0.660 \\
\hline XP_005299509.1PREDICTED:gelsolinisoformX2[Chrysemyspictabellii] & 0.848 & 0.530 & 0.719 & 0.699 \\
\hline XP_005310113.1PREDICTED:retina-specificcopperamineoxidase[Chrysemyspictabellii] & & 0.958 & 0.443 & 0.700 \\
\hline XP_008167453.1PREDICTED:spectrinalphachain,non-erythrocytic1isoformX8[Chrysemyspictabellii] & & 0.702 & & 0.702 \\
\hline XP_008177688.1PREDICTED:succinyl-CoAligase[GDP-forming]subunitbeta,mitochondrialisoformX2[Chrysemysp & 0.524 & 0.850 & 0.761 & 0.711 \\
\hline XP_005311741.1PREDICTED:stomatin-likeprotein2,mitochondrial[Chrysemyspictabellii] & & 0.714 & & 0.714 \\
\hline XP_005315376.1PREDICTED:succinatedehydrogenase[ubiquinone]iron-sulfursubunit,mitochondrial-like,partial[Ch & Chrysemy & y 0.718 & & 0.718 \\
\hline XP_005305943.1PREDICTED:short/branchedchainspecificacyl-CoAdehydrogenase,mitochondrialisoformX2[Chrys & 0.641 & 0.824 & & 0.733 \\
\hline XP_005301830.1PREDICTED:amineoxidase[flavin-containing]A[Chrysemyspictabellii] & 0.728 & 0.705 & 0.770 & 0.734 \\
\hline XP_005307398.1PREDICTED:spectrinbetachain,non-erythrocytic1isoformX3[Chrysemyspictabellii] & & 0.740 & & 0.740 \\
\hline XP_005301830.1PREDICTED:amineoxidase[flavin-containing]A[Chrysemyspictabellii] & 0.760 & 0.737 & 0.732 & 0.743 \\
\hline YP_009022047.1cytochromecoxidasesubunitII(mitochondrion)[Chrysemyspictabellii] & 0.579 & 0.966 & 0.684 & 0.743 \\
\hline YP_009022050.1cytochromecoxidasesubunitIII(mitochondrion)[Chrysemyspictabellii] & 0.749 & & & 0.749 \\
\hline XP_008168890.1PREDICTED:guaninenucleotide-bindingproteinsubunitbeta-4[Chrysemyspictabellii] & 1.066 & & 0.458 & 0.762 \\
\hline
\end{tabular}




\begin{tabular}{|c|c|c|c|c|}
\hline Protein ID & $\mathrm{R} 1$ & $\mathrm{R} 2$ & R3 & $\begin{array}{l}\text { Average } \\
\text { Ratio }\end{array}$ \\
\hline XP_005282046.1PREDICTED:ADP/ATPtranslocase1[Chrysemyspictabellii & 0.453 & 0.966 & 0.883 & 0.767 \\
\hline XP_005284475.1PREDICTED:myosinregulatorylightchain10[Chrysemyspictabellii] & 0.348 & 0.549 & 1.416 & 0.771 \\
\hline XP_005301780.1PREDICTED:CDGSHiron-sulfurdomain-containingprotein1[Chrysemyspictabellii] & 0.581 & 1.032 & 0.717 & 0.777 \\
\hline XP_005281953.1PREDICTED:hexokinase-1[Chrysemyspictabellii] & 1.088 & 0.706 & 0.557 & 0.784 \\
\hline XP_008161055.1PREDICTED:myosin-bindingproteinC,cardiac-typeisoformX8[Chrysemyspictabellii] & 0.421 & 0.572 & 1.359 & 0.784 \\
\hline XP_005299507.1PREDICTED:erythrocyteband7integralmembraneproteinisoformX2[Chrysemyspictabellii] & & & 0.792 & 0.792 \\
\hline XP_005286020.1PREDICTED:NADHdehydrogenase[ubiquinone]1betasubcomplexsubunit5, mitochondrialisoformX & 0.796 & & & 0.796 \\
\hline XP_005291208.1PREDICTED:cytochromec1,hemeprotein,mitochondrial[Chrysemyspictabellii] & 0.887 & 0.782 & 0.732 & 0.800 \\
\hline XP_005296226.1PREDICTED:cytosolaminopeptidase[Chrysemyspictabellii] & 0.630 & & 0.974 & 0.802 \\
\hline XP_008176595.1PREDICTED:titinisoformX50[Chrysemyspictabellii];XP_008176594.1PREDICTED:titinisoformX & 0.354 & 0.308 & 1.747 & 0.803 \\
\hline XP_005289913.1PREDICTED:cytochromeb-c1 complexsubunitRieske,mitochondrial[Chrysemyspictabellii] & 0.732 & 0.991 & 0.695 & 0.806 \\
\hline XP_008165710.1PREDICTED:creatinekinaseS-type,mitochondrial[Chrysemyspictabellii] & 0.826 & 0.781 & 0.815 & 0.807 \\
\hline XP_005299423.1PREDICTED:2,4-dienoyl-CoAreductase,mitochondrial[Chrysemyspictabellii] & 0.921 & 0.694 & & 0.808 \\
\hline XP_005291284.1PREDICTED:actin,alphaskeletalmuscle[Chrysemyspictabellii] & & & 0.809 & 0.809 \\
\hline XP_008162160.1PREDICTED:acyl-CoAsynthetasefamilymember2,mitochondrialisoformX2[Chrysemyspictabellii] & 0.810 & & & 0.810 \\
\hline XP_005280904.1PREDICTED:NADHdehydrogenase[ubiquinone]1alphasubcomplexsubunit2[Chrysemyspictabellii] & & 0.811 & & 0.811 \\
\hline XP_008167941.1PREDICTED:succinyl-CoAligase[ADP/GDP-forming]subunitalpha,mitochondrialisoformX4[Chry & 0.710 & 0.797 & 0.933 & 0.814 \\
\hline XP_005298323.1PREDICTED:fructose-bisphosphatealdolaseC[Chrysemyspictabellii] & 0.814 & & & 0.814 \\
\hline XP_008171870.1PREDICTED:dihydrolipoyldehydrogenase,mitochondrial[Chrysemyspictabellii] & 0.903 & 0.852 & 0.692 & 0.816 \\
\hline XP_005291429.1PREDICTED:succinatedehydrogenase[ubiquinone]cytochromebsmallsubunit,mitochondrial[Chrys & 0.862 & & 0.791 & 0.827 \\
\hline XP_008167561.1PREDICTED:fumaratehydratase,mitochondrialisoformX3[Chrysemyspictabellii] & 0.722 & 0.690 & 1.078 & 0.830 \\
\hline XP_005296358.1PREDICTED:epoxidehydrolase1-likeisoformX2[Chrysemyspictabellii] & 1.158 & 0.506 & & 0.832 \\
\hline XP_008177375.1PREDICTED:nuclearfactorNF-kappa-Bp105subunitisoformX1[Chrysemyspictabellii] & 0.832 & & & 0.832 \\
\hline XP_005281602.1PREDICTED:apolipoproteinO[Chrysemyspictabellii] & 0.791 & 0.875 & & 0.833 \\
\hline XP_005291601.1PREDICTED:superoxidedismutase[Mn],mitochondrial[Chrysemyspictabellii] & & 0.741 & 0.927 & 0.834 \\
\hline XP_008170401.1PREDICTED:LOWQUALITYPROTEIN:cytochromecoxidasesubunit4isoform1,mitochondrial[Ch & 0.441 & 0.926 & 1.161 & 0.843 \\
\hline XP_008176595.1PREDICTED:titinisoformX50[Chrysemyspictabellii] & 0.633 & 0.596 & 1.305 & 0.845 \\
\hline XP_008165710.1PREDICTED:creatinekinaseS-type,mitochondrial & 0.831 & 0.687 & 1.021 & 0.846 \\
\hline XP_005284219.1PREDICTED:thioredoxin-dependentperoxidereductase,mitochondrialisoformX1[Chrysemyspictab & 0.740 & 0.802 & 1.008 & 0.850 \\
\hline XP_008172424.1PREDICTED:ATPsynthasesubunite,mitochondrial[Chrysemyspictabellii] & 0.708 & 0.996 & & 0.852 \\
\hline XP_005303393.1PREDICTED:ATPsynthasesubunitO,mitochondrial[Chrysemyspictabellii] & 1.068 & 0.699 & 0.801 & 0.856 \\
\hline XP_005302390.1PREDICTED:ATPsynthasesubunitdelta,mitochondrial[Chrysemyspictabellii] & 0.892 & 0.826 & & 0.859 \\
\hline XP_008163617.1PREDICTED:sulfide:quinoneoxidoreductase,mitochondrialisoformX1[Chrysemyspictabellii] & & 0.860 & & 0.860 \\
\hline XP_005304790.1PREDICTED:cytochromeb-c1 complexsubunit2,mitochondrial[Chrysemyspictabellii] & 0.939 & 0.836 & 0.809 & 0.861 \\
\hline XP_005288429.1PREDICTED:cytochromeb-c1complexsubunit1,mitochondrial[Chrysemyspictabellii] & 0.858 & 0.884 & 0.847 & 0.863 \\
\hline XP_008173152.1PREDICTED:isocitratedehydrogenase[NAD]subunitalpha,mitochondrialisoformX2[Chrysemyspict & 0.359 & 1.145 & 1.088 & 0.864 \\
\hline XP_005305757.1PREDICTED:NADHdehydrogenase[ubiquinone]1alphasubcomplexsubunit5isoformX1[Chrysemys & 0.872 & & & 0.872 \\
\hline XP_005299945.1PREDICTED:NADHdehydrogenase[ubiquinone]1alphasubcomplexsubunit4[Chrysemyspictabellii] & 0.820 & 0.899 & 0.898 & 0.872 \\
\hline XP_005295693.1PREDICTED:D-beta-hydroxybutyratedehydrogenase,mitochondrial[Chrysemyspictabellii] & 0.598 & 1.065 & 0.954 & 0.873 \\
\hline XP_005296564.1PREDICTED:succinatedehydrogenase[ubiquinone]flavoproteinsubunit,mitochondrialisoformX2[C & 0.978 & 0.981 & 0.661 & 0.873 \\
\hline XP_008161651.1PREDICTED:calcium-bindingmitochondrialcarrierproteinAralar2isoformX4[Chrysemyspictabellii] & 0.874 & & & 0.874 \\
\hline XP_005285073.1PREDICTED:annexinA2[Chrysemyspictabellii] & 0.949 & 0.705 & 0.972 & 0.876 \\
\hline
\end{tabular}




\begin{tabular}{|c|c|c|c|c|}
\hline Protein ID & $\mathrm{R} 1$ & $\mathrm{R} 2$ & $\mathrm{R} 3$ & $\begin{array}{l}\text { Average } \\
\text { Ratio }\end{array}$ \\
\hline XP_005290933.1PREDICTED:cytochromec[Chrysemyspictabellii] & 0.827 & 0.926 & & 0.877 \\
\hline XP_008173916.1PREDICTED:cytochromecoxidasesubunit5A,mitochondrial[Chrysemyspictabellii] & 0.686 & 1.053 & 0.895 & 0.878 \\
\hline XP_005301962.1PREDICTED:ATPsynthaseF(0)complexsubunitC1,mitochondrial[Chrysemyspictabellii] & 0.882 & & & 0.882 \\
\hline XP_005286542.1PREDICTED:voltage-dependentanion-selectivechannelprotein3isoformX4[Chrysemyspictabellii] & 0.953 & 0.921 & 0.773 & 0.883 \\
\hline XP_005312088.1PREDICTED:prohibitin-2[Chrysemyspictabellii];XP_005312087.1PREDICTED:prohibitin-2[Chry & 0.776 & 1.004 & 0.871 & 0.884 \\
\hline XP_005278819.1PREDICTED:voltage-dependentanion-selectivechannelprotein2isoformX2[Chrysemyspictabellii] & 0.972 & 0.860 & 0.836 & 0.889 \\
\hline XP_005289504.1PREDICTED:NADHdehydrogenase[ubiquinone]flavoprotein1,mitochondrial[Chrysemyspictabellii & 0.879 & 0.873 & 0.918 & 0.890 \\
\hline XP_005293888.1PREDICTED:elongationfactorTu,mitochondrial[Chrysemyspictabellii] & 0.808 & 1.128 & 0.742 & 0.893 \\
\hline XP_005282702.1PREDICTED:NADHdehydrogenase[ubiquinone]flavoprotein2,mitochondrial[Chrysemyspictabellii & 0.716 & 1.244 & 0.726 & 0.895 \\
\hline XP_005307068.1PREDICTED:NADHdehydrogenase[ubiquinone]1alphasubcomplexsubunit9,mitochondrial[Chryse & 0.960 & 0.970 & 0.758 & 0.896 \\
\hline XP_008164277.1PREDICTED:ATPsynthasesubunitalpha,mitochondrial[Chrysemyspictabellii] & 0.870 & 0.845 & 0.976 & 0.897 \\
\hline XP_005305285.1PREDICTED:phosphatecarrierprotein,mitochondrialisoformX2[Chrysemyspictabellii] & 0.861 & 1.013 & 0.824 & 0.899 \\
\hline XP_008164197.1PREDICTED:sortingandassemblymachinerycomponent50homolog[Chrysemyspictabellii] & 0.989 & 0.836 & 0.875 & 0.900 \\
\hline XP_008176610.1PREDICTED:metaxin-2isoformX2[Chrysemyspictabellii] & 1.005 & 0.778 & 0.919 & 0.901 \\
\hline XP_005286542.1PREDICTED:voltage-dependentanion-selectivechannelprotein3isoformX4[Chrysemyspictabellii] & 0.927 & 0.971 & 0.809 & 0.903 \\
\hline XP_005301626.1PREDICTED:ubiquinonebiosynthesismonooxygenaseCOQ6isoformX2[Chrysemyspictabellii] & & 0.904 & & 0.904 \\
\hline XP_005297873.1PREDICTED:succinyl-CoAligase[GDP-forming]subunitbeta,mitochondrialisoformX1[Chrysemy sp & 0.746 & 0.995 & 0.972 & 0.904 \\
\hline XP_005311796.1PREDICTED:cytochromeb-c1 complexsubunit6,mitochondrial[Chrysemyspictabellii] & 0.929 & 0.881 & & 0.905 \\
\hline XP_005283737.1PREDICTED:mitochondrialpyruvatecarrier2[Chrysemyspictabellii] & 0.645 & 1.167 & 0.908 & 0.907 \\
\hline XP_005289125.1PREDICTED:actin,cytoplasmic1[Chrysemyspictabellii] & 1.296 & 0.522 & & 0.909 \\
\hline XP_005301976.1PREDICTED:prohibitin[Chrysemyspictabellii] & 0.903 & 0.992 & 0.833 & 0.909 \\
\hline XP_005312448.1PREDICTED:stress-70protein,mitochondrial[Chrysemyspictabellii] & 0.730 & 0.906 & 1.100 & 0.912 \\
\hline XP_005298651.1PREDICTED:aldehydedehydrogenase,mitochondrial[Chrysemyspictabellii] & 0.899 & 0.496 & 1.347 & 0.914 \\
\hline XP_005282046.1PREDICTED:ADP/ATPtranslocase1[Chrysemyspictabellii] & 0.503 & 1.181 & 1.058 & 0.914 \\
\hline XP_005285808.1PREDICTED:caveolin-1isoformX3[Chrysemyspictabellii] & 1.590 & 0.522 & 0.631 & 0.914 \\
\hline XP_008174644.1PREDICTED:isocitratedehydrogenase[NAD]subunitgamma,mitochondrial[Chrysemyspictabellii] & 0.918 & & & 0.918 \\
\hline XP_005305285.1PREDICTED:phosphatecarrierprotein,mitochondrialisoformX2[Chrysemyspictabellii] & 0.931 & 0.832 & 0.996 & 0.920 \\
\hline XP_008173484.1PREDICTED:ATPsynthasesubunitbeta,mitochondrial[Chrysemyspictabellii] & 0.927 & 0.895 & 0.945 & 0.922 \\
\hline XP_005297049.1PREDICTED:3-hydroxyisobutyratedehydrogenase,mitochondrial[Chrysemyspictabellii] & 0.840 & 0.793 & 1.137 & 0.923 \\
\hline XP_005307676.1PREDICTED:lysosome-associatedmembraneglycoprotein1[Chrysemyspictabellii] & 1.209 & 0.720 & 0.841 & 0.923 \\
\hline XP_005290314.1PREDICTED:L-2-hydroxyglutaratedehydrogenase,mitochondrial[Chrysemyspictabellii] & 0.857 & & 0.991 & 0.924 \\
\hline XP_005288429.1PREDICTED:cytochromeb-c1complexsubunit1,mitochondrial[Chrysemyspictabellii] & 0.749 & 0.832 & 1.192 & 0.924 \\
\hline XP_008162712.1PREDICTED:methylmalonate-semialdehydedehydrogenase[acylating],mitochondrial[Chrysemyspi & i0.987 & 0.845 & 0.947 & 0.926 \\
\hline XP_005291601.1PREDICTED:superoxidedismutase[Mn],mitochondrial[Chrysemyspictabellii] & 1.054 & 0.621 & 1.104 & 0.927 \\
\hline XP_005290019.1PREDICTED:acetyl-CoAacetyltransferase,mitochondrial[Chrysemyspictabellii] & 0.691 & 1.725 & 0.372 & 0.929 \\
\hline XP_005304790.1PREDICTED:cytochromeb-c1 complexsubunit2,mitochondrial[Chrysemyspictabellii] & 0.741 & 0.948 & 1.102 & 0.930 \\
\hline XP_005282220.1PREDICTED:succinyl-CoA:3-ketoacidcoenzymeAtransferase1,mitochondrialisoformX2[Chrysem & 0.691 & 1.300 & 0.801 & 0.931 \\
\hline XP_005289435.1PREDICTED:phosphoglyceratemutase1[Chrysemyspictabellii] & 0.945 & & & 0.945 \\
\hline XP_008174683.1PREDICTED:ES1 proteinhomolog,mitochondrial[Chrysemyspictabellii] & 1.031 & 0.651 & 1.157 & 0.947 \\
\hline XP_005290019.1PREDICTED:acetyl-CoAacetyltransferase,mitochondrial[Chrysemyspictabellii] & 0.749 & 1.319 & 0.778 & 0.948 \\
\hline YP_009022055.1NADHdehydrogenasesubunit6(mitochondrion)[Chrysemyspictabellii] & 1.056 & & 0.844 & 0.950 \\
\hline \multicolumn{4}{|l|}{ XP_005289504.1PREDICTED:NADHdehydrogenase[ubiquinone]flavoprotein1,mitochondrial[Chrysemyspictabellii] 0.950} & 0.950 \\
\hline
\end{tabular}




\begin{tabular}{|c|c|c|c|c|}
\hline Protein ID & $\mathrm{R} 1$ & $\mathrm{R} 2$ & R3 & $\begin{array}{l}\text { Average } \\
\text { Ratio }\end{array}$ \\
\hline XP_005291672.1PREDICTED:cytochromeb-c1complexsubunit7isoformX1[Chrysemyspictabellii] & 0.906 & 0.880 & 1.072 & 0.952 \\
\hline XP_005281953.1PREDICTED:hexokinase-1[Chrysemyspictabellii] & 1.182 & 1.070 & 0.609 & 0.954 \\
\hline XP_005278819.1PREDICTED:voltage-dependentanion-selectivechannelprotein2isoformX2[Chrysemyspictabellii] & 1.053 & 0.935 & 0.877 & 0.955 \\
\hline XP_008167258.1PREDICTED:ADP/ATPtranslocase2[Chrysemyspictabellii] & 0.578 & 1.228 & 1.061 & 0.956 \\
\hline XP_005291923.1PREDICTED:coiled-coil-helix-coiled-coil-helixdomain-containingprotein3,mitochondrialisoformX & 0.760 & & 1.152 & 0.956 \\
\hline XP_008176743.1PREDICTED:calcium-bindingmitochondrialcarrierproteinAralar1[Chrysemyspictabellii] & 0.798 & 0.943 & 1.152 & 0.965 \\
\hline XP_008170746.1PREDICTED:isocitratedehydrogenase[NADP]cytoplasmic[Chrysemyspictabellii] & & & 0.966 & 0.966 \\
\hline XP_005283491.1PREDICTED:proteinNipSnaphomolog2isoformX2[Chrysemyspictabellii] & 0.704 & 0.931 & 1.267 & 0.967 \\
\hline XP_005291975.1PREDICTED:ATPsynthasesubunitgamma,mitochondrialisoformX3[Chrysemyspictabellii] & 0.760 & 0.814 & 1.331 & 0.968 \\
\hline XP_005302894.1PREDICTED:cytochromeb-c1 complexsubunit8[Chrysemyspictabellii] & 0.969 & & & 0.969 \\
\hline XP_005289913.1PREDICTED:cytochromeb-c1 complexsubunitRieske,mitochondrial[Chrysemyspictabellii] & 1.175 & 0.902 & 0.836 & 0.971 \\
\hline XP_005301634.1PREDICTED:acetyl-coenzymeAsynthetase2-like,mitochondrialisoformX1[Chrysemyspictabellii] & 0.631 & 1.017 & 1.271 & 0.973 \\
\hline XP_005299830.1PREDICTED:ATPsynthasesubunitg,mitochondrial[Chrysemyspictabellii] & 0.963 & 0.973 & 0.988 & 0.974 \\
\hline XP_008175936.1PREDICTED:aspartateaminotransferase,mitochondrialisoformX2[Chrysemyspictabellii] & 0.895 & 0.901 & 1.136 & 0.978 \\
\hline XP_008169959.1PREDICTED:ATPsynthaseF(0)complexsubunitB1,mitochondrial[Chrysemyspictabellii] & 1.073 & 0.840 & 1.022 & 0.978 \\
\hline XP_008173362.1PREDICTED:enoyl-CoAhydratase,mitochondrial[Chrysemyspictabellii] & 0.892 & 0.769 & 1.276 & 0.979 \\
\hline XP_008164197.1PREDICTED:sortingandassemblymachinerycomponent50homolog[Chrysemyspictabellii] & 1.051 & 0.867 & 1.022 & 0.980 \\
\hline XP_005287580.1PREDICTED:NADP-dependentmalicenzyme,mitochondrialisoformX1[Chrysemyspictabellii] & 1.215 & 0.746 & & 0.981 \\
\hline XP_005310113.1PREDICTED:retina-specificcopperamineoxidase[Chrysemyspictabellii] & & 0.984 & & 0.984 \\
\hline XP_008166535.1PREDICTED:2-oxoglutaratedehydrogenase,mitochondrialisoformX3[Chrysemyspictabellii] & 0.943 & 0.981 & 1.030 & 0.985 \\
\hline XP_005291379.1PREDICTED:proteinFAM162AisoformX3[Chrysemyspictabellii] & 0.885 & 0.970 & 1.102 & 0.986 \\
\hline XP_005297517.1PREDICTED:ATPsynthasesubunitd,mitochondrial[Chrysemyspictabellii] & 1.026 & 0.878 & 1.056 & 0.987 \\
\hline XP_005279297.1PREDICTED:cytochromecoxidasesubunit5B,mitochondrial[Chrysemyspictabellii] & 0.969 & 0.809 & 1.184 & 0.988 \\
\hline XP_005294822.1PREDICTED:NADHdehydrogenase[ubiquinone]1betasubcomplexsubunit6[Chrysemyspictabellii] & & 0.988 & & 0.988 \\
\hline XP_005304055.1PREDICTED:NAD(P)transhydrogenase,mitochondrial-like[Chrysemyspictabellii] & 0.898 & 0.998 & 1.069 & 0.988 \\
\hline XP_008168049.1PREDICTED:succinatedehydrogenase[ubiquinone]iron-sulfursubunit,mitochondrial[Chrysemyspict & tabellii] & 0.990 & & 0.990 \\
\hline XP_008168434.1PREDICTED:acyl-coenzymeAthioesterase9,mitochondrialisoformX4[Chrysemyspictabellii] & 0.692 & & 1.293 & 0.992 \\
\hline XP_005284503.1PREDICTED:malatedehydrogenase,mitochondrial[Chrysemyspictabellii] & 0.687 & 1.066 & 1.228 & 0.994 \\
\hline XP_005298651.1PREDICTED:aldehydedehydrogenase,mitochondrial[Chrysemyspictabellii] & 0.851 & 0.476 & 1.656 & 0.994 \\
\hline XP_008168796.1PREDICTED:actin,aorticsmoothmuscleisoformX1[Chrysemyspictabellii] & 0.503 & 0.491 & 1.989 & 0.994 \\
\hline XP_005284174.1PREDICTED:trifunctionalenzymesubunitalpha,mitochondrialisoformX2[Chrysemyspictabellii] & 0.833 & 1.013 & 1.146 & 0.998 \\
\hline XP_005296740.1PREDICTED:NADH-cytochromeb5reductase3[Chrysemyspictabellii] & 1.003 & 1.112 & 0.879 & 0.998 \\
\hline XP_005301634.1PREDICTED:acetyl-coenzymeAsynthetase2-like,mitochondrialisoformX1[Chrysemyspictabellii] & 0.922 & 0.981 & 1.094 & 0.999 \\
\hline XP_005283844.1PREDICTED:NADHdehydrogenase[ubiquinone]1alphasubcomplexsubunit7[Chrysemyspictabellii] & 0.936 & 1.110 & 0.952 & 0.999 \\
\hline XP_005302646.1PREDICTED:aconitatehydratase,mitochondrial[Chrysemyspictabellii] & 1.142 & 1.071 & 0.788 & 1.000 \\
\hline XP_005291975.1PREDICTED:ATPsynthasesubunitgamma,mitochondrialisoformX3[Chrysemyspictabellii] & 0.903 & 1.056 & 1.053 & 1.004 \\
\hline XP_005296013.1PREDICTED:pyruvatedehydrogenaseE1componentsubunitbeta,mitochondrialisoformX2[Chrysem & 1.040 & 0.934 & 1.041 & 1.005 \\
\hline XP_005282276.1PREDICTED:NADHdehydrogenase[ubiquinone]iron-sulfurprotein4,mitochondrial,partial[Chrysem & 1.008 & & & 1.008 \\
\hline XP_005284172.1PREDICTED:trifunctionalenzymesubunitbeta,mitochondrial[Chrysemyspictabellii] & 0.846 & 0.951 & 1.234 & 1.010 \\
\hline XP_005302646.1PREDICTED:aconitatehydratase,mitochondrial[Chrysemyspictabellii] & 1.020 & 1.143 & 0.870 & 1.011 \\
\hline XP_008162642.1PREDICTED:cytosolicnon-specificdipeptidaseisoformX2[Chrysemyspictabellii] & & 1.013 & & 1.013 \\
\hline XP_008160750.1PREDICTED:heatshockprotein75kDa,mitochondrial[Chrysemyspictabellii] & & 1.013 & & 1.013 \\
\hline
\end{tabular}


Protein ID

XP_005284503.1PREDICTED:malatedehydrogenase,mitochondrial[Chrysemyspictabellii]

XP_005294591.1PREDICTED:sodium/potassium-transportingATPasesubunitbeta-1[Chrysemyspictabellii]

XP_005291360.1PREDICTED:glyceraldehyde-3-phosphatedehydrogenase[Chrysemyspictabellii]

XP_005311547.1PREDICTED:NADHdehydrogenase[ubiquinone]1alphasubcomplexsubunit10,mitochondı ial[Chrys

XP_005279297.1PREDICTED:cytochromecoxidasesubunit5B,mitochondrial[Chrysemyspictabellii]

XP_005300716.1PREDICTED:isocitratedehydrogenase[NADP],mitochondrial[Chrysemyspictabellii]

XP_005296359.1PREDICTED:epoxidehydrolase1-likeisoformX3[Chrysemyspictabellii]

XP_008166943.1PREDICTED:NAD(P)transhydrogenase,mitochondrial[Chrysemyspictabellii]

XP_008167422.1PREDICTED:carnitineO-acetyltransferaseisoformX2[Chrysemyspictabellii]

R1

0.928

$\mathrm{R} 2$

R3

Average Ratio

XP_005312088.1PREDICTED:prohibitin-2[Chrysemyspictabellii];XP_005312087.1PREDICTED:prohibitin-2[Chry 1.026 1.111 1.165

XP_005312096.1PREDICTED:glutathioneS-transferasekappa1 isoformX1[Chrysemyspictabellii]

$\begin{array}{lll}1.553 & 1.454 & 0.313\end{array}$

$\begin{array}{lll}1.321 & 0.919 & 1.094\end{array}$

$0.947 \quad 1.265 \quad 1.123$

XP_005300716.1PREDICTED:isocitratedehydrogenase[NADP],mitochondrial[Chrysemyspictabellii]

s $0.874 \quad 0.960 \quad 1.513$

$1.349 \quad 0.882$

XP_008171609.1PREDICTED:hydroxysteroiddehydrogenase-likeprotein2,partial[Chrysemyspictabellii]

$0.988 \quad 1.247$

XP_008174073.1PREDICTED:uncharacterizedproteinC6orf136homolog[Chrysemyspictabellii]

$\begin{array}{lll}1.212 & 0.829 & 1.320\end{array}$

XP_005294591.1PREDICTED:sodium/potassium-transportingATPasesubunitbeta-1[Chrysemyspictabellii]

XP_008170574.1PREDICTED:dihydrolipoyllysine-residueacetyltransferasecomponentofpyruvatedehydrogenasecom $0.823 \quad 1.083 \quad 1.467$

$\begin{array}{lll}1.228 & 1.399 & 0.750\end{array}$

$1.196 \quad 0.806 \quad 1.381$

XP_005289125.1PREDICTED:actin,cytoplasmic1[Chrysemyspictabellii]

XP_005288842.1PREDICTED:NADHdehydrogenase[ubiquinone]1betasubcomplexsubunit9isoformX2[Chrysemyspictabell 1.129

XP 005281550.1PREDICTED:succinate-semialdehydedehydrogenase,mitochondrial[Chrysemyspictabellii]

1.121

1.141

XP_005301651.1PREDICTED:dihydrolipoyllysine-residuesuccinyltransferasecomponentof2-oxoglutaratedehydroge

XP_005312172.1PREDICTED:mitochondrialfission1proteinisoformX2[Chrysemyspictabellii]

$1.145 \quad 1.125$

XP_005281630.1PREDICTED:pyruvatedehydrogenaseE1componentsubunitalpha,somaticform,mitochondrialisofor $1.114 \quad 1.231 \quad 1.060$

XP_005284172.1PREDICTED:trifunctionalenzymesubunitbeta,mitochondrial[Chrysemyspictabellii]

$0.948 \quad 1.078 \quad 1.390$

$0.9910 .863 \quad 1.566$

1.143

XP_005297049.1PREDICTED:3-hydroxyisobutyratedehydrogenase,mitochondrial[Chrysemyspictabellii]

XP_005313805.1PREDICTED:NADHdehydrogenase[ubiquinone]1alphasubcomplexsubunit6[Chrysemyspictabellii] $1.087 \quad 1.217 \quad 1.125$

XP_005287265.1PREDICTED:malatedehydrogenase,cytoplasmicisoformX3[Chrysemyspictabellii]

1.147

$\begin{array}{lll}1.287 & 0.954 & 1.231\end{array}$

1.160

XP_005302193.1PREDICTED:NADHdehydrogenase[ubiquinone]iron-sulfurprotein5[Chrysemyspictabellii]

1.2161 .108

XP_008169959.1PREDICTED:ATPsynthaseF(0)complexsubunitB1,mitochondrial[Chrysemyspictabellii]

XP_005296013.1PREDICTED:pyruvatedehydrogenaseE1componentsubunitbeta,mitochondrialisoformX2[Chrysem $1.153 \quad 1.1121 .224$

XP_005279748.1PREDICTED:long-chainspecificacyl-CoAdehydrogenase,mitochondrialisoformX3[Chrysemyspict $1.383 \quad 1.156 \quad 0.960$

$1.3051 .008 \quad 1.190$

XP_005307002.1PREDICTED:isoleucine--tRNAligase,mitochondrial[Chrysemyspictabellii]

XP_005293591.1PREDICTED:acetyl-coenzymeAsynthetase2-like,mitochondrialisoformX3[Chrysemyspictabellii] $1.101 \quad 1.292 \quad 1.113$

XP_005295334.1PREDICTED:mitochondrial2-oxoglutarate/malatecarrierproteinisoformX2[Chrysemyspictabellii] $1.367 \quad 1.022 \quad 1.120$

XP_008169449.1PREDICTED:NAD-dependentproteindeacylasesirtuin-5,mitochondrialisoformX2[Chrysemyspictab $1.558 \quad 0.977 \quad 0.982$

XP_005307252.1PREDICTED:ubiquinonebiosynthesisproteinCOQ7homologisoformX2[Chrysemyspictabellii]

1.174

1.3021 .051

$1.479 \quad 0.875$
1.084

1.085

1.085

1.089

1.092

1.093

1.093

1.094

1.099

1.101

1.107

1.111

1.112

1.116

1.116

1.117

1.120

1.124

1.126

1.128

1.129

1.131

1.135

1.135

1.135

1.139

1.140

1.143

1.143

1.147

1.157

1.160

1.162

1.163

1.166

1.168

1.169

1.169

1.173

1.174

1.176

1.177 
XP_005296564.1PREDICTED:succinatedehydrogenase[ubiquinone]flavoproteinsubunit,mitochondrialisoformX2[C $0.766 \quad 1.119 \quad 1.689$ 


\begin{tabular}{|c|c|c|c|c|}
\hline Protein ID & R1 & $\mathbf{R}$ & R3 & $\begin{array}{l}\text { Average } \\
\text { Ratio }\end{array}$ \\
\hline XP_005294358.1PREDICTED:10kDaheatshockprotein,mitochondrialisoformX3[Chrysemyspictabellii] & 0.989 & 1.184 & 1.783 & 1.319 \\
\hline XP_008170574.1PREDICTED:dihydrolipoyllysine-residueacetyltransferasecomponentofpyruvatedehydrogenasecomp & plex,mi & 1.321 & & 1.321 \\
\hline XP_005309566.1PREDICTED:CCR4-NOTtranscriptioncomplexsubunit1 isoformX7[Chrysemyspictabellii] & & 1.339 & & 1.339 \\
\hline XP_005279048.1PREDICTED:ubiquitin-60SribosomalproteinL40[Chrysemyspictabellii] & & & 1.342 & 1.342 \\
\hline XP_005300701.1PREDICTED:proteindisulfide-isomeraseA3[Chrysemyspictabellii] & 1.262 & 1.339 & 1.452 & 1.351 \\
\hline XP_005304316.1PREDICTED:4-trimethylaminobutyraldehydedehydrogenase[Chrysemyspictabellii] & 1.518 & 1.194 & & 1.356 \\
\hline XP_005292450.1PREDICTED:LETM1 andEF-handdomain-containingprotein1,mitochondrialisoformX2[Chrysemys & 0.997 & 1.255 & 1.840 & 1.364 \\
\hline XP_005294354.1PREDICTED:60kDaheatshockprotein,mitochondrial[Chrysemyspictabellii] & 1.120 & 1.253 & 1.720 & 1.365 \\
\hline XP_008174855.1PREDICTED:carnitineO-acetyltransferase-like[Chrysemyspictabellii] & & 1.366 & & 1.366 \\
\hline XP_005304055.1PREDICTED:NAD(P)transhydrogenase,mitochondrial-like[Chrysemyspictabellii] & 1.126 & 1.457 & 1.553 & 1.379 \\
\hline XP_005311675.1PREDICTED:LOWQUALITYPROTEIN:electrontransferflavoproteinsubunitalpha,mitochondrial[C & 1.075 & 1.160 & 1.909 & 1.381 \\
\hline XP_008168920.1PREDICTED:myosinlightchain3[Chrysemyspictabellii] & & & 1.388 & 1.388 \\
\hline XP_008174133.1PREDICTED:electrontransferflavoproteinsubunitbeta[Chrysemyspictabellii] & 0.929 & 1.045 & 2.221 & 1.399 \\
\hline XP_008164259.1PREDICTED:NAD-dependentmalicenzyme,mitochondrial[Chrysemyspictabellii] & 1.218 & 2.093 & 0.890 & 1.400 \\
\hline XP_008172109.1PREDICTED:sodium/potassium-transportingATPasesubunitalpha-1isoformX2[Chrysemyspictabell & 1.494 & 1.005 & 1.716 & 1.405 \\
\hline XP_005305607.1PREDICTED:O-acetyl-ADP-ribosedeacetylaseMACROD1isoformX2[Chrysemyspictabellii] & 1.557 & 1.298 & 1.361 & 1.405 \\
\hline XP_008170555.1PREDICTED:neuralcelladhesionmolecule1 isoformX16[Chrysemyspictabellii] & 1.374 & 1.206 & 1.660 & 1.414 \\
\hline XP_005295846.1PREDICTED:annexinA6[Chrysemyspictabellii] & & 1.422 & & 1.422 \\
\hline XP_005296688.1PREDICTED:L-lactatedehydrogenaseBchain[Chrysemyspictabellii] & 0.821 & 1.161 & 2.297 & 1.426 \\
\hline XP_005295100.1PREDICTED:mitochondrialcarrierhomolog2[Chrysemyspictabellii] & 1.437 & & & 1.437 \\
\hline XP_005291246.1PREDICTED:nidogen-1[Chrysemyspictabellii] & & & 1.444 & 1.444 \\
\hline XP_005288273.1PREDICTED:methylcrotonoyl-CoAcarboxylasebetachain,mitochondrial[Chrysemyspictabellii] & 1.444 & & 1.468 & 1.456 \\
\hline XP_005289114.1PREDICTED:ATPsynthasesubunitf,mitochondrial[Chrysemyspictabellii] & 0.911 & 2.212 & 1.323 & 1.482 \\
\hline XP_005300883.1PREDICTED:myoglobin[Chrysemyspictabellii] & 1.569 & 1.490 & 1.430 & 1.496 \\
\hline XP_005287959.1PREDICTED:hydroxyacyl-coenzymeAdehydrogenase,mitochondrial[Chrysemyspictabellii] & 1.001 & 1.044 & 2.496 & 1.514 \\
\hline XP_008175623.1PREDICTED:monofunctionalC1-tetrahydrofolatesynthase,mitochondrialisoformX3[Chrysemyspic & 1.554 & & & 1.554 \\
\hline XP_005290066.1PREDICTED:hemoglobinsubunitbeta[Chrysemyspictabellii] & 1.478 & 2.286 & 0.904 & 1.556 \\
\hline XP_005295339.1PREDICTED:beta-enolase[Chrysemyspictabellii] & 1.558 & & & 1.558 \\
\hline XP_005283657.1PREDICTED:myosin-15isoformX2[Chrysemyspictabellii] & 0.550 & 0.439 & 3.716 & 1.569 \\
\hline XP_008160877.1PREDICTED:pyruvatedehydrogenasekinase,isozyme2isoformX2[Chrysemyspictabellii] & 1.831 & 1.044 & 1.937 & 1.604 \\
\hline XP_008170124.1PREDICTED:proteinNipSnaphomolog3A[Chrysemyspictabellii] & 1.520 & 0.894 & 2.402 & 1.605 \\
\hline XP_008173472.1PREDICTED:citratesynthase,mitochondrial[Chrysemyspictabellii] & & 1.187 & 2.047 & 1.617 \\
\hline XP_005312065.1PREDICTED:triosephosphateisomerase[Chrysemyspictabellii] & 1.542 & 1.198 & 2.220 & 1.653 \\
\hline XP_005312784.1PREDICTED:glyceraldehyde-3-phosphatedehydrogenase,testis-specific[Chrysemyspictabellii] & 1.518 & & 1.801 & 1.660 \\
\hline XP_008170377.1PREDICTED:protein-glutaminegamma-glutamyltransferase2[Chrysemyspictabellii] & 0.996 & 1.531 & 2.486 & 1.671 \\
\hline XP_008160877.1PREDICTED:pyruvatedehydrogenasekinase,isozyme2isoformX2[Chrysemyspictabellii] & 0.877 & & 2.485 & 1.681 \\
\hline XP_005295736.1PREDICTED:creatinekinaseM-type[Chrysemyspictabellii] & 1.715 & & & 1.715 \\
\hline XP_005280053.1PREDICTED:cadherin-2[Chrysemyspictabellii] & & & 1.752 & 1.752 \\
\hline XP_005299362.1PREDICTED:electrontransferflavoprotein-ubiquinoneoxidoreductase,mitochondrialisoformX2[Chr & 1.036 & 2.306 & 1.924 & 1.755 \\
\hline XP_005312784.1PREDICTED:glyceraldehyde-3-phosphatedehydrogenase,testis-specific[Chrysemyspictabellii] & 1.519 & 0.808 & 2.943 & 1.757 \\
\hline XP_005279109.1PREDICTED:tropomyosinalpha-4chainisoformX1[Chrysemyspictabellii] & & & 1.783 & 1.783 \\
\hline XP_005296688.1PREDICTED:L-lactatedehydrogenaseBchain[Chrysemyspictabellii] & & & 1.819 & 1.819 \\
\hline
\end{tabular}




\begin{tabular}{|c|c|c|c|c|}
\hline Protein ID & R1 & R2 & R3 & $\begin{array}{l}\text { Average } \\
\text { ratio }\end{array}$ \\
\hline XP_005296740.1PREDICTED:NADH-cytochromeb5reductase3[Chrysemyspictabellii] & & & 1.832 & 1.832 \\
\hline XP_005314681.1PREDICTED:fructose-bisphosphatealdolaseA[Chrysemyspictabellii] & 0.988 & 1.142 & 3.612 & 1.914 \\
\hline XP_005310589.1PREDICTED:2-oxoisovaleratedehydrogenasesubunitalpha,mitochondrial[Chrysemyspictabellii] & & 3.229 & 0.699 & 1.964 \\
\hline XP_005284475.1PREDICTED:myosinregulatorylightchain10[Chrysemyspictabellii] & & & 2.080 & 2.080 \\
\hline XP_005291239.1PREDICTED:alpha-actinin-2isoformX1[Chrysemyspictabellii & 0.601 & 0.581 & 5.084 & 2.089 \\
\hline XP_005288141.1PREDICTED:hydroxyacid-oxoacidtranshydrogenase,mitochondrial[Chrysemyspictabellii] & 1.240 & 2.953 & & 2.096 \\
\hline XP_008175311.1PREDICTED:tripartitemotif-containingprotein72[Chrysemyspictabellii] & 1.147 & & 3.067 & 2.107 \\
\hline XP_005285898.1PREDICTED:creatinekinaseB-typeisoformX2[Chrysemyspictabellii] & 1.312 & 0.745 & 4.311 & 2.123 \\
\hline XP_008168016.1PREDICTED:LOWQUALITYPROTEIN:basementmembrane-specificheparansulfateproteoglycanco & coreprote & ein[Chr & 2.174 & 2.174 \\
\hline XP_005308617.1PREDICTED:collagenalpha-2(I)chain[Chrysemyspictabellii] & 0.851 & 1.070 & 4.622 & 2.181 \\
\hline XP_008168016.1PREDICTED:LOWQUALITYPROTEIN:basementmembrane-specificheparansulfateproteoglycanc & c 1.344 & 0.448 & 4.809 & 2.200 \\
\hline XP_005301998.1PREDICTED:collagenalpha-1(I)chain[Chrysemyspictabellii] & 0.811 & 0.834 & 5.157 & 2.267 \\
\hline XP_005304075.1PREDICTED:fibrillin-1isoformX1[Chrysemyspictabellii] & 1.100 & 0.362 & 5.367 & 2.276 \\
\hline XP_008165531.1PREDICTED:delta-1-pyrroline-5-carboxylatedehydrogenase,mitochondrial[Chrysemyspictabellii] & ] 4.309 & 1.103 & 1.539 & 2.317 \\
\hline XP_008172414.1PREDICTED:histoneH3type3-like[Chrysemyspictabellii] & 0.565 & 0.948 & 5.980 & 2.498 \\
\hline XP_005291934.1PREDICTED:keratin,typeIIcytoskeletal5isoformX2[Chrysemyspictabellii] & 5.301 & 1.519 & 0.872 & 2.564 \\
\hline XP_005305411.1PREDICTED:cysteineandglycine-richprotein3[Chrysemyspictabellii] & & & 2.610 & 2.610 \\
\hline XP_008162031.1PREDICTED:myosin-3[Chrysemyspictabellii] & & & 2.667 & 2.667 \\
\hline XP_005283491.1PREDICTED:proteinNipSnaphomolog2isoformX2[Chrysemyspictabellii] & & & 2.817 & 2.817 \\
\hline XP_008172294.1PREDICTED:LOWQUALITYPROTEIN:filamin-C[Chrysemyspictabellii] & 0.384 & & 5.255 & 2.820 \\
\hline XP_005291239.1PREDICTED:alpha-actinin-2isoformX1[Chrysemyspictabellii] & 0.527 & 0.512 & 8.343 & 3.127 \\
\hline XP_005307037.1PREDICTED:fourandahalfLIMdomainsprotein2isoformX1[Chrysemyspictabellii] & & 0.647 & 6.072 & 3.359 \\
\hline XP_005312549.1PREDICTED:histoneH2B7-like[Chrysemyspictabellii] & 0.663 & 1.023 & 8.464 & 3.383 \\
\hline XP_008168270.1PREDICTED:collagenalpha-5(IV)chainisoformX3[Chrysemyspictabellii & & & 3.514 & 3.514 \\
\hline XP_008173856.1PREDICTED:collagenalpha-3(VI)chainisoformX7[Chrysemyspictabellii] & 1.083 & 0.719 & \#\#\#\# & 4.016 \\
\hline XP_005290800.1PREDICTED:lamininsubunitgamma-1[Chrysemyspictabellii] & & & 4.085 & 4.085 \\
\hline XP_008174642.1PREDICTED:lamininsubunitalpha-2isoformX8[Chrysemyspictabellii] & & & 4.319 & 4.319 \\
\hline XP_008176331.1PREDICTED:troponinI,cardiacmuscle[Chrysemyspictabellii] & & & 4.366 & 4.366 \\
\hline XP_005292397.1PREDICTED:lamininsubunitbeta-1[Chrysemyspictabellii] & & & 4.496 & 4.496 \\
\hline XP_005282690.1PREDICTED:collagenalpha-1(VI)chain[Chrysemyspictabellii] & 1.318 & & 8.291 & 4.805 \\
\hline XP_005279757.1PREDICTED:desmin[Chrysemyspictabellii];XP_005308499.1PREDICTED:peripherin[Chrysemys & s 0.786 & & \#\#\#\# & 5.527 \\
\hline XP_008166670.1PREDICTED:sorbinandSH3domain-containingprotein2isoformX31[Chrysemyspictabellii] & & & 5.735 & 5.735 \\
\hline XP_008169939.1PREDICTED:collagenalpha-6(VI)chain-like[Chrysemyspictabellii] & & & 6.938 & 6.938 \\
\hline XP_008173419.1PREDICTED:collagenalpha-2(VI)chain[Chrysemyspictabellii] & & & 7.927 & 7.927 \\
\hline XP_008164967.1PREDICTED:collagenalpha-2(IV)chainisoformX2[Chrysemyspictabellii] & 1.061 & & \#\#\#\#\# & 8.454 \\
\hline XP_005312549.1PREDICTED:histoneH2B7-like[Chrysemyspictabellii] & 0.529 & & \#\#\#\# & 14.290 \\
\hline XP_008172414.1PREDICTED:histoneH3type3-like[Chrysemyspictabellii] & & & \#\#\#\# & 16.532 \\
\hline XP_008175328.1PREDICTED:dihydropyrimidinase-relatedprotein5,partial[Chrysemyspictabellii] & & & \#\#\#\# & 19.539 \\
\hline XP_005280702.1PREDICTED:smallconductancecalcium-activatedpotassiumchannelprotein3[Chrysemyspictabellii] & & 33.595 & 7.897 & 20.746 \\
\hline \multicolumn{5}{|l|}{ XP_005288436.1PREDICTED:histoneH2Atype2-B[Chrysemyspictabellii] } \\
\hline XP_005278922.1PREDICTED:elastin-likeisoformX3[Chrysemyspictabellii] & & & & \\
\hline
\end{tabular}


XP_005279748.1PREDICTED:long-chainspecificacyl-CoAdehydrogenase,mitochondrialisoformX3[Chrysemyspictabellii]

XP_005279757.1PREDICTED:desmin[Chrysemyspictabellii]

XP_005281459.1PREDICTED:acyl-coenzymeAthioesterase13isoformX1[Chrysemyspictabellii]

XP_005283034.1PREDICTED:nuclearproteinlocalizationprotein4homolog[Chrysemyspictabellii]

XP_005283319.1PREDICTED:ADP/ATPtranslocase3[Chrysemyspictabellii]

XP_005283737.1PREDICTED:mitochondrialpyruvatecarrier2[Chrysemyspictabellii]

XP_005284072.1PREDICTED:dol-P-Man:Man(5)GlcNAc(2)-PP-Dolalpha-1,3-mannosyltransferase[Chrysemyspictabellii]

XP_005286359.1PREDICTED:HIG1domainfamilymember1A,mitochondrial[Chrysemyspictabellii]

XP_005287412.1PREDICTED:mammalianependymin-relatedprotein1[Chrysemyspictabellii]

XP_005291639.1PREDICTED:RNA-bindingprotein12B[Chrysemyspictabellii];XP_005291638.1PREDICTED:RNA-bindingprotein12B[Chrysemyspictabe XP_005295693.1PREDICTED:D-beta-hydroxybutyratedehydrogenase,mitochondrial[Chrysemyspictabellii]

XP_005296039.1PREDICTED:lamininsubunitbeta-2[Chrysemyspictabellii]

XP_005299398.1PREDICTED:fibrinogenalphachain[Chrysemyspictabellii]

XP_005299507.1PREDICTED:erythrocyteband7integralmembraneproteinisoformX2[Chrysemyspictabellii]

XP_005299945.1PREDICTED:NADHdehydrogenase[ubiquinone]1alphasubcomplexsubunit4[Chrysemyspictabellii]

XP_008168716.1PREDICTED:aminopeptidaseN[Chrysemyspictabellii]

XP_005302192.1PREDICTED:microtubule-actincross-linkingfactorlisoformX27[Chrysemyspictabellii]

XP_005309079.1PREDICTED:olfactoryreceptor10A7-like[Chrysemyspictabellii]

XP_005310893.1PREDICTED:golginsubfamilyBmember1 isoformX3[Chrysemyspictabellii]

XP_005311675.1PREDICTED:LOWQUALITYPROTEIN:electrontransferflavoproteinsubunitalpha,mitochondrial[Chrysemyspictabellii]

XP_008162282.1PREDICTED:E3ubiquitin-proteinligaseArkadiaisoformX3[Chrysemyspictabellii]

XP_008170377.1PREDICTED:protein-glutaminegamma-glutamyltransferase2[Chrysemyspictabellii]

XP_008171292.1PREDICTED:myomesin-1[Chrysemyspictabellii]

XP_008171404.1PREDICTED:delta(3,5)-Delta(2,4)-dienoyl-CoAisomerase,mitochondrial[Chrysemyspictabellii]

XP_008174133.1PREDICTED:electrontransferflavoproteinsubunitbeta[Chrysemyspictabellii]

XP_008174802.1PREDICTED:LOWQUALITYPROTEIN:verylong-chainspecificacyl-CoAdehydrogenase,mitochondrial[Chrysemyspictabellii]

XP_008176811.1PREDICTED:lamininsubunitalpha-5isoformX3[Chrysemyspictabellii]

XP_008176998.1PREDICTED:smallsubunitprocessomecomponent20homolog[Chrysemyspictabellii]

XP_008176407.1PREDICTED:uncharacterizedproteinLOC103307431,partial[Chrysemyspictabellii]

XP_005303014.1PREDICTED:ATPsynthasesubunitepsilon,mitochondrial[Chrysemyspictabellii]

XP_005297802.1PREDICTED:annexinA1[Chrysemyspictabellii]

REV_XP_008167419.1PREDICTED:N-terminalXaa-Pro-LysN-methyltransferase1isoformX2[Chrysemyspictabellii]

XP_008166586.1PREDICTED:cytochromecoxidasesubunit6C-2[Chrysemyspictabellii]

XP_008161433.1PREDICTED:ankyrin-3isoformX1[Chrysemyspictabellii]

XP_005300700.1PREDICTED:creatinekinaseU-type,mitochondrial[Chrysemyspictabellii]

XP_008170746.1PREDICTED:isocitratedehydrogenase[NADP]cytoplasmic[Chrysemyspictabellii]

XP_005297343.1PREDICTED:cytochromecoxidasesubunit5B,mitochondrial-like[Chrysemyspictabellii]

XP_008162994.1PREDICTED:hydroxyacylglutathionehydrolase,mitochondrialisoformX4[Chrysemyspictabellii]

XP_005303948.1PREDICTED:citratelyasesubunitbeta-likeprotein,mitochondrialisoformX2[Chrysemyspictabellii]

XP_005282546.1PREDICTED:adiponectinisoformX2[Chrysemyspictabellii]

XP_005294070.1PREDICTED:2-oxoglutaratedehydrogenase-like,mitochondrial[Chrysemyspictabellii]

XP_005312430.1PREDICTED:myosinregulatorylightchain2,atrialisoform[Chrysemyspictabellii] 
XP_005279574.2PREDICTED:moesin[Chrysemyspictabellii]

XP_008174335.1PREDICTED:enoyl-CoAdeltaisomerase1,mitochondrialisoformX2[Chrysemyspictabellii]

XP_005284217.1PREDICTED:sideroflexin-4isoformX1[Chrysemyspictabellii]

XP_005297937.1PREDICTED:voltage-dependentanion-selectivechannelprotein1[Chrysemyspictabellii]

XP_005308072.1PREDICTED:3-hydroxyisobutyryl-CoAhydrolase,mitochondrialisoformX2[Chrysemyspictabellii]

XP_005306214.1PREDICTED:hemoglobinsubunitalpha-D[Chrysemyspictabellii]

XP_005288726.1PREDICTED:short-chainspecificacyl-CoAdehydrogenase,mitochondrial[Chrysemyspictabellii]

XP_005291857.1PREDICTED:phosphoglyceratekinase1[Chrysemyspictabellii]

XP_005302498.1PREDICTED:thiosulfatesulfurtransferase[Chrysemyspictabellii]

XP_008161767.1PREDICTED:sarcoplasmic/endoplasmicreticulumcalciumATPase2[Chrysemyspictabellii]

XP_005281459.1PREDICTED:acyl-coenzymeAthioesterase13isoformX1[Chrysemyspictabellii]

XP_005281130.1PREDICTED:thyroidadenoma-associatedproteinhomolog[Chrysemyspictabellii]

XP_005310780.1PREDICTED:alpha-aminoadipicsemialdehydedehydrogenase[Chrysemyspictabellii]

XP_005302197.1PREDICTED:adenylatekinase2,mitochondrialisoformX3[Chrysemyspictabellii]

XP_005299662.1PREDICTED:2-oxoisovaleratedehydrogenasesubunitbeta,mitochondrial[Chrysemyspictabellii]

XP_005279048.1PREDICTED:ubiquitin-60SribosomalproteinL40[Chrysemyspictabellii]

XP_005312055.1PREDICTED:cathepsinG-like[Chrysemyspictabellii]

XP_005291442.1PREDICTED:heatshockproteinbeta-2[Chrysemyspictabellii]

XP_005303528.1PREDICTED:sideroflexin-3[Chrysemyspictabellii]

XP_008175060.1PREDICTED:NADHdehydrogenase[ubiquinone]iron-sulfurprotein6,mitochondrial[Chrysemyspictabellii]

XP_008161784.1PREDICTED:diablohomolog,mitochondrial[Chrysemyspictabellii]

YP_009022049.1ATPsynthaseF0subunit6(mitochondrion)[Chrysemyspictabellii]

XP_005282036.1PREDICTED:long-chain-fatty-acid--CoAligase1[Chrysemyspictabellii]

XP_005301112.1PREDICTED:fourandahalfLIMdomainsprotein1 isoformX5[Chrysemyspictabellii]

XP_008174077.1PREDICTED:flotillin-1[Chrysemyspictabellii]

XP_005297533.1PREDICTED:28SribosomalproteinS7,mitochondrial[Chrysemyspictabellii]

XP_005304317.1PREDICTED:microsomalglutathioneS-transferase3[Chrysemyspictabellii]

XP_005314623.1PREDICTED:NADHdehydrogenase[ubiquinone]iron-sulfurprotein6,mitochondrial-like,partial[Chrysemyspictabellii]

XP_005306968.1PREDICTED:NADkinase2,mitochondrialisoformX2[Chrysemyspictabellii]

XP_005291489.1PREDICTED:endoplasmicreticulummannosyl-oligosaccharide1,2-alpha-mannosidase[Chrysemyspictabellii]

XP_005288436.1PREDICTED:histoneH2Atype2-B[Chrysemyspictabellii]

XP_005280172.1PREDICTED:filamin-AisoformX2[Chrysemyspictabellii]

XP_005282018.1PREDICTED:ectonucleotidepyrophosphatase/phosphodiesterasefamilymember6isoformX2[Chrysemyspictabellii]

XP_008164142.1PREDICTED:zincfingerandBTBdomain-containingprotein38[Chrysemyspictabellii]

XP_005283787.1PREDICTED:cytochromecoxidasesubunit7A2,mitochondrial[Chrysemyspictabellii]

XP_005296381.1PREDICTED:heatshockproteinHSP90-beta[Chrysemyspictabellii]

XP_005286359.1PREDICTED:HIG1domainfamilymember1A,mitochondrial[Chrysemyspictabellii]

XP_008171916.1PREDICTED:proteinDJ-1[Chrysemyspictabellii];XP_005287110.1PREDICTED:proteinDJ-1[Chrysemyspictabellii]

XP_008166223.1PREDICTED:sarcolemmalmembrane-associatedproteinisoformX10[Chrysemyspictabellii]

XP_005289018.1PREDICTED:acylpyruvaseFAHD1,mitochondrial[Chrysemyspictabellii]

XP_005289348.1PREDICTED:ATPsynthase-couplingfactor6,mitochondrial[Chrysemyspictabellii]

XP_005289421.1PREDICTED:aspartateaminotransferase,cytoplasmic[Chrysemyspictabellii] 
XP_005290067.1PREDICTED:hemoglobinsubunitbeta[Chrysemyspictabellii]

XP_005290189.1PREDICTED:myosin-7[Chrysemyspictabellii]

XP_005291609.1PREDICTED:peptidyl-prolylcis-transisomeraseA[Chrysemyspictabellii]

XP_005293301.1PREDICTED:sarcosinedehydrogenase,mitochondrial[Chrysemyspictabellii]

XP_005293963.1PREDICTED:long-chain-fatty-acid--CoAligase5[Chrysemyspictabellii]

XP_008168500.1PREDICTED:LIMdomain-bindingprotein3isoformX19[Chrysemyspictabellii]

XP_005295352.1PREDICTED:14-3-3proteinbeta/alpha[Chrysemyspictabellii]

XP_005296886.1PREDICTED:ferrochelatase,mitochondrial[Chrysemyspictabellii]

XP_008176722.1PREDICTED:glycerol-3-phosphatedehydrogenase,mitochondrialisoformX2[Chrysemyspictabellii]

XP_005300651.1PREDICTED:peptidyl-prolylcis-transisomeraseF,mitochondrial[Chrysemyspictabellii]

XP_005302529.1PREDICTED:histoneH1.0[Chrysemyspictabellii]

XP_005305696.1PREDICTED:proteinFAM161AisoformX1[Chrysemyspictabellii]

XP_005307578.1PREDICTED:glutaredoxin-relatedprotein5,mitochondrial[Chrysemyspictabellii]

XP_005307970.1PREDICTED:chaperoneactivityofbc1 complex-like,mitochondrial[Chrysemyspictabellii]

XP_005308031.1PREDICTED:alpha-actinin-3[Chrysemyspictabellii]

XP_005308612.1PREDICTED:probableacyl-CoAdehydrogenase6isoformX3[Chrysemyspictabellii]

XP_005310140.1PREDICTED:synapticvesiclemembraneproteinVAT-1homolog[Chrysemyspictabellii]

XP_005310776.1PREDICTED:endoplasmin[Chrysemyspictabellii]

XP_005311028.2PREDICTED:NADHdehydrogenase[ubiquinone]flavoprotein3,mitochondrialisoformX1[Chrysemyspictabellii]

XP_005314220.1PREDICTED:NADHdehydrogenase[ubiquinone]1alphasubcomplexsubunit11[Chrysemyspictabellii]

XP_008162404.1PREDICTED:zincfingerhomeoboxprotein3[Chrysemyspictabellii]

XP_008165659.1PREDICTED:P2Ypurinoceptor8-like[Chrysemyspictabellii]

XP_008165921.1PREDICTED:dyneinheavychain17,axonemal[Chrysemyspictabellii]

XP_008167097.1PREDICTED:hemicentin-2-like[Chrysemyspictabellii]

XP_008167919.1PREDICTED:glycylpeptideN-tetradecanoyltransferase2isoformX1[Chrysemyspictabellii]

XP_008168518.1PREDICTED:growthhormone-inducibletransmembraneprotein[Chrysemyspictabellii]

XP_008169017.1PREDICTED:RB1-induciblecoiled-coilprotein1 isoformX1[Chrysemyspictabellii]

XP_008171292.1PREDICTED:myomesin-1[Chrysemyspictabellii]

XP_008172796.1PREDICTED:prolinedehydrogenase1,mitochondrial[Chrysemyspictabellii]

XP_008173123.1PREDICTED:talin-1[Chrysemyspictabellii]

XP_008177328.1PREDICTED:PDZandLIMdomainprotein5isoformX13[Chrysemyspictabellii 
Appendix B: Mitochondrial responses to prolonged anoxia in brain of red-eared slider turtles

Matthew E. Pamenter, Crisostomo R. Gomez, Jeffrey G. Richards, William K. Milsom Published in Biology Letters, 13 January 2016, DOI: 10.1098/rsbl.2015.0797

\begin{abstract}
Mitochondria are central to aerobic energy production and play a key role in neuronal signalling. During anoxia, however, the mitochondria of most vertebrates initiate deleterious cell death cascades. Nonetheless, a handful of vertebrate species, including some freshwater turtles, are remarkably tolerant of low oxygen environments and survive months of anoxia without apparent damage to brain tissue. This tolerance suggests that mitochondria in the brains of such species are adapted to withstand prolonged anoxia, but little is known about potential neuroprotective responses. In this study, we address such mechanisms by comparing mitochondrial function between brain tissues isolated from cold-acclimated red-eared slider turtles (Trachemys scripta elegans) exposed to two weeks of either normoxia or anoxia. We found that brain mitochondria from anoxiaacclimated turtles exhibited a unique phenotype of remodelling relative to normoxic controls, including: (i) decreased citrate synthase and $\mathrm{F}_{1} \mathrm{~F}_{\mathrm{O}}$-ATPase activity but maintained protein content, (ii) markedly reduced aerobic capacity, and (iii) mild uncoupling of the mitochondrial proton gradient. These data suggest that turtle brain mitochondria respond to low oxygen stress with a unique suite of changes tailored towards neuroprotection.
\end{abstract}




\section{Introduction}

Mitochondria are the lynchpin of aerobic metabolism. In normoxia, mitochondria consume more than $90 \%$ of the oxygen acquired by an organism to facilitate the pumping of protons $\left(\mathrm{H}^{+}\right)$across the inner mitochondrial membrane [1]. This work generates the proton-motive force that energizes the phosphorylation of ADP to ATP via the $\mathrm{F}_{1} \mathrm{~F}_{\mathrm{O}^{-}}$ ATPase [2]. Through this action, mitochondria generate the majority of a cell's energy in an oxygen-dependent manner and are thus well suited to serve as biological oxygen sensors [2]. Fittingly, mitochondria also coordinate downstream cellular responses to hypoxia. For example, mitochondria (i) are the primary source of cellular reactive oxygen species (ROS) generation, which can trigger hypoxia-inducible factor-dependent gene transcription, and also directly modulate membrane protein activity; (ii) are a major sink for cellular $\mathrm{Ca}^{2+}$, a potent second messenger that mediates neuronal excitability and signalling; and (iii) affect the cellular energy balance and thereby the activity of AMPactivated protein kinase, a master switch of cellular energetics [2]. Through such mechanisms, mitochondria function as a signalling hub that coordinates the cells' defence strategy against low oxygen stress [2].

In anoxia, however, mitochondria become a liability. Deprived of oxygen to serve as the terminal electron acceptor in the electron transport chain (ETC), the mitochondrial $\mathrm{F}_{1} \mathrm{~F}_{\mathrm{O}^{-}}$ ATPase reverses, hydrolysing ATP into ADP in order to maintain the proton-motive force, and thereby robbing the cell of valuable fuel reserves [3]. In addition, mitochondrial dysfunction is a central contributor to hypoxic/anoxic cell death; either by triggering programmed cell death pathways or by generating deleterious bursts of ROS upon reoxygenation [2]. Nonetheless, hypoxic and anoxic environments are common, particularly in aquatic habitats, and these niches are populated by species with 
physiological adaptations allowing them to tolerate a lack of oxygen. Not surprisingly, studies of these species have revealed important adaptations at the mitochondrial level that limit the deleterious effects of hypoxia. For example, $\mathrm{F}_{1} \mathrm{~F}_{\mathrm{O}}$-ATPase activity is reduced by approximately $95 \%$ in skeletal muscle of the anoxia-tolerant frog Rana temporaria [4] and by approximately $85 \%$ in the heart of red-eared slider turtles (Trachemys scripta elegans) [5]. This adaptation is thought to prolong cellular viability by limiting ATP consumed by reversed activity of the $\mathrm{F}_{1} \mathrm{~F}_{\mathrm{O}}$-ATPase in anoxia.

Despite recent advances in our understanding of mitochondrial adaptations to anoxia in muscular tissue, very little is known regarding mitochondrial adaptations in the brains of anoxia-tolerant species. Such mechanisms are of particular interest because brain is exquisitely sensitive to anoxia as it produces a large majority of its ATP via oxidative phosphorylation [6]. Brain cells are also physiologically unique in that maintenance of neuronal energy charge and also of the mitochondrial $\mathrm{H}^{+}$gradient are obligatory to avoid deleterious increases in cytosolic $\mathrm{Ca}^{2+}$, which can trigger excitotoxic cell death [7]. As a result of these demands, brain cell function cannot be entirely shut down in anoxia, and indeed, anoxia-tolerant turtle neural networks retain some functionality in prolonged anoxia to facilitate behavioural responses to light cues consistent with a spring thaw [8]. The dearth of information regarding mitochondrial adaptations in the brain of anoxiatolerant species represents a major gap in our understanding of naturally evolved cellular anoxia-tolerance. Therefore, we exposed cold-acclimated red-eared slider turtles, which are among the most anoxia-tolerant vertebrates identified [9], to two weeks of chronic anoxia and examined the impact of this treatment on brain mitochondrial function. 


\section{Abridged methodology}

Twenty-two adult female red-eared slider turtles were cold-acclimated to $5^{\circ} \mathrm{C}$ for four to five weeks and then randomly divided into two groups: normoxic and anoxic $(n=11$ each). Turtles were held at these conditions for two weeks before experimentation.

A complete description of experimental approaches can be found in the electronic supplemental material section. Briefly, following treatment turtles were decapitated and whole brains were extracted, homogenized and then permeabilized with $4 \mathrm{mM}$ saponin for $45 \mathrm{~min}$ on ice [10]. $\mathrm{F}_{1} \mathrm{~F}_{\mathrm{O}}$-ATPase and citrate synthase (CS) enzyme activity and protein content were assessed in whole brain using spectrophotometric assays or Western blot approaches, respectively [5]. Permeabilized brain cell mitochondrial respiration and membrane potential $\left(\Psi_{\mathrm{m}}\right)$ were measured with an Oroboros Oxygraph $2 \mathrm{k}$ high-resolution respirometry system (Oroboros Instruments, Innsbruck, Austria) as follows: (i) respiratory flux through the ETC and $\Psi_{\mathrm{m}}$ were measured using a substrate-uncouplerinhibitor titration (SUIT) protocol [11]; (ii) the kinetics of mitochondrial $\mathrm{H}^{+}$conductance were assessed by simultaneously measuring $\Psi_{\mathrm{m}}$ and $\mathrm{O}_{2}$ consumption in succinate-fuelled mitochondria by stepwise titration of $0.25 \mathrm{mM}$ malonate, an inhibitor of the substrate oxidation component of state II respiration; (iii) the effect of simulated acute anoxia exposure (20 min) on mitochondrial function was assessed in ADP-fuelled mitochondria $[5]$.

\section{Results and Discussion}

Citrate synthase and $F_{1} F_{0}$-ATPase enzyme activity, but not protein content, are decreased in anoxic brain

We measured CS activity from brain tissue as a marker for oxidative capacity. In anoxic mitochondria, CS activity decreased by approximately $20 \%$ relative to normoxic animals 
(figure $1 a ; t_{10}=2.71, p=0.02$ ). This suggests an overall reduction in the aerobic capacity of brain in response to two weeks of anoxia. This change is tissue-specific to turtle brain because CS activity does not change in turtle heart following acclimatization to anoxia [5]. The anoxic decrease in CS activity is likely not indicative of a change in mitochondrial volume density, however, because total CS protein expression was not different between treatments (figure $1 b, c ; t_{10}=0.78, p=0.45$ ). The mechanism by which CS activity is decreased in anoxia may involve post-translational modifications but further experiments are required to evaluate this possibility. In addition, $\mathrm{F}_{1} \mathrm{~F}_{\mathrm{O}}$-ATPase activity decreased by approximately $80 \%$ in anoxic samples (figure $1 d ; t_{10}=0.04, p=$ 0.97 ), which is similar to the $85 \%$ decrease previously reported in anoxic turtle heart mitochondria [5]. $\mathrm{F}_{1} \mathrm{~F}_{\mathrm{O}}$-ATPase protein expression was unchanged by anoxia (figure $1 e_{2} f$; $\left.t_{10}=7.79, p<0.0001\right)$, indicating that post-translational modification of the $\mathrm{F}_{1} \mathrm{~F}_{\mathrm{O}}$-ATPase or cellular inhibitory factors may regulate $\mathrm{F}_{1} \mathrm{~F}_{\mathrm{O}}$-ATPase activity in anoxic brain [4]. 
(a)

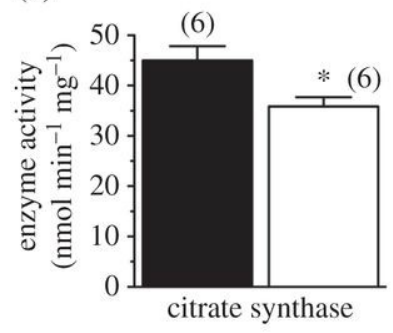

(c)

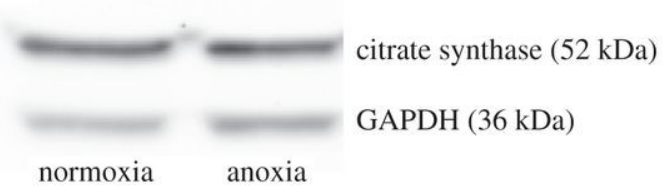

$(d)$
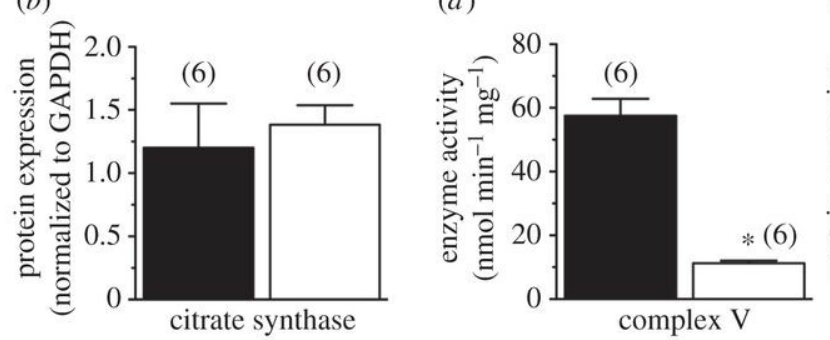

(f)

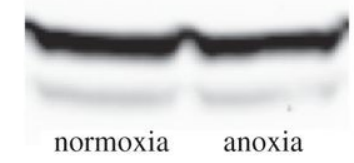

(e)

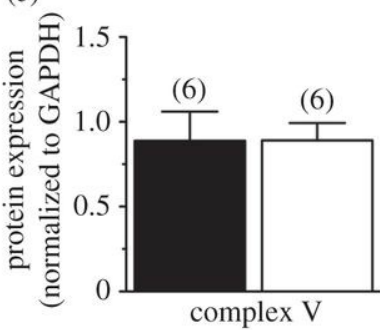

complex V (53 kDa)

GAPDH (36 kDa)

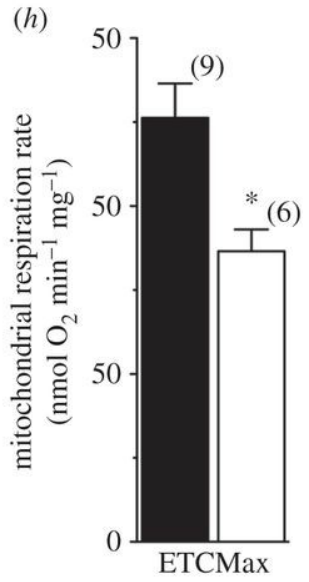

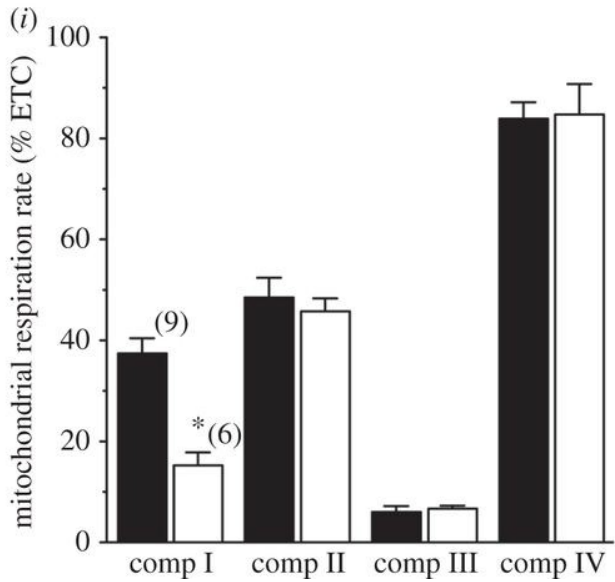

$(h)$ $(g)$

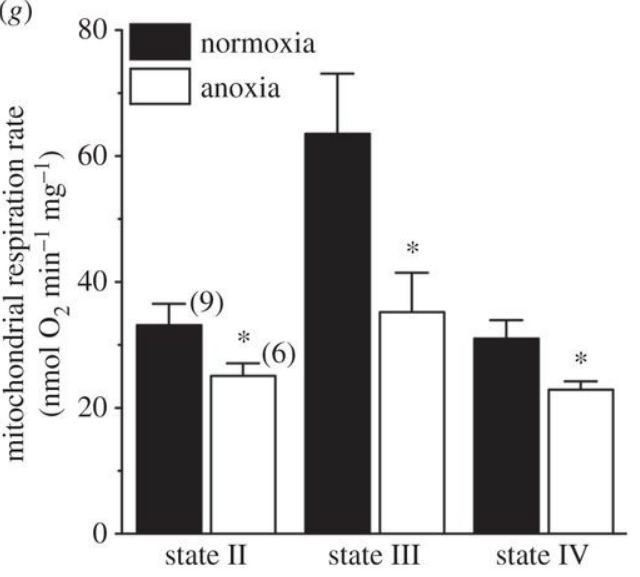

Figure B.1 ETC flux and complex V ( $\mathrm{F}_{1} \mathrm{~F}_{\mathrm{O}}$-ATPase $)$ activity are decreased following two weeks of anoxia. $(a, b)$ Summary of CS activity $(a)$ and protein expression $(b)$ in brains from turtles exposed to two weeks of normoxia (black bars) or anoxia (white bars). (c) Sample blots of CS protein expression. $(d, e)$ Summaries of complex V activity $(d)$ and protein expression $(e)$. (f) Sample blots of complex V protein expression. $(g)$ Mitochondrial respiratory flux rates. (h) Total ETC capacity. (i) Individual complex respiratory rates. Data are means \pm s.e.m. Numbers in parentheses indicate $n$. Asterisks indicate significant differences between normoxia- and anoxia-acclimated turtles $(p<$ $0.05)$.

\section{Electron transport chain flux and $\Psi_{\mathrm{m}}$ are reduced by chronic anoxia}

Next, we confirmed that anoxic brain mitochondria have decreased oxidative capacity by examining ETC respiratory flux and $\Psi_{\mathrm{m}}$ using a SUIT protocol. A two-way repeated measures ANOVA revealed a significant treatment effect between normoxia and anoxia on ETC respiratory flux (treatment: $F_{1,14}=52.11, p<0.0001$; interaction: $F_{1,14}=0.86, p$ 
$=0.64)$. Further analysis with Bonferonni post-tests revealed specific changes in state II (substrate-fuelled), III (ADP-fuelled) and $\mathrm{IV}_{\text {oligo }}$ (succinate-fuelled in the presence of oligomycin A) mitochondrial respiration rates, which were $24 \%, 55 \%$ and $26 \%$ lower, respectively, in anoxia-acclimated brain (figure $1 g$ ). Furthermore, analysis of the maximum total respiration capacity of the ETC in fully uncoupled mitochondria (by FCCP (carbonyl cyanide-4-phenylhydrazone addition) revealed a 31.5\% reduction in ETC capacity in anoxic brain (figure $1 h$ ). Measurements of the individual components of the ETC revealed that complex I activity decreased by $59 \%$ in anoxic brain but the activities of complexes II-IV were not different when these were normalized to their respective total ETC capacities (figure 1i). Therefore, the anoxic decreases in ETC capacity and $\mathrm{O}_{2}$ consumption are likely the result of reverse inhibition due to downregulation of the $\mathrm{F}_{1} \mathrm{~F}_{\mathrm{O}}$-ATPase in anoxia, with an additional minor contribution from decreased CS activity that likely inhibits complex I respiration. In addition, a twoway repeated measures ANOVA revealed a significant treatment effect between normoxia and anoxia on $\Psi_{\mathrm{m}}$ (treatment: $F_{1,14}=10.88, p<0.0001$; interaction: $F_{1,14}=$ $0.92, p=0.52$ ), matching the treatment effect observed for ETC flux; however, this trend did not reach significance with any individual treatment (electronic supplementary material, figure S1).

Overall, the respiratory flux pattern observed in figure 1 is divergent from anoxic turtle heart mitochondria [5]: anoxia-mediated changes in turtle brain result in a more robust downregulation of the ETC as a whole, whereas in turtle heart, reductions in the respiration rates of individual ETC complexes are observed. Conversely, the decrease in $\mathrm{F}_{1} \mathrm{~F}_{\mathrm{O}}$-ATPase activity is similar between turtle brain and heart, but reduced relative to 
skeletal muscle from hypoxia-acclimated frogs [4,5]. Interestingly, in both brain and heart mitochondria from anoxic turtles, the decrease in $\mathrm{F}_{1} \mathrm{~F}_{\mathrm{O}}$-ATPase activity is significantly greater than the associated decreases observed in ETC flux, indicating that even when $\mathrm{F}_{1} \mathrm{~F}_{\mathrm{O}}$-ATPase activity is markedly reduced during prolonged anoxia, there is still sufficient capacity in complex V to match ETC function.

\section{The mitochondrial $\mathrm{H}^{+}$gradient is less tightly coupled in anoxia and $\Psi_{\mathrm{m}}$ is depolarized}

Next, we compared kinetics of the mitochondrial $\mathrm{H}^{+}$gradient between treatments. In

general, a two-way repeated measures ANOVA revealed that mitochondria from anoxiaacclimated turtles had higher rates of $\mathrm{O}_{2}$ consumption and a more depolarized $\Psi_{\mathrm{m}}$ than mitochondria from normoxia-acclimated turtles (figure $2 a$; treatment: $F_{1,11}=9.22, p<$ 0.0001; interaction: $F_{1,11}=2.39, p=0.18$ ). This indicates either that anoxic brain mitochondria are leakier to $\mathrm{H}^{+}$or that other ion pumps are functioning at the expense of the $\mathrm{H}^{+}$gradient. For example, in vitro, turtle brain mitochondria become depolarized when exposed to acute anoxia due to the activation of mitochondrial ATP-sensitive $\mathrm{K}^{+}$ $\left(\mathrm{mK}_{\mathrm{ATP}}\right)$ channels [12]. $\mathrm{mK}_{\mathrm{ATP}}$ channel activation increases mitochondrial membrane permeability to $\mathrm{K}^{+}$, and the resulting $\mathrm{K}^{+}$flux through these channels must be opposed by the activity of $\mathrm{H}^{+}$-fuelled antiporters. This futile $\mathrm{K}^{+}$cycle thereby mildly uncouples the $\mathrm{H}^{+}$gradient from ATP production but initiates glutamatergic channel arrest [13], a key neuroprotective mechanism against anoxia in turtle brain. Channel arrest persists for at least the first three weeks of anoxic exposure in turtles [14]; mild uncoupling of the mitochondrial $\mathrm{H}^{+}$gradient due to $\mathrm{mK}_{\mathrm{ATP}}$ channel activation would explain the observed shift. 

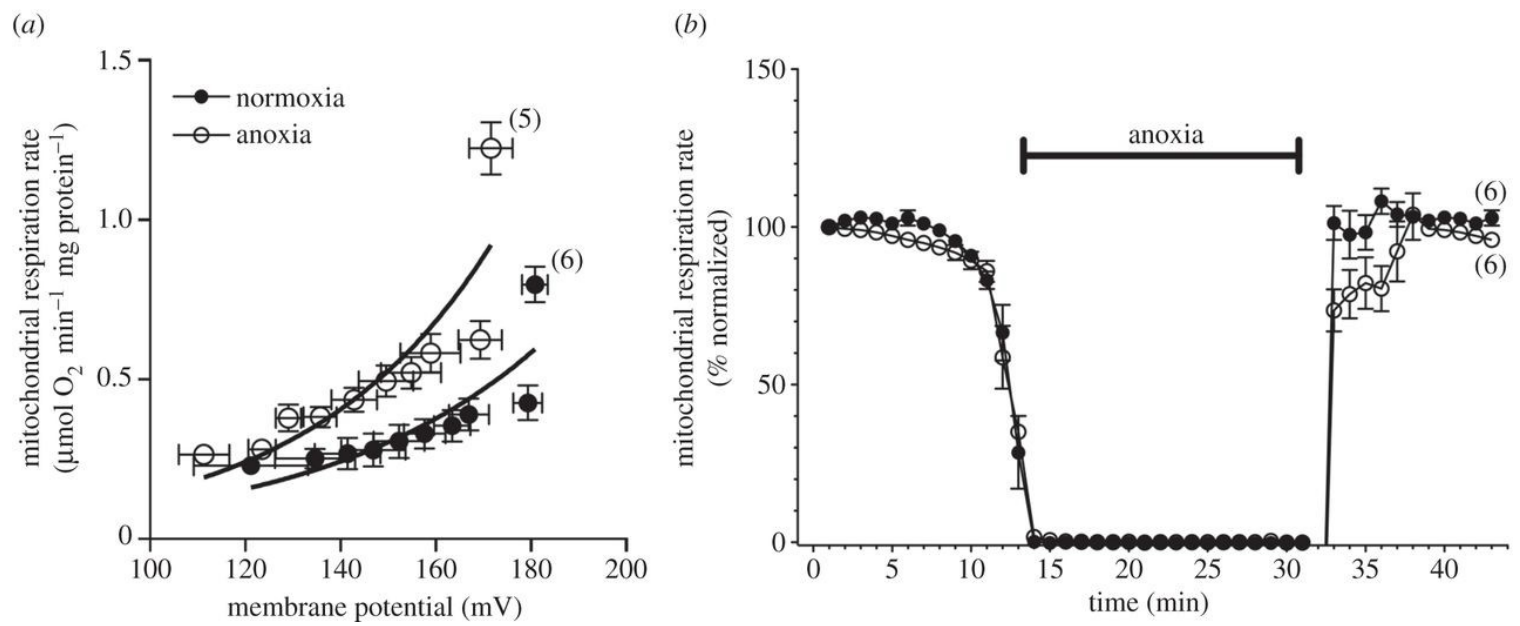

Figure B.2 The mitochondrial proton gradient is partially uncoupled following two weeks of anoxia. Anoxic mitochondria (open circles) have more leaky proton conductance kinetics than normoxic controls (closed circles) but are equally tolerant of an acute anoxic/reoxygenation challenge. (a) Comparison of proton conductance kinetics. (b) The effects of acute anoxia/reoxygenation on mitochondrial respiration. Data are means \pm s.e.m. Numbers in parentheses indicate $n$.

\section{Anoxia- and normoxia-acclimated brain mitochondria are equally tolerant of acute anoxic stress}

Finally, we tested the sensitivity of mitochondria to an acute anoxic challenge by comparing respiration rates in substrate-fuelled state III-respiring mitochondria before and after 20 min of anoxia with a repeated measures two-way ANOVA. We found no difference between respiration rates within or between groups (figure $2 b ; F_{1,11}=5.64, p=$ 0.84), indicating that both sets of mitochondria were undamaged by the anoxia/reperfusion stress. In support of this conclusion, previous examinations of mitochondrial ROS generation in anoxic turtle brain demonstrated decreased ROS levels during acute anoxia in vitro and deleterious bursts of ROS are not observed during reperfusion [15]. These data suggest that a unique suite of cytoprotective mechanisms are involved in preventing deleterious reoxygenation injury in turtle brain. 


\section{Summary}

We demonstrate that turtle brain mitochondria respond to two weeks of anoxiaacclimatization by decreasing: (i) $\mathrm{CS}$ and $\mathrm{F}_{1} \mathrm{~F}_{\mathrm{O}}$-ATPase activity, (ii) ETC respiratory flux, and (iii) $\mathrm{H}^{+}$gradient leak. However, brain mitochondria from normoxic and anoxic turtles are equally tolerant of an acute anoxic challenge, suggesting that these mitochondria possess endogenous defence mechanisms that are chronically activated and do not require mitochondrial remodelling during prolonged anoxic exposure. These results highlight that mitochondria from different species can respond very differently to similar environmental challenges. By reducing the respiratory capacity of mitochondria during prolonged anoxia, turtle brains are likely able to realize energy savings, while still retaining sufficient scope to resume normal function rapidly upon the detection of light cues indicating a spring thaw [8]. Our results demonstrate that turtle brain mitochondria exhibit a hybrid adaptive response to anoxia that is likely tailored to the specific limitations and demands of brain function during anoxia.

1. Rolfe DF, Brown GC. Cellular energy utilization and molecular origin of standard metabolic rate in mammals. Physiol Rev. 1997;77(3):731-58.

2. Pamenter ME. Mitochondria: a multimodal hub of hypoxia tolerance. Can J Zool. 2014;92(7):56989.

3. Nicholls DG. The influence of respiration and ATP hydrolysis on the proton-electrochemical gradient across the inner membrane of rat-liver mitochondria as determined by ion distribution. Eur J Biochem. 1974;50(1):305-15.

4. St-Pierre J, Brand MD, Boutilier RG. Mitochondria as ATP consumers: cellular treason in anoxia. Proc Natl Acad Sci U S A. 2000;97(15):8670-4.

5. Galli GL, Lau GY, Richards JG. Beating oxygen: chronic anoxia exposure reduces mitochondrial F1FO-ATPase activity in turtle (Trachemys scripta) heart. J Exp Biol. 2013;216(Pt 17):3283-93.

6. Suarez R.K. Thinking with and without oxygen: energy metabolism in vertebrate brains Can J Zool. 1987;66:1041-5.

7. Choi DW. Excitotoxic cell death. J Neurobiol. 1992;23(9):1261-76. 
8. Madsen JG, Wang T, Beedholm K, Madsen PT. Detecting spring after a long winter: coma or slow vigilance in cold, hypoxic turtles? Biology letters. 2013;9(6):20130602.

9. Bickler PE, Buck LT. Hypoxia tolerance in reptiles, amphibians, and fishes: life with variable oxygen availability. Annu Rev Physiol. 2007;69:145-70.

10. Pesta D, Gnaiger E. High-resolution respirometry: OXPHOS protocols for human cells and permeabilized fibers from small biopsies of human muscle. Methods Mol Biol. 2012;810:25-58.

11. Lanza IR, Nair KS. Functional assessment of isolated mitochondria in vitro. Methods Enzymol. 2009;457:349-72.

12. Hawrysh PJ, Buck LT. Anoxia-mediated calcium release through the mitochondrial permeability transition pore silences NMDA receptor currents in turtle neurons. J Exp Biol. 2013.

13. Pamenter ME, Shin DSH, Cooray M, Buck LT. Mitochondrial ATP-sensitive K+ channels regulate NMDAR activity in the cortex of the anoxic western painted turtle. J Physiol-London. 2008;586(4):1043-58.

14. Bickler PE, Donohoe PH, Buck LT. Hypoxia-induced silencing of NMDA receptors in turtle neurons. J Neurosci. 2000;20(10):3522-8.

15. Pamenter ME, Richards MD, Buck LT. Anoxia-induced changes in reactive oxygen species and cyclic nucleotides in the painted turtle. J Comp Physiol [B]. 2007;177(4):473-81. 
Appendix C: Inhibitory Factor-1 Alignment

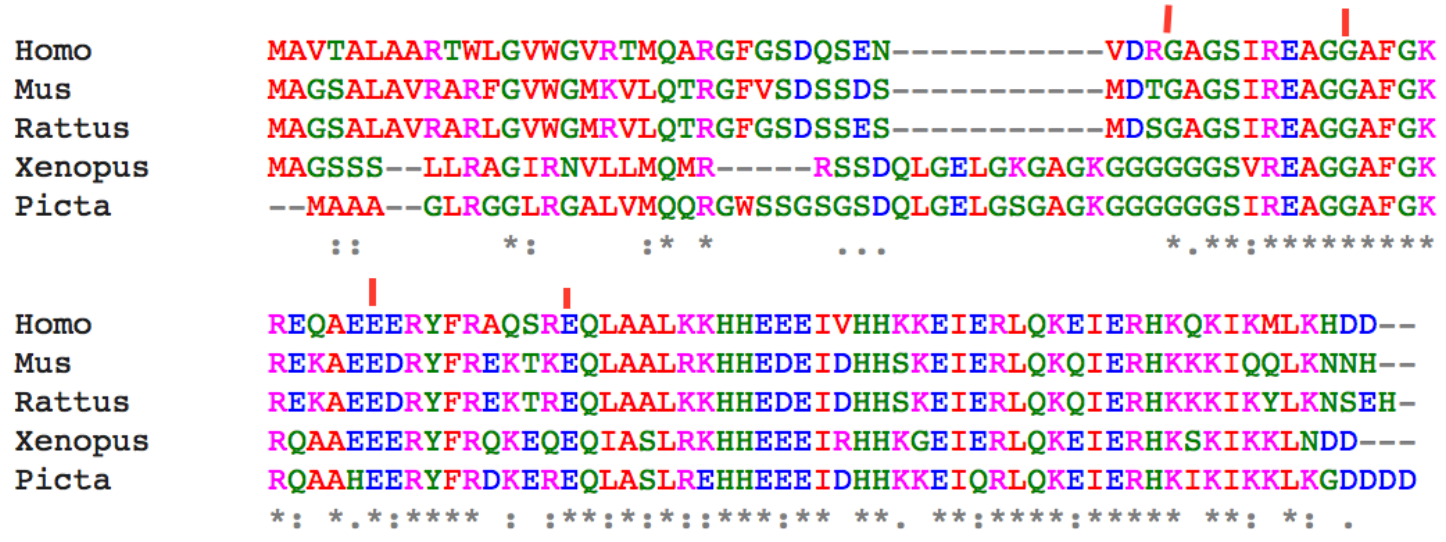

